\title{
ADAS analysis of the differential emission measure structure of the inner solar corona
}

\section{Application of the data adaptive smoothing approach to the SERTS-89 active region spectrum}

A. C. Lanzafame ${ }^{1}$, D. H. Brooks ${ }^{2, \star}$, J. Lang ${ }^{3}$, H. P. Summers ${ }^{2}$, R. J. Thomas ${ }^{4}$, and A. M. Thompson ${ }^{5}$

1 Dipartimento di Fisica e Astronomia, Università di Catania, via S. Sofia 78, 95123 Catania, Italy

2 Dept. of Physics and Applied Physics, University of Strathclyde, 107 Rottenrow, Glasgow G4 0NG, UK

3 Rutherford Appleton Laboratory, Chilton, Didcot, OX11 0QX, UK

4 Laboratory for Astronomy and Solar Physics, Code 680, NASA-Goddard Space Flight Center, Greenbelt, MD 20771, USA

5 Schlumberger GeoQuest Simulation Sofware Development, 11 Foxcombe Court, Abingdon, OX14 1DZ, UK

Received 14 September 2001 / Accepted 16 November 2001

\begin{abstract}
The differential emission measure (DEM) of a solar active region is derived from SERTS-89 rocket data between 170 and $450 \AA$ (Thomas \& Neupert 1994). The integral inversion to infer the DEM distribution from spectral line intensities is performed by the data adaptive smoothing approach (Thompson 1990, 1991). Our analysis takes into account the density dependence of both ionisation fractions and excitation coefficients according to the collisional-radiative theory as implemented in ADAS, the Atomic Data and Analysis Structure (McWhirter \& Summers 1984; Summers 1994; Summers 2001). Our strategy aims at checking, using observational data, the validity and limitations of the DEM method used for analysing solar EUV spectra. We investigate what information it is possible to extract, within defined limitations, and how the method can assist in a number of cases, e.g. abundance determination, spectral line identification, intensity predictions, and validation of atomic cross-sections. Using the above data and theory, it is shown that a spurious multiple peak in the DEM distribution between $\log \left(T_{\mathrm{e}}\right)=6.1$ and 6.7 , where $T_{\mathrm{e}}$ is the electron temperature, may derive from an inaccurate treatment of the population densities of the excited levels and ionisation fractions or from using an integral inversion technique with arbitrary smoothing. Therefore, complex DEM structures, like those proposed for solar and stellar coronae by several authors, must be considered with caution. We address also the issue of systematic differences between iso-electronic sequences and show that these cannot be unambiguously detected in the coronal lines observed by SERTS. Our results indicate that a substantial improvement is required in the atomic modelling of the complex element Fe. The elemental abundance ratio $\mathrm{Si} / \mathrm{Ne}$ is found to be close to its photospheric value. The same result may be true for the $\mathrm{Fe} / \mathrm{Ne}$ abundance, but this latter result is uncertain because of the problems found with $\mathrm{Fe}$.
\end{abstract}

Key words. Sun: atmosphere - Sun: corona - Sun: UV radiation - atomic data - methods: data analysis techniques: spectroscopic

\section{Introduction}

The derivation of the emission measure from spectra of the solar corona and transition region is a first step in extracting physical quantities from observational data, and therefore in understanding the coronal morphology and in testing proposals for possible heating mechanisms. A further refinement is to determine the differential

\footnotetext{
Send offprint requests to: A. C. Lanzafame,

e-mail: acl@sunct.ct.astro.it

* Present address: Kwasan Observatory, Kyoto University, Yamashina, Kyoto 607-8471, Japan
}

emission measure, which gives the distribution of emission measure as a function of the emitting plasma's temperature along the observed line of sight. The validity of analysis methods based on emission measure, however, is controversial. Mathematically, the determination of emission measure involves the inversion of a Fredholm integral equation of the first kind, which is an ill-posed problem. Physically, such methods rely on the hypothesis of ionisation equilibrium, which can be violated by the evolution of the plasma on time-scales comparable to the ionisation/recombination time-scales. Furthermore, large errors may arise from noise or blending in the 
observational data and from uncertainties in the fundamental theoretical atomic data and their derived quantities which enter the kernel of the integral equation.

Other important issues in such analyses concern the density dependence of atomic populations. In conditions typical of the solar corona, both the ionisation balance and excitation rates depend significantly on the electron density. The former is principally because dielectronic recombination is sensitive to electron density. Considering excitation, several iso-electronic sequences allow the presence of metastable levels, which can have population densities comparable to the ground level. The population distribution amongst ground and metastable levels is sensitive to electron density. In general, at coronal densities, levels of an LS term are not populated according to their statistical weight, so that LSJ resolution in the kernel calculations becomes mandatory.

Analysis of coronal spectra by means of the DEM method (e.g. Brosius et al. 1996 for SERTS-91, 93 data) has led to the suggestion that the distribution of plasma in temperature might exhibit a double peak between $\log \left(T_{\mathrm{e}}\right)=6.1$ and 6.7. According to Brosius et al. (1996), this could indicate distinct contributions from both quiet Sun and active regions, the higher temperature peak being due to flaring or to some other enhanced level of activity. Previous analyses on the SERTS-89 observations, which are studied in this paper, have either suggested a DEM structure with a single high temperature peak around $\log \left(T_{\mathrm{e}}\right) \sim 6.5$ (Brickhouse et al. 1995) or with a triple peak between $\log \left(T_{\mathrm{e}}\right) \sim 6$ and 6.7 (Landi \& Landini 1997).

On energetic grounds, however, it is difficult to accept the reality of such multiple peaks in the DEM structure. From a simple one dimensional viewpoint, this type of DEM distribution would imply the existence of conductive flux in opposite directions in a very limited range of temperature and, presumably, height. This, in turn, would require the existence of a localised, at least in temperature, sink of energy between peaks, which cannot be justified in terms of the radiative losses of the plasma. Conversely, if we accept that the spectrum is a composite of thermally de-coupled regions (as inferred in Brosius et al. 1996), a well defined double-peaked plasma distribution in temperature would imply the presence of two separate heating regimes in the observed volume of plasma. In either case, we show here that the existence of such structures in the SERTS-89 observations remains unproven, since an inaccurate treatment of atomic level populations or an integral inversion technique with arbitrary smoothing can also lead to a similar but spurious multiple peak in the DEM.

In this paper, we derive the DEM between $\log \left(T_{\mathrm{e}}\right) \sim 5$ and 6.8 and the elemental abundances of $\mathrm{Mg}$, Si and $\mathrm{S}$ relative to Ne from the SERTS-89 rocket spectrum of a solar active region. Estimates of the abundance of $\mathrm{C}, \mathrm{O}, \mathrm{Na}, \mathrm{Al}$ and $\mathrm{Fe}$ are also given, but with larger uncertainties. The spectrum has been analysed using the DEM and is an advance on the work of Young et al. (1998), who performed consistency checks using line ratios. The analysis based on the DEM allows comparison of the atomic modelling of the different atomic species and gives further insight to the analysis of the spectrum. We examine the propagation of kernel uncertainties on the differential emission measure analysis in the processing of fundamental atomic data. We demonstrate how an inaccurate treatment of the atomic level populations which does not properly include the density dependence of ionisation/recombination and excitation processes can lead to a spurious double-peaked DEM feature near $\log \left(T_{\mathrm{e}}\right) \sim 6$.

We also investigate systematic differences between iso-electronic sequences which can reveal important deviations from ionisation equilibrium. Systematic discrepancies amongst iso-electronic sequences have been proposed by Lang et al. (1990) as possibly indicating error in the atomic data. Judge et al. (1995) found highly significant and systematic discrepancies in the emission measure analysis of transition region lines observed with SOLSTICE on the UARS spacecraft. These authors suggest that the most likely explanation for such discrepancies is the breakdown of the equilibrium ionisation balance by dynamic and diffusive effects (but see discussion in Sect. 4.6). We show that such highly significant and systematic discrepancies cannot unambiguously be detected in the SERTS-89 data.

\section{Method}

In this section we discuss the method used to derive the differential emission measure, starting with the relevant part of the collisional-radiative theory for the line emissivity.

\subsection{Collisional-radiative theory for the line emissivity}

The intensity of a spectral line from a column of optically thin plasma of cross-sectional area $A$, due to a transition from upper level $j$ to lower level $k$, may be written as

$I_{j \rightarrow k}=\frac{1}{4 \pi A} \iiint A_{j \rightarrow k} N_{j} \mathrm{~d} x \mathrm{~d} y \mathrm{~d} z$,

where $N_{j}$ denotes the population density of ions in the upper state $j, A_{j \rightarrow k}$ is the radiative transition probability for the transition, and the integral is taken over the volume of the plasma viewed.

The excited population may be expressed in terms of the ground and metastable populations of the ionisation stage to which it belongs and to those of the adjacent higher ionisation stage by a quasi-equilibrium collisionalradiative calculation as

$N_{j}=\sum_{\rho=1}^{M_{z}} \mathcal{F}_{j \rho}^{(\mathrm{exc})} N_{\mathrm{e}} N_{\rho}+\sum_{\nu=1}^{M_{z+1}} \mathcal{F}_{j \nu}^{(\mathrm{rec})} N_{\mathrm{e}} N_{\nu}^{+}$,

where $M_{z}$ is the number of metastable levels of the ionisation stage to which the excited population $N_{j}$ belongs; $M_{z+1}$ the number of metastables of the next higher ionisation stage; $N_{\rho}$ the population of metastable level $\rho$ of 
ionisation stage $z ; N_{\nu}^{+}$the population of metastable level $\nu$ of ionisation stage $z+1 ; \mathcal{F}_{j \rho}^{(\text {exc })}$ and $\mathcal{F}_{j \nu}^{(\text {rec })}$ are the effective contributions to $N_{j}$ due to excitation from the metastables and from electron capture respectively; $N_{\mathrm{e}}$ is the electron density.

Usually, only contributions to the population of the excited state by excitation from the metastables of the same ionisation stage need to be considered, so that

$N_{j}=\sum_{\rho=1}^{M_{z}} \mathcal{F}_{j \rho}^{(\mathrm{exc})} N_{\mathrm{e}} N_{\rho}$

In differential emission measure analysis, the assumption of ionisation balance is made. Although a time dependent ionisation could be used, the method would be specific to a particular model for the dynamic behaviour of the plasma and the universality of the emission measure technique would be lost. Thus, with the ionisation balance assumption,

$N_{\rho} \equiv N_{\rho}^{(z)}=\frac{N_{\rho}^{(z)}}{N_{\mathrm{tot}}} \frac{N_{\mathrm{tot}}}{N_{\mathrm{H}}} \frac{N_{\mathrm{H}}}{N_{\mathrm{e}}} N_{\mathrm{e}}$,

where the ratio $N_{\rho}^{(z)} / N_{\text {tot }}$ is evaluated in equilibrium at the local temperature and density. It is assumed that the abundance of the element, $\mathcal{A}(Z) \equiv N_{\text {tot }} / N_{\mathrm{H}}$ with $Z$ the nuclear charge of the element, does not vary with depth in the solar atmosphere observed.

Gathering terms,

$A_{j \rightarrow k} N_{j}=\mathcal{A}(Z) N_{\mathrm{e}}^{2} G_{j \rightarrow k}\left(T_{\mathrm{e}}, N_{\mathrm{e}}\right)$,

where

$G_{j \rightarrow k}\left(T_{\mathrm{e}}, N_{\mathrm{e}}\right)=A_{j \rightarrow k} \frac{N_{\mathrm{H}}}{N_{\mathrm{e}}} \sum_{\rho=1}^{M_{z}} \mathcal{F}_{j \rho}^{(\mathrm{exc})} \frac{N_{\rho}^{(z)}}{N_{\mathrm{tot}}}$,

$T_{\mathrm{e}}$ being the electron temperature. Then the spectral intensity may be written as

$I_{j \rightarrow k}=\frac{\mathcal{A}(Z)}{4 \pi A} \iiint G_{j \rightarrow k}\left(T_{\mathrm{e}}, N_{\mathrm{e}}\right) N_{\mathrm{e}}^{2} \mathrm{~d} x \mathrm{~d} y \mathrm{~d} z$.

It is convenient to change the variable of the integral to electron temperature. However, the atomic coefficient depends on both electron temperature and electron density so it is necessary to make some assumption about the relation between them. Two common assumptions are that the plasma electron density or pressure is constant over the relatively small range of temperature where $G\left(T_{\mathrm{e}}, N_{\mathrm{e}}\right)$ has significant values. That is, a model assumption is important even though the $G$ function is usually written as a function of temperature alone. Also, we introduce the concept of surfaces of constant temperature of which there may be more than one in the viewed volume (Craig \& Brown 1976). The intensity becomes

$I_{j \rightarrow k}=\frac{\mathcal{A}(Z)}{4 \pi} \int_{T_{a}}^{T_{b}} G_{j \rightarrow k}\left(T_{\mathrm{e}}\right) \phi\left(T_{\mathrm{e}}\right) \mathrm{d} T_{\mathrm{e}}$, where the quantity $\phi\left(T_{\mathrm{e}}\right)$ is called the differential emission measure (DEM), defined as

$\phi\left(T_{\mathrm{e}}\right) \equiv \frac{1}{A} \sum_{l} \int_{S_{l}\left(T_{\mathrm{e}}\right)}\left|\nabla T_{\mathrm{e}}\right|_{l}^{-1} N_{\mathrm{e}}^{2} \mathrm{~d} S_{l}$.

The sum is taken over isothermal surfaces $S_{l}\left(T_{\mathrm{e}}\right)$ indexed by $l$, and $\left|\nabla T_{\mathrm{e}}\right|_{l}$ is the modulus of the temperature gradient perpendicular to a surface. In this definition $\phi\left(T_{\mathrm{e}}\right)$ is the average value of the differential emission measure over the area viewed by the spectrometer. Note that $\phi\left(T_{\mathrm{e}}\right)$ is the part of the integral one seeks to extract since it provides direct information about physical conditions within the emitting plasma. The limits of the integral, $T_{a}$ and $T_{b}$ in Eq. (8) are the minimum and the maximum electron temperatures in the part of the atmosphere contributing to the spectrum.

\subsection{Evaluation of kernel}

In our investigation we consider kernels $G$ under the two common assumptions above, i.e. uniform electron pressure or uniform electron density. As discussed in Sect. 2.1, the $G$ kernels are in fact functions of both electron temperature and electron density, and so, to determine the emission measure differential in temperature, we must take into account the relation between these two variables. The dependence of $G$ on the electron density is, in many cases, much weaker than the dependence on the electron temperature, so that this relation need only be approximate. Clearly, if we knew already the exact relation between $N_{\mathrm{e}}$ and $T_{\mathrm{e}}$ we would not need to derive the DEM.

Beside the dependence of the ionisation balance on $N_{\mathrm{e}}$, at finite electron density there is an increase of metastable populations at the expense of the ground level. The metastable populations can become comparable to that of the ground, which is depleted compared to the zero density limit. Therefore, even resonance lines may show a marked dependence on electron density, which is not treated in the two-level coronal approximation. On the other hand, the collisional-radiative approach, outlined in Sect. 2.1, does take into account the redistribution of population amongst the low-levels, since all the populations are treated simultaneously in the calculations. Note that in this paper we do not treat the ionisation and recombination amongst metastable levels of adjacent ionisation stages (see Eq. (2)) in detail (i.e. the so called metastable resolved approximation), but rather we adopt a stage-tostage ionisation balance as described in Sect. 3 .

To study the dependence of the estimated DEM on the approximation made in the atomic coefficients, we have computed $G$ functions over grids of uniform electron pressure and uniform electron density. In the first case, the dependence of $N_{\mathrm{e}}$ on $T_{\mathrm{e}}$ is determined by the equation of state of a perfect gas. The electron density used for evaluating the DEM and the abundance of elements is taken from a selection of density sensitive line ratios as described in Sect. 4.1. However, in order to examine the propagation 
of kernel uncertainties on the differential emission measure analysis, we have extended the uniform pressure grid from $P_{\mathrm{e}}=10^{14}$ to $10^{18} \mathrm{~cm}^{-3} \mathrm{~K}$, with an additional very low value at $10^{10}$ to represent the zero density limit, and the uniform electron density grid from $N_{\mathrm{e}}=10^{8}$ to $10^{12} \mathrm{~cm}^{-3}$.

\subsection{Differential emission measure}

We estimate the DEM by the data adaptive smoothing approach (Thompson 1990, 1991) which is briefly summarised below.

To derive the differential emission measure we require to solve the integral equation

$I_{i}=\frac{\mathcal{A}(Z)}{4 \pi} \int_{T_{a}}^{T_{b}} G_{i}\left(T_{\mathrm{e}}\right) \phi\left(T_{\mathrm{e}}\right) \mathrm{d} T_{\mathrm{e}}$

for a set of, say, $m$ lines $(i=1,2, \ldots, m)$. In Eq. (10), $I_{i}$ is the observed intensity of the $i$ th spectral line, $G_{i}\left(T_{\mathrm{e}}\right)$ is its contribution function (see Sect. 2.2), $\phi\left(T_{\mathrm{e}}\right)$ the emission measure differential in temperature and $T_{\mathrm{e}}$ the electron temperature. Hereafter we explicitly assume that $G$ is a function of $T_{\mathrm{e}}$ only, as discussed in Sect. 2.2, and index each transition instead of specifying the levels from which the transition originates.

The integral is first discretised by the product integration method (Baker 1977) as:

$$
\begin{aligned}
I_{i} & =\frac{\mathcal{A}(Z)}{4 \pi} \sum_{j=1}^{n} \phi_{j}^{\star} \int_{T_{j-1}}^{T_{j}} G_{i}\left(T_{\mathrm{e}}\right) \phi_{0}\left(T_{\mathrm{e}}\right) \mathrm{d} T_{\mathrm{e}} \\
\phi_{j}^{\star} & \equiv \frac{\int_{T_{j-1}}^{T_{j}} G_{i}\left(T_{\mathrm{e}}\right) \phi\left(T_{\mathrm{e}}\right) \mathrm{d} T_{\mathrm{e}}}{\int_{T_{j-1}}^{T_{j}} G_{i}\left(T_{\mathrm{e}}\right) \phi_{0}\left(T_{\mathrm{e}}\right) \mathrm{d} T_{\mathrm{e}}},
\end{aligned}
$$

for $i=1,2, \ldots, m$, where $\phi_{j}^{\star}$ represents a weighted average of $\phi\left(T_{\mathrm{e}}\right) / \phi_{0}\left(T_{\mathrm{e}}\right)$ between $T_{j-1}$ and $T_{j}$, and $\phi_{0}\left(T_{\mathrm{e}}\right)$ an initial estimate of $\phi\left(T_{\mathrm{e}}\right)$ toward which the solution is smoothed. This process can be viewed as scaling the solution using an expected gross behaviour of $\phi\left(T_{\mathrm{e}}\right)$ as represented by $\phi_{0}\left(T_{\mathrm{e}}\right)$. The advantage is to reduce the dynamic range of the problem before the actual regularised solution (see below) is obtained. This has been proved to prevent uneven smoothing, where the solution is over-smoothed at large values of $\phi$ and under-smoothed at low values when the source function (the differential emission measure) spans a large dynamic range.

The prior function $\phi_{0}\left(T_{\mathrm{e}}\right)$ is evaluated as follows: $G_{i}\left(T_{\mathrm{e}}\right)$ is approximated by $\bar{G}_{i} \delta\left(T_{\mathrm{e}}-T_{i}^{\max }\right)$, where

$\bar{G}_{i} \equiv \int_{0}^{\infty} G_{i}\left(T_{\mathrm{e}}\right) \mathrm{d} T_{\mathrm{e}}$

$T_{i}^{\max }$ is the temperature corresponding to the maximum of $G_{i}\left(T_{\mathrm{e}}\right)$ and $\delta$ is Dirac's delta function. A crude estimate of $\phi\left(T_{\mathrm{e}}\right)$ is then

$\bar{\phi}\left(T_{i}^{\max }\right)=\frac{4 \pi}{\mathcal{A}(Z)} \frac{I_{i}}{\bar{G}_{i}}$,

for $i=1,2, \ldots m$. A cubic B-spline (Cox \& Hayes 1973) is now fitted to the values $\log \left(\bar{\phi}\left(T_{i}^{\max }\right)\right)$ to obtain a smooth representation of $\phi_{0}\left(T_{\mathrm{e}}\right)$. This representation can only yield features comparable to the typical kernel in width, estimated to be $\approx 1 / 2$ decade. The knot points of the Bspline representation are therefore selected approximately $1 / 2$ decade apart. In other words, we obtain

$\log \left(\phi_{0}\left(T_{\mathrm{e}}\right)\right) \equiv S\left(\log \left(T_{\mathrm{e}}\right)\right)$

where $S\left(\log \left(T_{\mathrm{e}}\right)\right)$ denotes the B-spline representation with interior knots about $1 / 2$ decade apart.

The B-spline fit described above provides a satisfactory estimate of $\phi_{0}\left(T_{\mathrm{e}}\right)$ between the maximum and the minimum values of $T_{i}^{\max }$. It is necessary, however, to extrapolate $\phi_{0}\left(T_{\mathrm{e}}\right)$ beyond these boundaries. This is done as follows. For

$T_{\mathrm{e}}>\max \left(T_{i}^{\max }\right),\left(\frac{\mathrm{d} \phi_{0}}{\mathrm{~d} T_{\mathrm{e}}}\right)_{\max \left(T_{i}^{\max }\right)}>0$

or

$T_{\mathrm{e}}<\min \left(T_{i}^{\max }\right), \quad\left(\frac{\mathrm{d} \phi_{0}}{\mathrm{~d} T_{\mathrm{e}}}\right)_{\min \left(T_{i}^{\max }\right)}<0$,

$\log \left(\phi_{0}\left(T_{\mathrm{e}}\right)\right)$ is extrapolated linearly. This allows the value of $\phi_{0}\left(T_{\mathrm{e}}\right)$ to decrease smoothly while ensuring that it is always positive.

For

$T_{\mathrm{e}}>\max \left(T_{i}^{\max }\right),\left(\frac{\mathrm{d} \phi_{0}}{\mathrm{~d} T_{\mathrm{e}}}\right)_{\max \left(T_{i}^{\max }\right)}<0$

or

$T_{\mathrm{e}}<\min \left(T_{i}^{\max }\right), \quad\left(\frac{\mathrm{d} \phi_{0}}{\mathrm{~d} T_{\mathrm{e}}}\right)_{\min \left(T_{i}^{\max }\right)}>0$,

$\phi_{0}\left(T_{\mathrm{e}}\right)$ is extrapolated linearly. This is done because any rapid power-law variation in $\phi_{0}\left(T_{\mathrm{e}}\right)$ beyond the maximum and minimum of $T_{i}^{\max }$ is likely to lead to a gross inconsistency between the values of $\bar{\phi}\left(T_{i}^{\max }\right)$ and the corresponding average value of $\phi_{0}\left(T_{\mathrm{e}}\right)$.

Adding a term for the inevitable measurement noise, Eq. (11) can then be written as

$g_{i}=\sum_{j=1}^{n} H_{i j} f_{j}+\varepsilon_{i}$

for $i=1,2, \ldots m$, which is the canonical form for inverse problems. In Eq. (20), the $f_{j} \equiv \phi_{j}^{\star}$ are the quantities to be estimated at the recovery points $T_{j}, j=1,2, \ldots n$, the $g_{i} \equiv I_{i} / s_{i}$ are the data, $\varepsilon_{i} s_{i}$ are the data noises so that the $\varepsilon_{i}$ can be regarded as Gaussian errors of constant variance and $s_{i}$ weighting parameters or estimates of the noise variance on each spectral line, and

$H_{i j} \equiv \frac{\mathcal{A}(Z)}{4 \pi} \frac{1}{s_{i}} \int_{T_{j-1}}^{T_{j}} G_{i}\left(T_{\mathrm{e}}\right) \phi_{0}\left(T_{\mathrm{e}}\right) \mathrm{d} T_{\mathrm{e}}$,

for $i=1,2, \ldots m ; j=1,2, \ldots n$. 
Equation (20) is solved by a regularisation approach. In the method of regularisation, the extra information required to stabilise the inversion is introduced by a smoothness condition on the source function $\phi$. A solution is obtained by solving the optimisation problem

$$
\min _{\hat{f}}\left\{\sum_{i=1}^{m}\left(g_{i}-\sum_{j=1}^{n} H_{i j} \hat{f}_{j}\right)^{2}+\lambda \Phi(\hat{f})\right\}
$$

where $\lambda$ is a smoothing parameter representing the weight attached to the smoothing constraint $\Phi(\hat{f})$ (a linear functional of $\hat{f})$ and $\hat{f}$ is the estimate of $f$. The functional $\Phi(\hat{f})$ represents a priori information about the function $f$. A choice for this functional derives from the minimisation of the norm of the second derivative of the solution. In other words, of all the solutions that can fit the data, we choose the one that minimises

$\|\Phi(\hat{f})\|_{2}^{2}=\left\|\hat{f}^{\prime \prime}\right\|_{2}^{2}=\int\left|\hat{f}^{\prime \prime}(y)\right|^{2} \mathrm{~d} y$.

This choice of the linear functional defines the second order regularisation and is the one adopted for the solution of Eq. (20).

Representing the second-order derivative by secondorder differences, we have

$\Phi(\hat{f})=\sum_{j=1}^{n}\left(\hat{f}_{j+1}-2 \hat{f}_{j}+\hat{f}_{j-1}\right)^{2}$.

In order to avoid explicit end conditioning, $\hat{f}_{0}=\hat{f}_{n+1}=0$.

The solution of Eq. (20) by the regularisation approach specified by (22) can be expressed in matrix form as

$\left(\mathrm{H}^{T} \mathrm{H}+\lambda \Phi\right) \hat{\mathrm{f}}=\mathrm{H}^{T} \mathrm{~g}$,

where, in our case, the functional $\Phi$ is given by (24).

In order to choose the smoothing parameter the databased method described by Golub et al. (1979) (cf. Thompson 1990, 1991) is used. $\lambda$ is selected according to:

$\min _{\lambda} \frac{\|\mathrm{H} \hat{f}-g\|^{2}}{\left(\operatorname{trace}\left[\mathrm{H}^{T} \mathrm{H}+\lambda \mathrm{C}\right]\right)^{2}}$

where $\mathrm{C}$ is the Hessian matrix of $\Phi(\hat{f})$. This method has the attractive property that we do not need to know explicitly the value of the noise variance of the data points but only their ratio. That is, if the true standard deviation of the noise on the $i$ th element is $\sigma_{i}=\sigma_{0} s_{i}$, then the scaling factor $\sigma_{0}$ can be calculated a-posteriori using

$\sigma_{0}^{2}=\frac{\|\mathrm{H} \hat{f}-\mathrm{g}\|^{2}}{\left(\operatorname{trace}\left[\mathrm{H}^{T} \mathrm{H}+\lambda \mathrm{C}\right]\right)}$.

\section{Atomic data}

\subsection{Energy levels, radiative transition probabilities and effective collision strengths}

\subsubsection{Li-like ions}

For CIV the energy levels, with fine structure resolved up to $4 \mathrm{f}^{2} \mathrm{~F}_{7 / 2}$, were taken from the Kelly (1987) compilation. The radiative transition probabilities of Wiese et al. (1966) were used. As recommended in the assessment by McWhirter (1994), the close coupling effective collision strengths of Burke (1992) were adopted, the necessary fine-structure components being obtained from comparisons with the proportions derived by Zhang et al. (1990) for O VI.

For the other Li-like ions where fine structure resolved levels up to $5 \mathrm{~g}^{2} \mathrm{G}_{9 / 2}$ were included in our model ions, the energy levels, $A$ values and effective collision strengths of Zhang et al. (1990) were used. The relativistic distorted wave effective collision strength data of Zhang et al. (1990) were modified as described by McWhirter (1994) to allow for the effects of resonances and to bring them into closer agreement with close-coupling results. The data needed for S XIV, Ar XVI and Ca XVIII were interpolated from the energy levels, transition probabilities and modified effective collision strength data for OVI, SiXII, TiXIX and Zn XxviI.

\subsubsection{Be-like ions}

For the Be-like ions the first 20 energy levels up to $2 \mathrm{~s} 3 \mathrm{~d}^{1} \mathrm{D}_{2}$ were included in our models. For $\mathrm{O} v$ the energy levels from Moore (1993) and the $A$ values of Hibbert (1980) were used. As recommended in the review by Berrington (1995) the effective collision strengths for O v from Kato et al. (1990) were chosen, with revisions from Kato (1995).

For 2-2 transitions in the other Be-like ions a file with data for the ions Ne VII, Si XI, CaXVII and Fe XXIII was used to obtain the necessary values, directly for Si XI and by interpolation for Na VIII, MgIX, Alx and S xiII. The energy levels of Edlén (1983a, 1985c) were preferred for NeviI, Sixi, CaxviI and FexxiII. The $A$ values were those calculated by Nussbaumer \& Storey (1979a) for Ne VII, Mühlethaler \& Nussbaumer (1976) for Si XI and Nussbaumer \& Storey (1979b) for CaXVII and FexXIII. For the effective collision strengths, as recommended by Berrington (1995) in his review, the R-matrix close coupling calculations of Berrington et al. (1981, 1985a and 1985b) were adopted for Ne VII and Si XI, the results of Dufton et al. (1983) for Ca XVII and the results of Keenan et al. (1993a) for Fe XxiII.

For the $n=3$ energy levels and $2-3$ and $3-3$ transition $A$ values and effective collision strengths, for ions apart from Ov, a file with data for Ne vII, Si XI, Ar XV, TixIX and FexXIII was used to obtain the necessary values, again directly for $\mathrm{SiXI}$ and by interpolation for the other ions. For NeVII $n=3$ energy levels the data of Tondello \& Paget (1970) were supplemented by the data of Bashkin \& Stoner (1975). For Si XI, Ar XV and TixIX the energies given by Fawcett (1984, 1985) were adopted, while for FeXXIII the results of Corliss \& Sugar (1982) supplemented by data from Fawcett (1984, $1985)$ were used. For the transition probabilities for $2-$ 3 transitions from $2 \mathrm{~s}^{2}$ and $2 \mathrm{~s} 2 \mathrm{p}$ levels to levels 3 the data 
of Fawcett $(1984,1985)$ were chosen and for transitions from $2 \mathrm{p}^{2}$ levels to $n=3$ levels the results of Sampson et al. (1984) were used. For 3-3 transitions the Superstructure code (Eissner et al. 1974) results from Summers (1995) were adopted. For 2-3 transitions and 3-3 allowed transitions the relativistic Coulomb-Born effective collision strengths of Sampson et al. (1984) and the impact parameter results from Summers (1995) were used, respectively.

\subsubsection{B-like ions}

For each ion the first 15 fine-structure resolved energy levels (up to $2 \mathrm{p}^{32} \mathrm{P}_{3 / 2}$ ) were included in our model ions. The energy levels adopted were from Edlén (1983b). For the radiative transition probability between the $1 / 2$ and $3 / 2$ levels of the ground term in each ion the multi-configuration Hartree-Fock results of Froese Fischer (1983) were used. For the other transitions in each ion the transition probabilities of Merkelis et al. (1995) were input, apart from Ne VI where the results of Dankwort \& Treffetz (1978) were adopted where available. Sampson et al. (1994) have reviewed the available collision strengths for the B-like sequence. They anticipated and recommended the close coupling results of Zhang et al. (1994) which we used.

\subsubsection{C-like ions}

The first 46 fine-structure resolved energy levels were included for each model ion of this sequence. The energies of the $n=2$ levels were taken from Edlén (1985a); those for $n=3$ levels were taken from Wiese et al. (1966) for O III and from the Superstructure code (Eissner et al. 1974) results from Summers (1995) for the others. The radiative and distorted wave collision data were from publications by Bhatia and co-workers, notably Bhatia \& Kastner (1993) for O III, Bhatia \& Doschek (1993a, 1995 and 1993b) for Nev, Mg VII and Si IX, respectively, and Bhatia et al. (1987) for S XI.

\subsubsection{N-like ions}

Energy levels for NeIV were taken from Kelly (1987) except for the $2 \mathrm{~s}^{2} 2 \mathrm{p}^{2}\left({ }^{3} \mathrm{P}\right) 3 \mathrm{~s}^{4} \mathrm{P}, 2 \mathrm{~s}^{2} 2 \mathrm{p}^{2}\left({ }^{3} \mathrm{P}\right) 3 \mathrm{~s}^{2} \mathrm{P}$ and $2 \mathrm{~s}^{2} 2 \mathrm{p}^{2}\left({ }^{1} \mathrm{D}\right) 3 \mathrm{~s}^{2} \mathrm{D}$ levels which were taken from Bhatia \& Kastner (1988). Oscillator strengths were from the Superstructure code (Eissner et al. 1974) results of P. R. Young for the CHIANTI database (Dere et al. 1997). Collision strengths were from Ramsbottom et al. (1998), calculated in the close-coupling approximation using the multichannel R-matrix method.

Energy levels for Mg VI were from Edlén (1984) except for $2 \mathrm{~s}^{2} 2 \mathrm{p}^{2}\left({ }^{3} \mathrm{P}\right) 3 \mathrm{~s}^{4} \mathrm{P}, 2 \mathrm{~s}^{2} 2 \mathrm{p}^{2}\left({ }^{3} \mathrm{P}\right) 3 \mathrm{~s}^{2} \mathrm{P}, 2 \mathrm{~s}^{2} 2 \mathrm{p}^{2}\left({ }^{1} \mathrm{D}\right) 3 \mathrm{~s}^{2} \mathrm{D}$, and $2 \mathrm{~s}^{2} 2 \mathrm{p}^{2}\left({ }^{1} \mathrm{~S}\right) 3 \mathrm{~s}^{2} \mathrm{~S}$ which were from the NIST Standard Reference Database (Martin et al. 1995). $A$ values were obtained from a 4 configuration model of Mg VI used in Superstructure, produced for the CHIANTI database by
P. R. Young. Effective collision strengths were from Bhatia \& Young (1998).

Si VIII and Sx energy levels were from the NIST database (Martin et al. 1995), oscillator strengths and effective collision strengths (in the distorted wave approximation) were from Bhatia \& Mason (1980).

\subsubsection{O-like ions}

The first 10 fine-structure resolved levels (up to $2 \mathrm{p}^{6}{ }^{1} \mathrm{~S}_{0}$ ) were included. Energy levels were from the NIST database (Martin et al. 1995).

Ne III and $\mathrm{MgV}$ oscillator strengths were from unpublished calculations by A. K. Bhatia included in the CHIANTI database. Effective collision strengths for the ground configuration and $T_{\mathrm{e}}<10^{6} \mathrm{~K}$ were from Butler \& Zeippen (1994) close-coupling calculations. Effective collision strengths for the ground configuration and $T_{\mathrm{e}}>10^{6} \mathrm{~K}$ and for other transitions were from the distorted-wave unpublished calculations of A. K. Bhatia included in the CHIANTI database. Oscillator strengths and effective collision strengths for Si VII (in the distorted wave approximation) were from Bhatia et al. (1979).

\subsubsection{Fe ions}

For Ne-like FexviI, 37 fine-structure levels up to $2 \mathrm{~s} 2 \mathrm{p}^{61} \mathrm{D}_{2}$ where included. All data were taken from Bhatia \& Doschek (1992) except for the energy of the higher $2 \mathrm{~s} 2 \mathrm{p}^{6} 3 \mathrm{l}$ levels which were from the NIST database (Martin et al. 1995).

For Na-like FexVI, the first 21 fine-structure resolved levels (up to $5 \mathrm{~g}^{2} \mathrm{G}_{9 / 2}$ ) were included in our model ion. The data for this sequence were taken from the work of Sampson et al. (1990) who calculated collision data in the relativistic distorted wave approximation.

Mg-like Fe XV data were taken from Superstructure and distorted wave calculations by Bhatia \& Mason (1997).

The energy levels for Al-like Fe XIV were from the NIST database (Martin et al. 1995); oscillator strengths from Fischer \& Liu (1986); effective collision strengths from Dufton \& Kingston (1991) and Storey et al. (1996).

The Fe XIII (Si-like) energy levels were from Penn \& Kuhn (1994), Jupén et al. (1993) and the NIST database (Martin et al. 1995). Oscillator strengths were from a 24 configuration model Superstructure calculation for the CHIANTI database. Effective collision strengths were from Fawcett \& Mason (1989).

The model for Fe XII (P-like) included the first 41 finestructure levels. Energy levels were taken from Jupén et al. (1993) and Corliss \& Sugar (1982). Oscillator strengths were from a 24 configuration model Superstructure calculation for the CHIANTI database. Effective collision strengths were from Tayal et al. (1987) and Flower (1977).

The Fe XI model (S-like) included 47 fine-structure levels. Energy levels were from the NIST database (Martin et al. 1995) and Jupén et al. (1993). Oscillator strengths 
were from a 13 configuration model Superstructure calculation for the CHIANTI database. Effective collision strengths were from unpublished calculations of Bhatia and Doschek, included in the CHIANTI database.

The Fex atomic model (Cl-like) included 54 finestructure levels. Energy levels were from the NIST database (Martin et al. 1995) and from Jupén et al. (1993). Oscillator strengths were from a 12 configuration model Superstructure calculation for the CHIANTI database. Effective collision strengths were from Bhatia \& Doschek (1995).

For the Ar-like Fe IX, 13 fine-structure levels were included. Energy levels were from the NIST database (Martin et al. 1995). Oscillator strengths were from a 10 configuration model Superstructure calculation for the CHIANTI database. Effective collision strengths were from Fawcett \& Mason (1991).

\subsection{Ionisation and recombination coefficients}

The ionisation and recombination coefficients of Arnaud \& Rothenflug (1985) have been used for all elements except Fe, for which the Arnaud \& Raymond (1992) results have been adopted. Such coefficients have been modified to take into account the effect of finite electron density as in Summers (1974).

The exclusion of iron lines from the determination of the DEM allows an independent test for the iron ionisation balance. Our results indicate that a substantial improvement is required for this complex element (see Sects. 4.5.1-4.5.9).

\section{Results}

\subsection{Electron density from line ratio analysis}

We estimate the electron density for the evaluation of the kernels using selected density-sensitive line ratios. The selection eliminates density-sensitive ratios which use lines known to be affected by blends or ratios the lines of which are inconsistent with other density-insensitive ratios including them. Despite the large number of identified lines, only a few density sensitive line ratios satisfy these requirements, and these are listed in Table 1, where the peak temperature of line formation and the electron density calculated with ADAS are also reported (see also Young et al. 1998).

$\operatorname{MgV}(276.582 \AA)$ is a marginal detection by Dwivedi et al. (1998) and is used together with the $\operatorname{MgV}(351.117 \AA)$ to estimate the electron density at $\log \left(T_{\mathrm{e}}\right) \sim$ 5.45. $\operatorname{Mg}$ VII $(280.744 \AA)$ is an additional identification by Dwivedi et al. (1998), whose ratio with Mg VII $(367.675 \AA)$ allows an estimate of the electron density at $\log \left(T_{\mathrm{e}}\right) \sim 5.80$.

Figure 1 shows $N_{\mathrm{e}}$ from the selected line ratios vs. $T_{\mathrm{e}}$, compared with models with constant $P_{\mathrm{e}}$ or constant $N_{\mathrm{e}}$. The density at $\log \left(T_{\mathrm{e}}\right) \sim 5.45$ inferred from the $\mathrm{Mg}$ V 276.582/351.117 $\AA$ ratio would lead to the
Table 1. Selected density-sensitive line ratios for the evaluation of the kernels. $T_{\mathrm{p}}$ is the peak temperature of line formation.

\begin{tabular}{llll}
\hline Ion & Ratio $(\AA)$ & $\log \left(T_{\mathrm{p}}\right)$ & $\log \left(N_{\mathrm{e}}\right)$ \\
\hline $\mathrm{Mg}$ V & $276.582 / 351.117$ & 5.45 & $9.3_{-0.3}^{+0.2}$ \\
$\mathrm{Mg}$ VII & $280.744 / 367.675$ & 5.80 & $9.5_{-1.1}^{+0.5}$ \\
$\mathrm{Si} \mathrm{IX}$ & $258.082 / 296.113$ & 6.05 & $9.9_{-0.5}^{+0.3}$ \\
$\mathrm{Si}$ X & $356.029 / 347.408$ & 6.15 & $9.3_{-0.4}^{+0.4}$ \\
S XII & $299.540 / 288.420$ & 6.30 & $9.5_{-0.4}^{+0.3}$ \\
\hline
\end{tabular}



Fig. 1. Electron density from selected line ratios (see Table 1). Dotted lines indicate the limiting constant $P_{\mathrm{e}}$ models which are compatible with the selected line ratios, excluding $\mathrm{Mg} \mathrm{V}$ $276.582 / 351.117 \AA$ at $\log \left(T_{\mathrm{e}}\right) \sim 5.45$. Dashed lines indicate the limiting constant $N_{\mathrm{e}}$ models which are compatible with the selected line ratios.

conclusion that the plasma is closer to having constant $N_{\mathrm{e}}$ rather than constant $P_{\mathrm{e}}$, which would imply the breakdown of hydrostatic equilibrium. Stronger evidence for constant $N_{\mathrm{e}}$ comes from the possibility that Si IX (258.082 $\AA$ ) may be blended or affected by inaccuracies in intensity calibration at the low wavelength bandpass of the instrument (see Sect.4.4.4). The corrected Si IX 258.082/296.113 $\AA$ ratio would be in closer agreement with the other diagnostics of Table 1 and would indicate that the plasma is closer to having constant electron density rather than constant electron pressure. However, in order to investigate the consequences of assuming a constant electron pressure, we use both constant $P_{\mathrm{e}}$ and constant $N_{\mathrm{e}}$ approximations for the evaluation of the kernels.

Given the high reliability of the SxII 299.540/ $288.420 \AA$ ratio, we consider $P_{\mathrm{e}}=6 \times 10^{15} \mathrm{~cm}^{-3} \mathrm{~K}$ the most likely electron pressure in the uniform pressure approximation and $N_{\mathrm{e}}=3 \times 10^{9} \mathrm{~cm}^{-3}$ the most likely electron density in the uniform density approximation. In what follows, therefore, we shall discuss in detail results obtained with kernels evaluated in those two cases. However, note that much larger grids of uniform $P_{\mathrm{e}}$ and uniform $N_{\mathrm{e}}$ have also been considered. 


\subsection{The emission measure differential in temperature}

In Table 2 the lines used for the integral inversion are listed. Observed intensities are compared with theoretical values from the DEM modelling with $G$ functions computed in the uniform density approximation $\left(\log \left(N_{\mathrm{e}}\right)=\right.$ $\left.9.5 \mathrm{~cm}^{-3}\right)$ and uniform pressure approximation $\left(\log \left(P_{\mathrm{e}}\right)=\right.$ $15.8 \mathrm{~cm}^{-3} \mathrm{~K}$ ). In Tables $2-13$ there are entries indicating the chi-square in the $i$ th line, i.e.

$\chi_{i}^{2}=\left(\frac{I_{i}^{\mathrm{th}}-I_{i}^{\mathrm{obs}}}{\sigma_{i}}\right)^{2}$,

such that the chi-square of the model fitting is

$\chi^{2}=\sum_{j} \chi_{j}^{2}$

with $j$ spanning the lines used for the integral inversion. In Eq. (28), $I_{i}^{\text {th }}$ and $I_{i}^{\text {obs }}$ are the theoretical and observed intensity respectively, and $\sigma_{i}=\sigma_{0} s_{i}$ (see Sect. 2.3). The quantity $\chi_{i}^{2}$ is used as a statistical indicator of significant discrepancies. $\left(\sigma_{0} \chi_{i}\right)^{2}$ will be on the order of unity or less if the model is successful in reproducing the line intensity, but significantly larger than unity for any line that deviates from the model. Since $\sigma_{i}=\sigma_{0} s_{i}$, and defining $s_{i}=e_{i}^{\text {obs }}$ (the observational accuracy) as weighting factors, such deviations will largely reflect discrepancies from the model. To facilitate the comparison between the uniform electron density and the uniform electron pressure approximations, in Tables $2-13$ we report the product $\left(\sigma_{0} \chi_{i}\right)^{2}$ in the $i$ th line. In the uniform density approximation $\left(\log \left(N_{\mathrm{e}}\right)=9.5 \mathrm{~cm}^{-3}\right)$ we obtain $\sigma_{0}=0.49$, $\lambda=15.8$ and $\chi^{2}=8.8$. In the uniform pressure approximation $\left(\log \left(P_{\mathrm{e}}\right)=15.8 \mathrm{~cm}^{-3} \mathrm{~K}\right)$ we obtain $\sigma_{0}=0.35$, $\lambda=9.0$ and $\chi^{2}=8.2$. Note that all the lines used for the integral inversion are reproduced within the observational uncertainties.

The selection was carried out eliminating lines known to be affected by blends or inconsistent with densityinsensitive line ratios, as done for the density sensitive line ratios in Sect.4.1. The use of more than one line within $\Delta \log \left(T_{\mathrm{p}}\right)=0.05$, where $T_{\mathrm{p}}$ is the peak temperature of line formation, was avoided, the consequence of which is the selection of one line per ion at most. This latter constraint is adopted because the selection of lines forming at overlapping or quasi-overlapping temperatures makes the matrix $H_{i j}$ (Eq. (21)) numerically ill-conditioned (see Craig \& Brown 1986; McIntosh et al. 2000). By adopting the automatic smoothing procedure described in Sect. 2.3, the inclusion of many lines sampling approximately the same temperature range causes the smoothing parameter $\lambda$ to increase significantly in order to compensate for the ill-conditioning of the matrix $H_{i j}$. This results in an oversmoothed solution which fails to reproduce the observed intensities within the observational uncertainties.

The information from other lines neither affected by known blends nor inconsistent with density-insensitive line ratios is here used in the forward sense, i.e. the DEM is used to predict the intensities of such lines and the


Fig. 2. Differential emission measure (DEM) for an averaged solar active region using EUV line intensities observed by SERTS-89. The DEM in the upper panel has been obtained assuming a uniform $P_{\mathrm{e}}$ model in the evaluation of $G$ functions. The value adopted $\left(\log \left(P_{\mathrm{e}}\right)=15.8 \mathrm{~cm}^{-3} \mathrm{~K}\right)$ is taken from selected density sensitive line ratios (see Sect.4.1). The ratio with the DEM obtained assuming uniform $N_{\mathrm{e}}$ is is shown in the lower panel $\left(\log \left(N_{\mathrm{e}}\right)=9.5 \mathrm{~cm}^{-3}\right)$.

theoretical intensities are then compared with the observations. This latter comparison confirms that higher accuracy is obtained by avoiding the use in the integral inversion of lines forming at overlapping or quasioverlapping temperatures.

An attempt to select lines on the basis of their insensitivity to electron density has also been carried out. This latter procedure aims at obtaining a DEM as insensitive as possible to electron density. However, the temperature coverage and the elimination of lines known to be affected by blends or inconsistent with density-insensitive line ratios are found to be much more critical constraints and it is not possible to apply all criteria because this would lead to too small a set of lines for the integral inversion.

Figure 2 shows the DEM obtained assuming a uniform $P_{\mathrm{e}}$ model in the evaluation of the $G$ functions $\left(\log \left(P_{\mathrm{e}}\right)=\right.$ $15.8 \mathrm{~cm}^{-3} \mathrm{~K}$, upper panel) compared with the DEM obtained assuming uniform $N_{\mathrm{e}}\left(\log \left(N_{\mathrm{e}}\right)=9.5 \mathrm{~cm}^{-3}\right.$, lower panel). The difference of the DEM between the two approximations is within $10 \%$. Below $\log \left(T_{\mathrm{e}}\right)=5.8$, where the two models differ more significantly (see Fig. 1), the density sensitive $\operatorname{MgV}(351.117 \AA)$ line at $\log \left(T_{\mathrm{e}}\right)=5.45$ is better reproduced by the uniform $P_{\mathrm{e}}$ model, suggesting 
Table 2. Lines used for the integral inversion. $\lambda^{\text {ad. }}$ is our preferred laboratory wavelength and $\lambda^{\text {obs. }}$ the fitted wavelength by Thomas \& Neupert (1994) and Young et al. (1998). $T_{\mathrm{p}}$ is the peak temperature of line formation. The observed intensities are $I^{\text {obs }}$ and their uncertainties $e^{\text {obs }}$. Theoretical intensities $I^{\text {th }}$ together with the corresponding $\left(\sigma_{0} \chi_{i}\right)^{2}$ are given in the two cases where the $G$ functions are computed in the uniform density approximation $\left(\log \left(N_{\mathrm{e}}\right)=9.5 \mathrm{~cm}^{-3}\right)$ and uniform pressure approximation $\left(\log \left(P_{\mathrm{e}}\right)=15.8 \mathrm{~cm}^{-3} \mathrm{~K}\right)$. Intensities are in $\mathrm{erg}^{\mathrm{cm}}{ }^{-2} \mathrm{~s}^{-1} \mathrm{sr}^{-1}$. Parentheses indicate the power of ten to which the number must be raised.

\begin{tabular}{|c|c|c|c|c|c|c|c|c|c|c|}
\hline Ion & $\lambda^{\text {ad. }}$ & Transition & $\lambda^{\text {obs. }}$ & $\log \left(T_{\mathrm{p}}\right)$ & $I^{\mathrm{obs}}$ & $e^{\text {obs }}$ & $\begin{array}{c}I^{\mathrm{th}} \\
\log \left(N_{\mathrm{e}}\right.\end{array}$ & $\begin{array}{l}\left(\sigma_{0} \chi_{i}\right)^{2} \\
=9.5\end{array}$ & $\begin{array}{c}I^{\mathrm{th}} \\
\log \left(P_{\mathrm{e}}\right)\end{array}$ & $\begin{array}{l}\left(\sigma_{0} \chi_{i}\right)^{2} \\
=15.8\end{array}$ \\
\hline Ne III & $379.308^{\mathrm{N}}$ & $2 \mathrm{~s}^{2} 2 \mathrm{p}^{4}{ }^{1} \mathrm{D}_{2}-2 \mathrm{~s} 2 \mathrm{p}^{5}{ }^{1} \mathrm{P}_{1}^{0}$ & 379.306 & 5.05 & 7.6 & 2.2 & 7.4 & $8.3(-3)$ & 7.4 & $8.3(-3)$ \\
\hline Ne IV & $357.825^{\mathrm{E}}$ & $2 \mathrm{~s}^{2} 2 \mathrm{p}^{3}{ }^{2} \mathrm{D}_{3 / 2}^{0}-2 \mathrm{~s} 2 \mathrm{p}^{4}{ }^{2} \mathrm{P}_{1 / 2}$ & 357.889 & 5.30 & 7.8 & 3.9 & 8.6 & $4.2(-2)$ & 8.4 & $2.4(-2)$ \\
\hline $\mathrm{Mg} \mathrm{V}$ & $351.085^{\mathrm{E}}$ & $2 \mathrm{~s}^{2} 2 \mathrm{p}^{4}{ }^{3} \mathrm{P}_{2}-2 \mathrm{~s} 2 \mathrm{p}^{5}{ }^{3} \mathrm{P}_{1}^{0}$ & 351.117 & 5.45 & 13.1 & 4.6 & 13.4 & $4.3(-3)$ & 12.8 & $4.3(-3)$ \\
\hline $\mathrm{Ne} V$ & $359.375^{\mathrm{E}}$ & $2 \mathrm{~s}^{2} 2 \mathrm{p}^{2}{ }^{3} \mathrm{P}_{2}-2 \mathrm{~s} 2 \mathrm{p}^{3}{ }^{3} \mathrm{~S}_{1}^{0}$ & 359.378 & 5.50 & 26.3 & 4.3 & 26.3 & 0.0 & 26.5 & $2.2(-3)$ \\
\hline Ne VI & $401.928^{\mathrm{E}}$ & $2 \mathrm{~s}^{2} 2 \mathrm{p}^{2} \mathrm{P}_{3 / 2}^{0}-2 \mathrm{~s} 2 \mathrm{p}^{2}{ }^{2} \mathrm{P}_{3 / 2}$ & 401.936 & 5.60 & 84.6 & 9.8 & 83.4 & $1.5(-2)$ & 83.6 & $1.0(-2)$ \\
\hline Na VIII & $411.166^{\mathrm{E}}$ & $2 \mathrm{~s}^{2}{ }^{1} \mathrm{~S}_{0}-2 \mathrm{~s} 2 \mathrm{p}{ }^{1} \mathrm{P}_{1}^{0}$ & 411.164 & 5.85 & 26.0 & 3.6 & 27.0 & $7.7(-2)$ & 27.4 & $1.5(-1)$ \\
\hline Mg VIII & $315.015^{\mathrm{E}}$ & $2 \mathrm{~s}^{2} 2 \mathrm{p}^{2} \mathrm{P}_{3 / 2}^{0}-2 \mathrm{~s} 2 \mathrm{p}^{2}{ }^{2} \mathrm{P}_{3 / 2}$ & 315.024 & 5.90 & 253.0 & 31.0 & 242.0 & $1.4(-1)$ & 238.0 & $2.3(-1)$ \\
\hline $\operatorname{Mg} I X$ & $368.057^{\mathrm{E}}$ & $2 \mathrm{~s}^{2}{ }^{1} \mathrm{~S}_{0}-2 \mathrm{~s} 2 \mathrm{p}{ }^{1} \mathrm{P}_{1}^{0}$ & 368.063 & 6.00 & 1070.0 & 122.0 & 1051.2 & $2.4(-2)$ & 1067.3 & $4.9(-4)$ \\
\hline Si IX & $341.950^{\mathrm{E}}$ & $2 \mathrm{~s}^{2} 2 \mathrm{p}^{2}{ }^{3} \mathrm{P}_{0}-2 \mathrm{~s} 2 \mathrm{p}^{3}{ }^{3} \mathrm{D}_{1}^{0}$ & 341.974 & 6.05 & 29.4 & 4.9 & 34.3 & 1.0 & 33.0 & $5.5(-1)$ \\
\hline $\mathrm{Alx}$ & $332.788^{\mathrm{E}}$ & $2 \mathrm{~s}^{2}{ }^{1} \mathrm{~S}_{0}-2 \mathrm{~s} 2 \mathrm{p}{ }^{1} \mathrm{P}_{1}^{0}$ & 332.782 & 6.10 & 159.0 & 19.4 & 159.7 & $1.3(-3)$ & 160.1 & $3.2(-3)$ \\
\hline $\operatorname{Six}$ & $272.005^{\mathrm{E}}$ & $2 \mathrm{~s}^{2} 2 \mathrm{p}^{2} \mathrm{P}_{1 / 2}^{0}-2 \mathrm{~s} 2 \mathrm{p}^{2}{ }^{2} \mathrm{~S}_{1 / 2}$ & 271.992 & 6.15 & 131.0 & 25.0 & 122.4 & $1.2(-1)$ & 119.5 & $2.1(-1)$ \\
\hline SiXI & $365.429^{\mathrm{E}}$ & $2 \mathrm{~s} 2 \mathrm{p}^{3} \mathrm{P}_{2}^{0}-2 \mathrm{p}^{2}{ }^{3} \mathrm{P}_{2}$ & 365.419 & 6.20 & 39.8 & 5.9 & 31.9 & 1.8 & 34.6 & $7.8(-1)$ \\
\hline S XI & $246.895^{\mathrm{E}}$ & $2 \mathrm{~s}^{2} 2 \mathrm{p}^{2}{ }^{3} \mathrm{P}_{2}-2 \mathrm{~s} 2 \mathrm{p}^{3}{ }^{3} \mathrm{P}_{2}^{0}$ & 246.887 & 6.25 & 104.0 & 44.0 & 108.6 & $1.1(-2)$ & 116.7 & $8.3(-2)$ \\
\hline S XII & $288.420^{\mathrm{E}}$ & $2 \mathrm{~s}^{2} 2 \mathrm{p}^{2} \mathrm{P}_{1 / 2}^{0}-2 \mathrm{~s} 2 \mathrm{p}^{2}{ }^{2} \mathrm{D}_{3 / 2}$ & 288.401 & 6.35 & 135.0 & 21.0 & 143.8 & $1.8(-1)$ & 142.6 & $1.3(-1)$ \\
\hline S XIV & $417.645^{\mathrm{E}}$ & $2 \mathrm{~s}^{2} \mathrm{~S}_{1 / 2}-2 \mathrm{p}{ }^{2} \mathrm{P}_{3 / 2}^{0}$ & 417.640 & 6.45 & 184.0 & 21.0 & 180.1 & $3.4(-2)$ & 179.2 & $5.2(-2)$ \\
\hline Ar XVI & $353.860^{\mathrm{E}}$ & $2 \mathrm{~s}^{2} \mathrm{~S}_{1 / 2}-2 \mathrm{p}^{2} \mathrm{P}_{3 / 2}^{0}$ & 353.963 & 6.65 & 7.7 & 3.7 & 10.6 & $6.1(-1)$ & 10.2 & $4.6(-1)$ \\
\hline Ca XviII & $302.205^{\mathrm{E}}$ & $2 \mathrm{~s}^{2} \mathrm{~S}_{1 / 2}-2 \mathrm{p}^{2} \mathrm{P}_{3 / 2}^{0}$ & 302.167 & 6.80 & 25.3 & 10.0 & 19.7 & $3.0(-1)$ & 20.9 & $1.9(-1)$ \\
\hline
\end{tabular}

E Wavelength from Edlén (1983a, 1983b, 1984, 1985a, 1985b, 1985c).

$\mathrm{N}$ Wavelength from NIST standard reference database.

that the error bars on the $\operatorname{Mgv}(276.582 \AA)$ line should be larger than those given by Dwivedi et al. (1998). At higher temperatures, Si XI $(365.429 \AA)$ is well reproduced in the uniform $P_{\mathrm{e}}$ but not in the uniform $N_{\mathrm{e}}$ approximation, although the discrepancy is not severe in this latter case $\left(\left(\sigma_{0} \chi_{i}\right)^{2}=1.8\right.$, see Table 2 and discussion in Sect.4.4.2).

In order to examine the propagation of kernel uncertainties on the differential emission measure analysis, we have further computed the DEM over uniform $P_{\mathrm{e}}$ and uniform $N_{\mathrm{e}} G$-function grids as described in Sect.2.2. The accuracy of the reconstructed intensities gets worse as we go to lower or higher values than $\log \left(P_{\mathrm{e}}\right)=15.8$ (uniform pressure approximation) or $\log \left(N_{\mathrm{e}}\right)=9.5$ (uniform density approximation). It was not possible to obtain a solution for the zero density limit $\left(P_{\mathrm{e}}=10^{10} \mathrm{~cm}^{-3} \mathrm{~K}\right)$ using the method introduced in Sect. 2.3, while other methods (see Thompson \& Craig 1992) produced a spurious extra peak at approximately $\log \left(T_{\mathrm{e}}\right)=6.1$. A similar behaviour, with substantial spurious extra peaks having different heights or appearing for different values of uniform $P_{\mathrm{e}}$ or $N_{\mathrm{e}}$, is also found under the following conditions: 1 - when collisional data of lower accuracy are used; 2 when the temperature coverage criteria described above are not applied; and 3 - when lines more sensitive to $N_{\mathrm{e}}$ are included in the integral inversion.

\subsection{Elemental abundances}

In evaluating elemental abundances, we start by assuming that the $\mathrm{Ne}$ abundance (with respect to $\mathrm{H}$ ) in the transition region and corona is the same as in the photosphere. In other words, we assume that high-FIP elements (i.e. elements with their first ionisation potential - FIP - greater than approximately $10 \mathrm{eV}$ ) have coronal abundances close to their photospheric values. This assumption is necessary since we are unable to obtain elemental abundances relative to $\mathrm{H}$ using the SERTS- 89 spectrum alone, and therefore our abundances must be taken relative to one of the elements emitting in the SERTS-89 spectrum. Alternatively, we could have assumed, without loss of validity of our results, that low-FIP elements have photospheric abundances and that high-FIP elements are depleted in the corona. In this latter case, all abundances would have been scaled by a constant factor (approximately from the higher dotted line to the lower in Fig. 3) and the DEM would have been multiplied by the same factor. 


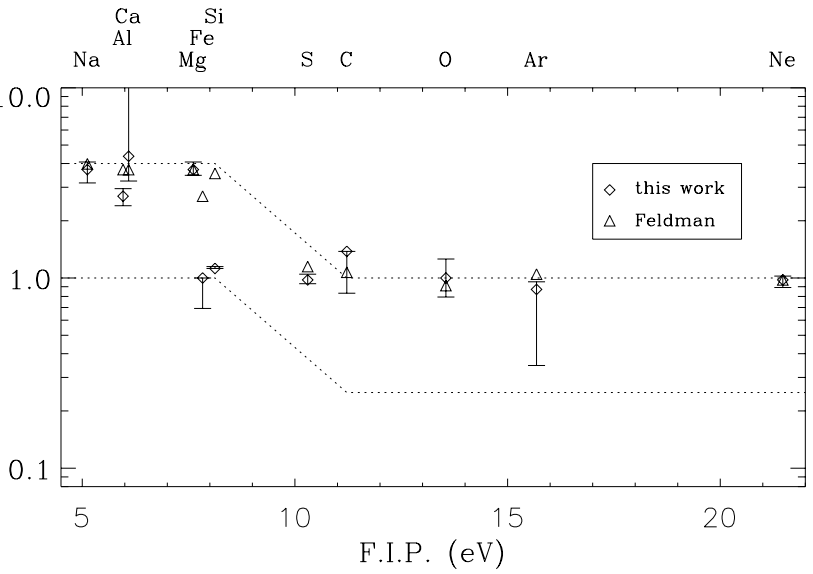

Fig. 3. Elemental abundances for the SERTS-89 active region compared with the Feldman et al. (1992) coronal abundances. Abundances are plotted as ratios with the photospheric values taken from Feldman (1992). Bars on the abundances indicate the range in which all the lines of that species (not affected by blends or by inaccuracies in the atomic data) are fitted within the observational errors. Only a lower limit to the Ca abundance is reported (see Sect. 4.4.1).

We have selected all observed lines not emitted by $\mathrm{Ne}$ ions which do not show evident blending or problems in the atomic data and adjusted the elemental abundances to get the minimum deviation from the observations. Such a procedure allows a quite accurate determination of the abundance ratios of elements whose lines form at close temperatures. In such cases, the uncertainties in the DEM reconstruction tend to cancel out and the dominant errors on the abundance ratios derive from the atomic data and observational uncertainties.

The results are shown in Fig. 3 together with the Feldman et al. (1992) coronal abundances for comparison. In Fig. 3, abundances are shown as ratios to their photosperic values (taken from Feldman 1992). We also show the abundance range in which all the selected lines of each element are reproduced within the observational uncertainties.

Our results are quite close to those of Feldman et al. (1992), except for Si $(\mathrm{FIP}=8.12 \mathrm{eV})$, which we find closer to its photospheric value. The Fe abundance too is found close to its photospheric value, but this conclusion is quite uncertain and based on Fe XI and Fe XII only. In fact, we cannot reconcile the Fe ionisation balance with the DEM obtained from lines of other elements (see Sects.4.5.14.5.9). Our results would suggest, in the active region observed by SERTS-89, a lower cut-off for the FIP effect, which is usually observed at around $10 \mathrm{eV}$. It also suggests that the transition from low-FIP to high-FIP elements is much steeper than in the Feldman abundances, i.e. between about 7.6 and $8.1 \mathrm{eV}$ rather than 8 and $10.5 \mathrm{eV}$, which may be important in trying to explain the FIP effect.

The range in which the spectral lines of an element are reproduced within the observational uncertainties shows, in the cases of $\mathrm{C}, \mathrm{Mg}$ and $\mathrm{Ar}$, a marked asymmetry with respect to the adopted value. This is because the abundance which produces the minimum deviation from observations may coincide with lower or upper limits for other lines of the same elements. Uncertainties in the atomic data could be the ultimate cause of this behaviour.

\subsection{Analysis of the SERTS-89 spectrum}

Spectral lines not included in the integral inversion are compared with observations in a forward sense, i.e. by comparing the intensities predicted using the DEM of Fig. 2 (in the uniform pressure approximation with $\log \left(P_{\mathrm{e}}\right)=15.8 \mathrm{~cm}^{-3} \mathrm{~K}$ and in the uniform density approximation with $\left.\log \left(N_{\mathrm{e}}\right)=9.5 \mathrm{~cm}^{-3}\right)$ with the observed intensities. We present this analysis by iso-electronic sequences except for the $\mathrm{Fe}$ ions which are discussed individually.

\subsubsection{Li-like lines}

In Table 3 we report the comparison of the Li-like lines with observations.

The CIV lines are all reproduced within the observational uncertainties except C IV $(419.713 \AA)$, whose theoretical intensity is $20-35 \%$ lower than observed. The C IV (419.713 $\AA$ ) line was identified as Cax by Behring et al. (1976) and by Dere (1978), and as a blend with Cax by Feldman et al. (1987). However, Keenan et al. (1993b) found good agreement between SERTS-89 measurements and theoretical line ratios of unblended CIV. Our analysis indicates that Ca X may contribute by up to $4.4 \mathrm{erg} \mathrm{cm}^{2} \mathrm{~s}^{-1} \mathrm{sr}^{-1}$.

The formation temperatures of the C IV lines overlap with the O-like ion Ne III. Ne III (379.308 $\AA$ ) is used for the integral inversion (see Table 2) and reproduced well within the observational uncertainties. This demonstrates consistency amongst the two ions and warrants the ratio of the lines as an abundance diagnostic.

$\operatorname{SxIV}(417.645 \AA)$ is used for the integral inversion to sample the region around $\log \left(T_{\mathrm{p}}\right)=6.45$ and is reproduced within the observational uncertainties. The theoretical S XIV (445.673 $\AA$ ) line is 30\% stronger than observed, which may be due to instrumental vignetting near the long-wavelength range of the instrument (Young et al. 1998).

$\operatorname{Ar}$ XVI $(353.860 \AA)$ is used in the integral inversion to sample the temperature range around $\log \left(T_{\mathrm{p}}\right)=6.65$ and is reproduced within the observational uncertainties. Note, however, that the DEM in this temperature region is rather poorly sampled, ArXVI being the only ion sampling the range $\log \left(T_{\mathrm{p}}\right)=6.45$ to 6.80 (see Table 2). Ar XVI (389.069 $\AA$ ) is blended with an Fe XVII line (Thomas \& Neupert 1994) and our results indicate that Ar XVI contributes about $40 \%$ of the blend's intensity.

Caxvini (302.205 $\AA$ ) is used in the integral inversion to sample the temperature range around $\log \left(T_{\mathrm{p}}\right)=6.80$, 
Table 3. Comparison of the observed intensities with those derived from the DEM for the Li-like iso-electronic sequence. Wavelengths are in $\AA$. Intensities in erg $\mathrm{cm}^{-2} \mathrm{~s}^{-1} \mathrm{sr}^{-1}$. See text for description.

\begin{tabular}{|c|c|c|c|c|c|c|c|c|c|c|}
\hline Ion & $\lambda^{\text {ad. }}$ & Transition & $\lambda^{\text {obs. }}$ & $\log \left(T_{\mathrm{p}}\right)$ & $I^{\mathrm{obs}}$ & $e^{\mathrm{obs}}$ & $\begin{array}{c}I^{\text {th }} \\
\log (N\end{array}$ & $\begin{array}{l}\left(\sigma_{0} \chi_{i}\right)^{2} \\
\text { e) }=9.5\end{array}$ & $\begin{array}{c}I^{\text {th }} \\
\log \left(P_{\mathrm{e}}\right)\end{array}$ & $\begin{array}{l}\left(\sigma_{0} \chi_{i}\right)^{2} \\
=15.8\end{array}$ \\
\hline C IV & $312.420^{\mathrm{N}}$ & $2 \mathrm{~s}^{2} \mathrm{~S}_{1 / 2}-3 \mathrm{p}{ }^{2} \mathrm{P}_{3 / 2}^{0}$ & & & & & 6.6 & & 7.8 & \\
\hline \multirow[t]{2}{*}{$\mathrm{C}$ IV } & $312.451^{\mathrm{N}}$ & $2 \mathrm{~s}{ }^{2} \mathrm{~S}_{1 / 2}-3 \mathrm{p}{ }^{2} \mathrm{P}_{1 / 2}^{0}$ & & & & & 3.3 & & 3.9 & \\
\hline & M - & & 312.429 & 5.05 & 14.2 & 7.2 & 9.9 & $3.6(-1)$ & 11.7 & $1.2(-1)$ \\
\hline C IV & $384.031^{\mathrm{N}}$ & $2 \mathrm{p}^{2} \mathrm{P}_{1 / 2}^{0}-3 \mathrm{~d}^{2} \mathrm{D}_{3 / 2}$ & 384.032 & 5.05 & 8.6 & 3.3 & 5.1 & 1.1 & 6.0 & $6.2(-1)$ \\
\hline C IV & $384.173^{\mathrm{N}}$ & $2 \mathrm{p}^{2} \mathrm{P}_{3 / 2}^{0}-3 \mathrm{~d}^{2} \mathrm{D}_{5 / 2}$ & & & & & 9.2 & & 10.8 & \\
\hline \multirow[t]{2}{*}{$\mathrm{C}_{\mathrm{IV}}$} & $384.189^{\mathrm{N}}$ & $2 \mathrm{p}^{2} \mathrm{P}_{3 / 2}^{0}-3 \mathrm{~d}^{2} \mathrm{D}_{3 / 2}$ & & & & & 1.0 & & 1.2 & \\
\hline & M - & & 384.165 & 5.05 & 9.5 & 2.5 & 10.2 & $7.8(-2)$ & 12.0 & 1.0 \\
\hline C IV & $419.525^{\mathrm{N}}$ & $2 \mathrm{p}{ }^{2} \mathrm{P}_{1 / 2}^{0}-3 \mathrm{~s}^{2} \mathrm{~S}_{1 / 2}$ & & 5.05 & & & 4.0 & & 4.9 & \\
\hline C IV & $419.713^{\mathrm{N}}$ & $2 \mathrm{p}^{2} \mathrm{P}_{3 / 2}^{0}-3 \mathrm{~s}^{2} \mathrm{~S}_{1 / 2}$ & 419.718 & 5.05 & 12.4 & 2.5 & 8.0 & $\mathrm{~b}$ & 9.8 & $\mathrm{~b}$ \\
\hline S XIV & $417.645^{\mathrm{E}}$ & $2 \mathrm{~s}^{2} \mathrm{~S}_{1 / 2}-2 \mathrm{p}^{2} \mathrm{P}_{3 / 2}^{0}$ & 417.640 & 6.45 & 184.0 & 21.0 & 180.1 & $3.4(-2)$ & 179.2 & $5.2(-2)$ \\
\hline S XIV & $445.673^{\mathrm{E}}$ & $2 \mathrm{~s}^{2} \mathrm{~S}_{1 / 2}-2 \mathrm{p}{ }^{2} \mathrm{P}_{1 / 2}^{0}$ & 445.660 & 6.45 & 65.5 & 7.7 & 86.2 & 7.2 & 85.8 & 6.9 \\
\hline Ar XVI & $353.860^{\mathrm{E}}$ & $2 \mathrm{~s}^{2} \mathrm{~S}_{1 / 2}-2 \mathrm{p}{ }^{2} \mathrm{P}_{3 / 2}^{0}$ & 353.963 & 6.65 & 7.7 & 3.7 & 10.6 & $6.1(-1)$ & 10.2 & $4.6(-1)$ \\
\hline Ar XVI & $389.069^{\mathrm{E}}$ & $2 \mathrm{~s}^{2} \mathrm{~S}_{1 / 2}-2 \mathrm{p}{ }^{2} \mathrm{P}_{1 / 2}^{0}$ & 389.075 & 6.60 & 12.8 & 2.2 & 4.9 & $\mathrm{~b}$ & 4.7 & $\mathrm{~b}$ \\
\hline Ca XviII & $302.205^{\mathrm{E}}$ & $2 \mathrm{~s}^{2} \mathrm{~S}_{1 / 2}-2 \mathrm{p}^{2} \mathrm{P}_{3 / 2}^{0}$ & 302.167 & 6.80 & 25.3 & 10.0 & 19.7 & $3.0(-1)$ & 20.9 & $1.9(-1)$ \\
\hline Ca XVIII & $344.760^{\mathrm{E}}$ & $2 \mathrm{~s}{ }^{2} \mathrm{~S}_{1 / 2}-2 \mathrm{p}{ }^{2} \mathrm{P}_{1 / 2}^{0}$ & 344.772 & 6.75 & 13.6 & 4.8 & 9.0 & $9.2(-1)$ & 9.5 & $7.3(-1)$ \\
\hline
\end{tabular}

b: Blended.

E Wavelength from Edlén (1983a).

$\mathrm{N}$ Wavelength from NIST standard reference database.

which is the highest temperature in our analysis (see Table 2). The DEM at this limit is obviously less well determined and it is constrained mainly by the $\mathrm{Ca}$ abundance. Our DEM analysis allows evaluation only of a lower limit to the $\mathrm{Ca}$ abundance, which is essentially the same as the Feldman et al. (1992) coronal abundance (see Sect. 4.3). The theoretical Ca XVIII (344.760 $\AA$ ) intensity is reproduced within the observational uncertainties.

\subsubsection{Be-like lines}

The comparison for the Be-like ions is reported in Table 4.

$\mathrm{O} \mathrm{v}(215.245 \AA)$ is a weak feature observed in second order, close to the first order Mg VIII (430.45 $\AA$ ). Assuming a photospheric abundance for $\mathrm{O}$ (see Sect.4.3), the theoretical intensity is only $10 \%$ of that observed and below the instrumental sensitivity limit at these wavelengths. O v $(248.460 \AA)$ lies close to the low wavelength range of the instrument bandpass, where the sensitivity is lowest, and the predicted intensity is less than $30 \%$ of that observed. The O v $(220.352 \AA)$ intensity is predicted to be approximately $13 \mathrm{erg} \mathrm{cm}^{-2} \mathrm{~s}^{-1} \mathrm{sr}^{-1}$, below the instrumental sensitivity limit at these wavelengths. Looking at the O v (215.245 ^)-O v (220.352 ̊) branching ratio and the lack of detection of O v $(220.352 \AA)$, Young et al. (1998) flagged O v $(215.245 \AA)$ as a possible misidentification. Our DEM analysis essentially confirms this conclusion, although the comparison with other lines indicates a possible inaccuracy of the intensity calibration at the low wavelength range of the instrument bandpass (see below).

Na VIII (411.166 $\AA$ ) is used in the integral inversion and reproduced within the observational uncertainties. Its formation temperature $\left(\log \left(T_{\mathrm{p}}\right)=5.85\right)$ is close to the C-like Mg VII lines (see Sect. 4.4.4).

$\operatorname{Mg}$ IX (368.057 $\AA$ ) is used in the integral inversion to sample the temperature region around $\log \left(T_{\mathrm{p}}\right)=6.00$ and is reproduced within the observational uncertainties. Of the other MgIX lines those at $443.967 \AA$ and $448.298 \AA$ are not reproduced within the observational uncertainties, the theoretical intensities being a factor 1.6 and 2.3 that observed, respectively. This may be caused by instrumental vignetting and/or errors in the quoted sensitivity of the instrument close to the longwavelength range of the instrument (see Young et al. 1998; 
Table 4. As for Table 3 for the Be-like iso-electronic sequence.

\begin{tabular}{|c|c|c|c|c|c|c|c|c|c|c|}
\hline Ion & $\lambda^{\text {ad. }}$ & Transition & $\lambda^{\text {obs. }}$ & $\log \left(T_{\mathrm{p}}\right)$ & $I^{\text {obs }}$ & $e^{\text {obs }}$ & $\begin{array}{c}I^{\text {th }} \\
\log \left(N_{\mathrm{e}}\right.\end{array}$ & $\begin{array}{l}\left(\sigma_{0} \chi_{i}\right)^{2} \\
=9.5\end{array}$ & $\begin{array}{c}I^{\text {th }} \\
\log \left(P_{\mathrm{e}}\right)\end{array}$ & $\begin{array}{l}\left(\sigma_{0} \chi_{i}\right)^{2} \\
=15.8\end{array}$ \\
\hline $\mathrm{OV}$ & $215.040^{\mathrm{N}}$ & $2 \mathrm{~s} 2 \mathrm{p}^{3} \mathrm{P}_{0}^{0}-2 \mathrm{~s} 3 \mathrm{~s}^{3} \mathrm{~S}_{1}$ & & 5.40 & & & 1.7 & & 1.9 & \\
\hline $\mathrm{OV}$ & $215.103^{\mathrm{N}}$ & $2 \mathrm{~s} 2 \mathrm{p}{ }^{3} \mathrm{P}_{1}^{0}-2 \mathrm{~s} 3 \mathrm{~s}^{3} \mathrm{~S}_{1}$ & & 5.40 & & & 5.1 & & 5.6 & \\
\hline $\mathrm{Ov}$ & $215.245^{\mathrm{N}}$ & $2 \mathrm{~s} 2 \mathrm{p}^{3} \mathrm{P}_{2}^{0}-2 \mathrm{~s} 3 \mathrm{~s}^{3} \mathrm{~S}_{1}$ & 215.288 & 5.40 & 79.4 & 35.0 & 8.5 & 4.1 & 9.3 & 4.0 \\
\hline $\mathrm{Ov}$ & $220.352^{\mathrm{N}}$ & $2 \mathrm{~s} 2 \mathrm{p}{ }^{1} \mathrm{P}_{1}^{0}-2 \mathrm{~s} 3 \mathrm{~d}^{1} \mathrm{D}_{2}$ & & 5.40 & & & 12.9 & & 12.0 & \\
\hline $\mathrm{Ov}$ & $248.460^{\mathrm{N}}$ & $2 \mathrm{~s} 2 \mathrm{p}{ }^{1} \mathrm{P}_{1}^{0}-2 \mathrm{~s} 3 \mathrm{~s}{ }^{1} \mathrm{~S}_{0}$ & 248.460 & 5.40 & 59.7 & 34.0 & 15.7 & 1.7 & 14.4 & 1.8 \\
\hline Na VIII & $411.166^{\mathrm{E}}$ & $2 \mathrm{~s}^{2}{ }^{1} \mathrm{~S}_{0}-2 \mathrm{~s} 2 \mathrm{p}{ }^{1} \mathrm{P}_{1}^{0}$ & 411.164 & 5.85 & 26.0 & 3.6 & 27.0 & $7.7(-2)$ & 27.4 & $1.5(-1)$ \\
\hline Mg IX & $368.057^{\mathrm{E}}$ & $2 \mathrm{~s}^{2}{ }^{1} \mathrm{~S}_{0}-2 \mathrm{~s} 2 \mathrm{p}{ }^{1} \mathrm{P}_{1}^{0}$ & 368.063 & 6.00 & 1070.0 & 122.0 & 1051.2 & $2.4(-2)$ & 1067.3 & $4.9(-4)$ \\
\hline $\operatorname{Mg}$ IX & $438.698^{\mathrm{E}}$ & $2 \mathrm{~s} 2 \mathrm{p}^{1} \mathrm{P}_{1}^{0}-2 \mathrm{p}^{2}{ }^{1} \mathrm{~S}_{0}$ & & 5.95 & & & 2.3 & & 2.3 & \\
\hline Mg IX & $439.170^{\mathrm{E}}$ & $2 \mathrm{~s} 2 \mathrm{p}^{3} \mathrm{P}_{1}^{0}-2 \mathrm{p}^{2}{ }^{3} \mathrm{P}_{2}$ & 439.173 & 5.95 & 9.4 & 2.4 & 11.5 & $7.7(-1)$ & 12.0 & 1.2 \\
\hline $\operatorname{Mg} I X$ & $441.201^{\mathrm{E}}$ & $2 \mathrm{~s} 2 \mathrm{p}^{3} \mathrm{P}_{0}^{0}-2 \mathrm{p}^{2}{ }^{3} \mathrm{P}_{1}$ & 441.221 & 5.95 & 7.7 & 2.8 & 9.2 & $2.9(-1)$ & 9.5 & $4.1(-1)$ \\
\hline $\operatorname{Mg} I X$ & $443.408^{\mathrm{E}}$ & $2 \mathrm{~s} 2 \mathrm{p}^{3} \mathrm{P}_{1}^{0}-2 \mathrm{p}^{2}{ }^{3} \mathrm{P}_{1}$ & 443.371 & 5.95 & 5.6 & 1.9 & 6.8 & $4.0(-1)$ & 7.0 & $5.4(-1)$ \\
\hline Mg IX & $443.967^{\mathrm{E}}$ & $2 \mathrm{~s} 2 \mathrm{p}^{3} \mathrm{P}_{2}^{0}-2 \mathrm{p}^{2}{ }^{3} \mathrm{P}_{2}$ & 443.956 & 5.95 & 19.6 & 3.3 & 31.9 & $1.4(+1)$ & 33.1 & $1.7(+1)$ \\
\hline $\operatorname{Mg} I X$ & $445.969^{\mathrm{E}}$ & $2 \mathrm{~s} 2 \mathrm{p}^{3} \mathrm{P}_{1}^{0}-2 \mathrm{p}^{2}{ }^{3} \mathrm{P}_{0}$ & & 5.95 & & & 0.3 & & 0.3 & \\
\hline $\mathrm{Mg}$ IX & $448.298^{\mathrm{E}}$ & $2 \mathrm{~s} 2 \mathrm{p}^{3} \mathrm{P}_{2}^{0}-2 \mathrm{p}^{2}{ }^{3} \mathrm{P}_{1}$ & 448.279 & 5.95 & 4.7 & 1.5 & 10.6 & $1.5(+1)$ & 10.9 & $1.7(+1)$ \\
\hline $\mathrm{Alx}$ & $332.788^{\mathrm{E}}$ & $2 \mathrm{~s}^{2}{ }^{1} \mathrm{~S}_{0}-2 \mathrm{~s} 2 \mathrm{p}{ }^{1} \mathrm{P}_{1}^{0}$ & 332.782 & 6.10 & 159.0 & 19.4 & 159.7 & $1.3(-3)$ & 160.1 & $3.2(-3)$ \\
\hline Si XI & $303.326^{\mathrm{E}}$ & $2 \mathrm{~s}^{2}{ }^{1} \mathrm{~S}_{0}-2 \mathrm{~s} 2 \mathrm{p}{ }^{1} \mathrm{P}_{1}^{0}$ & 303.324 & 6.20 & 2930.0 & 330.0 & 1427.6 & $2.1(+1)$ & 1440.4 & $2.0(+1)$ \\
\hline Si XI & $358.343^{\mathrm{E}}$ & $2 \mathrm{~s} 2 \mathrm{p}{ }^{1} \mathrm{P}_{1}^{0}-2 \mathrm{p}^{2}{ }^{1} \mathrm{~S}_{0}$ & & 6.20 & & & 2.9 & & 2.9 & \\
\hline Si XI & $358.656^{\mathrm{E}}$ & $2 \mathrm{~s} 2 \mathrm{p}^{3} \mathrm{P}_{1}^{0}-2 \mathrm{p}^{2}{ }^{3} \mathrm{P}_{2}$ & & 6.20 & & & 11.5 & & 12.5 & \\
\hline Si XI & $361.410^{\mathrm{E}}$ & $2 \mathrm{~s} 2 \mathrm{p}^{3} \mathrm{P}_{0}^{0}-2 \mathrm{p}^{2}{ }^{3} \mathrm{P}_{1}$ & 361.406 & 6.20 & 23.7 & 4.3 & 9.6 & $1.1(+1)$ & 10.3 & 9.7 \\
\hline Si XI & $364.494^{\mathrm{E}}$ & $2 \mathrm{~s} 2 \mathrm{p}^{3} \mathrm{P}_{1}^{0}-2 \mathrm{p}^{2}{ }^{3} \mathrm{P}_{1}$ & & 6.20 & & & 7.0 & & 7.5 & \\
\hline Si XI & $365.429^{\mathrm{E}}$ & $2 \mathrm{~s} 2 \mathrm{p}^{3} \mathrm{P}_{2}^{0}-2 \mathrm{p}^{2}{ }^{3} \mathrm{P}_{2}$ & 365.419 & 6.20 & 39.8 & 5.9 & 31.9 & 1.8 & 34.6 & $7.8(-1)$ \\
\hline Si XI & $368.286^{\mathrm{E}}$ & $2 \mathrm{~s} 2 \mathrm{p}^{3} \mathrm{P}_{1}^{0}-2 \mathrm{p}^{2}{ }^{3} \mathrm{P}_{0}$ & & 6.20 & & & 0.3 & & 0.3 & \\
\hline Si XI & $371.492^{\mathrm{E}}$ & $2 \mathrm{~s} 2 \mathrm{p}^{3} \mathrm{P}_{2}^{0}-2 \mathrm{p}^{2}{ }^{3} \mathrm{P}_{1}$ & 371.499 & 6.20 & 14.5 & 3.7 & 10.8 & 1.0 & 11.5 & $6.6(-1)$ \\
\hline S XIII & $256.685^{\mathrm{E}}$ & $2 \mathrm{~s}^{2}{ }^{1} \mathrm{~S}_{0}-2 \mathrm{~s} 2 \mathrm{p}{ }^{1} \mathrm{P}_{1}^{0}$ & 256.683 & 6.40 & 527.0 & 70.0 & 376.2 & 4.6 & 380.2 & 4.4 \\
\hline
\end{tabular}

E Wavelength from Edlén (1983a, 1985c).

$\mathrm{N}$ Wavelength from NIST standard reference database.

Keenan et al. 1994). The electron density derived from the density sensitive $443.967 / 368.057 \AA$ ratio is therefore affected by large errors.

$\mathrm{Al} \times(332.788 \AA)$ is used in the integral inversion to sample the temperature range around $\log \left(T_{\mathrm{p}}\right)=6.10$ and is in excellent agreement with observations.

$\operatorname{SiXI}(365.429 \AA)$ is used in the integral inversion to sample the temperature range around $\log \left(T_{\mathrm{p}}\right)=6.20$. Note that this line is well reproduced in the uniform $P_{\mathrm{e}}$ but not in the uniform $N_{\mathrm{e}}$ approximation, although the discrepancy is not severe in this latter case $\left(\left(\sigma_{0} \chi_{i}\right)^{2}=1.8\right)$. The population density of the upper level of this transition is, in fact, density sensitive, especially below $\log \left(N_{\mathrm{e}}\right)=10$, and the ratio of this line with the density insensitive $\mathrm{SiXI}(303.326 \AA)$ is taken as a density diagnostic (see, e.g., Young et al. 1998).
The observed Si XI (365.429 $) / \operatorname{Si~XI~(303.326~\AA )~line~ratio~}$ indicates $\log \left(N_{\mathrm{e}}\right)=9.2_{-0.2}^{+0.2}$, slightly lower than the electron density estimated in Table 1 and Fig. 1. However, Si XI $(303.326 \AA)$ is not reproduced within the observational uncertainties and its intensity is approximately twice that predicted. Note that this line is close to the strong He II ( $303.78 \AA$ ) and may be affected by background radiation. This situation suggests that Si XI $(303.326 \AA)$ may suffer by radiative pumping, blends, or uncertainties in the atomic data (see also Lang et al. 2001). Our results indicate that Fe XIII $(303.320 \AA)$ contributes by approximately $90 \mathrm{erg} \mathrm{cm}^{-2} \mathrm{~s}^{-1} \mathrm{sr}^{-1}$ to this feature (see Table 11), and therefore it is insufficient to explain the discrepancy. Another candidate is S XIII (303.384 $\AA$ ), but its intensity is predicted to be negligible (see below). 
SiXI $(358.656 \AA)$ is reported as blended with Fe XI (358.621 $\AA)$, Ne IV (358.688 $\AA$ ) and with an Fe XIV line by Young et al. (1998) and the DEM predicts a contribution of $17 \%$ of the intensity of the blend (see also Sect.4.5.3). From a branching ratio analysis, Young et al. (1998) found that FexI (358.621 $\AA$ ) is a factor 3 too strong, consistent with the presence of a blend, and that the SixI component provides around $14 \mathrm{erg} \mathrm{cm}^{-2} \mathrm{~s}^{-1} \mathrm{sr}^{-1}$.

Si XI (361.410 $\AA)$ is not reproduced within the observational uncertainties, its predicted intensity being a factor 0.4 of that observed. This suggests the presence of blends, as problems in the transition probabilities are excluded by theta pinch measurements (König et al. 1996).

Si XI (364.494 $\AA$ ) contributes by only $3 \%$ to the blend with Fe XII (364.467 $\AA$ ). Note that, in this case, the DEM prediction is about half of the intensity predicted by Young et al. (1998) from branching ratio analysis, which is obviously due to the discrepancies affecting the other line in the ratio, viz. Si XI (361.410 $)$.

Si XI $(371.492 \AA)$ is reproduced within the observational uncertainties.

The only SxIII line in the SERTS-89 spectrum (256.685 $\AA$ ) has a theoretical intensity about $30 \%$ lower than observed, outside the observational error bars. This suggests the presence of blends contributing by approximately 150 erg $\mathrm{cm}^{-2} \mathrm{~s}^{-1} \mathrm{sr}^{-1}$ or calibration inaccuracy at the shortest wavelength. Other S XIII multiplets in the SERTS-89 wavelength range are the $2 \mathrm{~s} 2 \mathrm{p}^{3} \mathrm{P}-2 \mathrm{p}^{2}{ }^{3} \mathrm{P}$ and $2 \mathrm{~s} 2 \mathrm{p}^{3} \mathrm{P}-2 \mathrm{p}^{2}{ }^{1} \mathrm{D}$, but our analysis predicts negligible intensities for them.

\subsubsection{B-like lines}

The comparison for the B-like lines is reported in Table 5.

Ne VI $(401.928 \AA)$ is used in the integral inversion to sample the temperature region around $\log \left(T_{\mathrm{p}}\right)=5.60$ with excellent agreement between theory and observations. Good agreement is found also for $\operatorname{NeVI}(399.826 \AA)$ and Ne VI $(401.154 \AA)$.

Ne VI $(403.270 \AA)$ is blended with $\operatorname{Mg}$ VI $(403.307 \AA)$ and our DEM analysis indicates that it contributes 18.5 erg $\mathrm{cm}^{-2} \mathrm{~s}^{-1} \mathrm{sr}^{-1}$. Note, however, that the DEM predicts the Mg VI $(403.307 \AA)$ intensity a factor 2 higher than observed (see Sect.4.4.5), which suggests inaccuracy in the atomic data for $\mathrm{Mg}$ VI.

Ne VI (433.172 $\AA$ ) and Ne VI (435.641 $\AA$ ) are a factor 1.8 and 2.3 higher than observed, respectively. This discrepancy may be attributed to the inaccuracy in the calibration of the instrument at the longest wavelengths as discussed by Young et al. (1998).

$\operatorname{Mg}$ VIII $(315.015 \AA)$ is used in the integral inversion to sample the region around $\log \left(T_{\mathrm{p}}\right)=5.90$ and is reproduced within the observational uncertainties. Of the other lines of the $2 \mathrm{~s}^{2} 2 \mathrm{p}^{2} \mathrm{P}-2 \mathrm{~s} 2 \mathrm{p}^{2}{ }^{2} \mathrm{P}$ multiplet, Mg VIII (313.743 $\AA$ ) and Mg VIII (317.028 $\AA$ ) are reproduced within the observational uncertainties, while
Mg VIII (311.772 $\AA$ ) is blended with a Ni XV line, contributing $60 \%$ of the total intensity.

Mg VIII (335.231 $\AA$ ) has an expected intensity of $42 \mathrm{erg} \mathrm{cm}^{-2} \mathrm{~s}^{-1} \mathrm{sr}^{-1}$, which is completely masked by the strong Fexvi $(335.396 \AA)$ line. The other line of the $2 \mathrm{~s}^{2} 2 \mathrm{p}^{2} \mathrm{P}-2 \mathrm{~s} 2 \mathrm{p}^{2}{ }^{2} \mathrm{~S}$ multiplet at $338.983 \AA$ is in excellent agreement with observations.

Predicted intensities of the $2 \mathrm{~s}^{2} 2 \mathrm{p}^{2} \mathrm{P}-2 \mathrm{~s} 2 \mathrm{p}^{2}{ }^{2} \mathrm{D}$ Mg VIII multiplet at 430.454 and $436.733 \AA$ are a factor two brighter than observed. This is consistent with the inaccuracy in the SERTS calibration at these wavelengths suggested earlier (see also Bhatia \& Thomas 1998). In the selfblended feature, the weak $\mathrm{Mg}$ VIII $(436.660 \AA)$ contributes $13 \mathrm{erg} \mathrm{cm} \mathrm{cm}^{-2} \mathrm{~s}^{-1} \mathrm{sr}^{-1}$ to the stronger $\mathrm{Mg}$ VIII (436.733 $\AA$ ).

The formation temperature of AlIx overlaps with $\mathrm{Mg}$ IX, making it a good tool for investigating the $\mathrm{Al} / \mathrm{Mg}$ abundance ratio, but unfortunately none of the observed Al Ix lines are reproduced satisfactorily. Only one line of the $2 \mathrm{~s}^{2} 2 \mathrm{p}^{2} \mathrm{P}-2 \mathrm{~s} 2 \mathrm{p}^{2} \mathrm{P}$ multiplet is reported in the Thomas \& Neupert (1994) catalogue (at 282.431 $\AA$ ), and the DEM predicts its intensity to be half that observed. The predicted intensity of Al IX (284.015 $\AA$ ) makes it potentially observable, but, as outlined by Young et al. (1998), it lies close to the very strong $\operatorname{FexV}(284.147 \AA)$ line and cannot be reliably fitted. The Al IX $(286.364 \AA)$ predicted intensity is below the instrumental sensitivity limit at these wavelengths. Both lines of the $2 \mathrm{~s}^{2} 2 \mathrm{p}^{2} \mathrm{P}$ $2 \mathrm{~s} 2 \mathrm{p}^{2}{ }^{2} \mathrm{~S}$ doublet are observed, but the predicted intensity is a factor 0.4 of that observed for the $305.055 \AA$ line and 0.2 for the $300.560 \AA$. Although their intensity ratio may suggest a blend affecting the $300.560 \AA$, the overall discrepancy remains unsolved. The other observed Al IX multiplet is the $2 \mathrm{~s}^{2} 2 \mathrm{p}^{2} \mathrm{P}-2 \mathrm{~s} 2 \mathrm{p}^{2} 2 \mathrm{D}$. Al Ix (384.950 $\left.\mathrm{A}\right)$ and Al IX (392.425 $\AA$ ) predicted intensities are a factor 1.8 and 1.2 higher than observed, respectively.

Si $x(272.005 \AA)$ is used in the integral inversion to sample the temperature region around $\log \left(T_{\mathrm{p}}\right)=6.15$ and is in good agreement with the observations. The other line of the $2 \mathrm{~s}^{2} 2 \mathrm{p}^{2} \mathrm{P}-2 \mathrm{~s} 2 \mathrm{p}^{2}{ }^{2} \mathrm{~S}$ doublet at $277.277 \AA$ is also in good agreement with observations. Of the $2 \mathrm{~s}^{2} 2 \mathrm{p}^{2} \mathrm{P}-2 \mathrm{~s} 2 \mathrm{p}^{2}{ }^{2} \mathrm{P}$ quartet, Si x (261.043 $\AA$ ) is in excellent agreement with observation. Si X $(256.366 \AA)$ contributes $185 \mathrm{erg} \mathrm{cm}^{-2} \mathrm{~s}^{-1} \mathrm{sr}^{-1}$ to the blend with He II. The other two lines, Si x (253.787 $\AA$ ) and Si x (258.371 $)$ are not reproduced within the observational uncertainties, their theoretical intensities being a factor 0.5 and 1.3 of that observed, respectively. Young et al. (1998) found that the branching ratio of these two lines shows a strong discrepancy with observations and suggested that the SERTS-89 values for these lines may be in error. Keenan et al. (2000a) estimated the observed $253.787 / 356.027 \AA$ ratio a factor 3 higher than expected but pointed out that Si x $(253.787 \AA)$ is well resolved in the SERTS- 89 spectrum and should be accurately measured. The Six line at $292.170 \AA$ is predicted to have an intensity of only $0.2 \mathrm{erg} \mathrm{cm}^{-2} \mathrm{~s}^{-1} \mathrm{sr}^{-1}$, and therefore we confirm the misidentification of the line at $292.25 \AA$ as noted by Young et al. (1998). The $2 \mathrm{~s} 2 \mathrm{p}^{2}{ }^{2} \mathrm{P}-$ $2 \mathrm{~s} 2 \mathrm{p}^{2}{ }^{2} \mathrm{D}$ Si $\mathrm{x}$ triplet is observed as one line at $347.406 \AA$ 
Table 5. As for Table 3 for the B-like iso-electronic sequence.

\begin{tabular}{|c|c|c|c|c|c|c|c|c|c|c|}
\hline Ion & $\lambda^{\text {ad. }}$ & Transition & $\lambda^{\text {obs. }}$ & $\log \left(T_{\mathrm{p}}\right)$ & $I^{\mathrm{obs}}$ & $e^{\text {obs }}$ & $\begin{array}{c}I^{\mathrm{th}} \\
\log (\Lambda\end{array}$ & $\begin{array}{l}\left(\sigma_{0} \chi_{i}\right)^{2} \\
=9.5\end{array}$ & $\begin{array}{c}I^{\text {th }} \\
\log \left(P_{\mathrm{e}}\right.\end{array}$ & $\begin{array}{l}\left(\sigma_{0} \chi_{i}\right)^{2} \\
=15.8\end{array}$ \\
\hline Ne VI & $399.826^{\mathrm{E}}$ & $2 \mathrm{~s}^{2} 2 \mathrm{p}^{2} \mathrm{P}_{1 / 2}^{0}-2 \mathrm{~s} 2 \mathrm{p}^{2}{ }^{2} \mathrm{P}_{3 / 2}$ & 399.837 & 5.60 & 14.9 & 2.8 & 16.4 & $2.9(-1)$ & 16.4 & $2.9(-1)$ \\
\hline $\mathrm{NeVI}$ & $401.154^{\mathrm{E}}$ & $2 \mathrm{~s}^{2} 2 \mathrm{p}^{2} \mathrm{P}_{1 / 2}^{0}-2 \mathrm{~s} 2 \mathrm{p}^{2}{ }^{2} \mathrm{P}_{1 / 2}$ & 401.139 & 5.60 & 29.9 & 4.0 & 31.7 & $2.0(-1)$ & 31.8 & $2.3(-1)$ \\
\hline $\mathrm{Ne}$ VI & $401.928^{\mathrm{E}}$ & $2 \mathrm{~s}^{2} 2 \mathrm{p}^{2} \mathrm{P}_{3 / 2}^{0}-2 \mathrm{~s} 2 \mathrm{p}^{2}{ }^{2} \mathrm{P}_{3 / 2}$ & 401.936 & 5.60 & 84.6 & 9.8 & 83.4 & $1.5(-2)$ & 83.6 & $1.0(-2)$ \\
\hline $\mathrm{Ne}$ VI & $403.270^{\mathrm{E}}$ & $2 \mathrm{~s}^{2} 2 \mathrm{p}^{2} \mathrm{P}_{3 / 2}^{0}-2 \mathrm{~s} 2 \mathrm{p}^{2}{ }^{2} \mathrm{P}_{1 / 2}$ & 403.296 & 5.60 & 45.6 & 5.6 & 18.5 & $\mathrm{~b}$ & 18.5 & $\mathrm{~b}$ \\
\hline $\mathrm{Ne}$ VI & $433.172^{\mathrm{E}}$ & $2 \mathrm{~s}^{2} 2 \mathrm{p}^{2} \mathrm{P}_{1 / 2}^{0}-2 \mathrm{~s} 2 \mathrm{p}^{2}{ }^{2} \mathrm{~S}_{1 / 2}$ & 433.161 & 5.60 & 7.5 & 3.0 & 13.9 & 4.5 & 13.9 & 4.5 \\
\hline $\mathrm{Ne}$ VI & $435.641^{\mathrm{E}}$ & $2 \mathrm{~s}^{2} 2 \mathrm{p}^{2} \mathrm{P}_{3 / 2}^{0}-2 \mathrm{~s} 2 \mathrm{p}^{2}{ }^{2} \mathrm{~S}_{1 / 2}$ & 435.632 & 5.60 & 9.8 & 2.3 & 23.2 & $3.4(+1)$ & 23.3 & $3.4(+1)$ \\
\hline Mg VIII & $311.772^{\mathrm{E}}$ & $2 \mathrm{~s}^{2} 2 \mathrm{p}^{2} \mathrm{P}_{1 / 2}^{0}-2 \mathrm{~s} 2 \mathrm{p}^{2}{ }^{2} \mathrm{P}_{3 / 2}$ & 311.778 & 5.90 & 79.1 & 14.1 & 48.2 & $\mathrm{~b}$ & 47.5 & $\mathrm{~b}$ \\
\hline Mg VIII & $313.743^{\mathrm{E}}$ & $2 \mathrm{~s}^{2} 2 \mathrm{p}^{2} \mathrm{P}_{1 / 2}^{0}-2 \mathrm{~s} 2 \mathrm{p}^{2}{ }^{2} \mathrm{P}_{1 / 2}$ & 313.736 & 5.90 & 80.3 & 12.3 & 90.9 & $7.4(-1)$ & 88.7 & $4.7(-1)$ \\
\hline Mg VIII & $315.015^{\mathrm{E}}$ & $2 \mathrm{~s}^{2} 2 \mathrm{p}^{2} \mathrm{P}_{3 / 2}^{0}-2 \mathrm{~s} 2 \mathrm{p}^{2}{ }^{2} \mathrm{P}_{3 / 2}$ & 315.024 & 5.90 & 253.0 & 31.0 & 242.0 & $1.4(-1)$ & 238.0 & $2.3(-1)$ \\
\hline Mg VIII & $317.028^{\mathrm{E}}$ & $2 \mathrm{~s}^{2} 2 \mathrm{p}^{2} \mathrm{P}_{3 / 2}^{0}-2 \mathrm{~s} 2 \mathrm{p}^{2}{ }^{2} \mathrm{P}_{1 / 2}$ & 317.008 & 5.90 & 57.5 & 13.1 & 57.3 & $2.3(-4)$ & 55.9 & $1.5(-2)$ \\
\hline Mg VIII & $335.231^{\mathrm{E}}$ & $2 \mathrm{~s}^{2} 2 \mathrm{p}^{2} \mathrm{P}_{1 / 2}^{0}-2 \mathrm{~s} 2 \mathrm{p}^{2}{ }^{2} \mathrm{~S}_{1 / 2}$ & & 5.90 & & & 42.4 & & 41.6 & \\
\hline Mg VIII & $338.983^{\mathrm{E}}$ & $2 \mathrm{~s}^{2} 2 \mathrm{p}^{2} \mathrm{P}_{3 / 2}^{0}-2 \mathrm{~s} 2 \mathrm{p}^{2}{ }^{2} \mathrm{~S}_{1 / 2}$ & 339.000 & 5.90 & 53.8 & 8.4 & 52.7 & $1.7(-2)$ & 51.8 & $5.7(-2)$ \\
\hline Mg VIII & $430.454^{\mathrm{E}}$ & $2 \mathrm{~s}^{2} 2 \mathrm{p}^{2} \mathrm{P}_{1 / 2}^{0}-2 \mathrm{~s} 2 \mathrm{p}^{2}{ }^{2} \mathrm{D}_{3 / 2}$ & 430.445 & 5.90 & 40.3 & 4.9 & 81.3 & $7.0(+1)$ & 79.1 & $6.3(+1)$ \\
\hline Mg VIII & $436.660^{\mathrm{E}}$ & $2 \mathrm{~s}^{2} 2 \mathrm{p}^{2} \mathrm{P}_{3 / 2}^{0}-2 \mathrm{~s} 2 \mathrm{p}^{2}{ }^{2} \mathrm{D}_{3 / 2}$ & & 5.90 & & & 13.0 & & 12.7 & \\
\hline Mg VIII & $436.733^{\mathrm{E}}$ & $2 \mathrm{~s}^{2} 2 \mathrm{p}^{2} \mathrm{P}_{3 / 2}^{0}-2 \mathrm{~s} 2 \mathrm{p}^{2}{ }^{2} \mathrm{D}_{5 / 2}$ & 436.726 & 5.90 & 67.5 & 8.0 & 132.7 & $6.6(+1)$ & 131.1 & $6.3(+1)$ \\
\hline $\mathrm{Al}$ IX & $280.134^{\mathrm{E}}$ & $2 \mathrm{~s}^{2} 2 \mathrm{p}{ }^{2} \mathrm{P}_{1 / 2}^{0}-2 \mathrm{~s} 2 \mathrm{p}^{2}{ }^{2} \mathrm{P}_{3 / 2}$ & & 6.00 & & & 7.1 & & 7.1 & \\
\hline $\mathrm{Al}$ IX & $282.420^{\mathrm{E}}$ & $2 \mathrm{~s}^{2} 2 \mathrm{p}^{2} \mathrm{P}_{1 / 2}^{0}-2 \mathrm{~s} 2 \mathrm{p}^{2}{ }^{2} \mathrm{P}_{1 / 2}$ & 282.431 & 6.00 & 28.4 & 16.7 & 13.7 & 1.2 & 13.2 & 1.3 \\
\hline $\mathrm{Al}$ IX & $284.025^{\mathrm{E}}$ & $2 \mathrm{~s}^{2} 2 \mathrm{p}^{2} \mathrm{P}_{3 / 2}^{0}-2 \mathrm{~s} 2 \mathrm{p}^{2}{ }^{2} \mathrm{P}_{3 / 2}$ & & 6.00 & & & 35.8 & & 35.7 & \\
\hline $\mathrm{Al}$ IX & $286.375^{\mathrm{E}}$ & $2 \mathrm{~s}^{2} 2 \mathrm{p}^{2} \mathrm{P}_{3 / 2}^{0}-2 \mathrm{~s} 2 \mathrm{p}^{2}{ }^{2} \mathrm{P}_{1 / 2}$ & & 6.00 & & & 9.6 & & 9.2 & \\
\hline $\mathrm{Al}$ IX & $300.585^{\mathrm{E}}$ & $2 \mathrm{~s}^{2} 2 \mathrm{p}^{2} \mathrm{P}_{1 / 2}^{0}-2 \mathrm{~s} 2 \mathrm{p}^{2}{ }^{2} \mathrm{~S}_{1 / 2}$ & 300.564 & 6.00 & 30.6 & 11.3 & 7.0 & 4.4 & 7.0 & 4.4 \\
\hline $\mathrm{Al}$ IX & $305.069^{\mathrm{E}}$ & $2 \mathrm{~s}^{2} 2 \mathrm{p}^{2} \mathrm{P}_{3 / 2}^{0}-2 \mathrm{~s} 2 \mathrm{p}^{2}{ }^{2} \mathrm{~S}_{1 / 2}$ & 305.093 & 6.00 & 17.3 & 7.8 & 7.1 & 1.7 & 7.1 & 1.7 \\
\hline $\mathrm{Al}$ IX & $385.011^{\mathrm{E}}$ & $2 \mathrm{~s}^{2} 2 \mathrm{p}^{2} \mathrm{P}_{1 / 2}^{0}-2 \mathrm{~s} 2 \mathrm{p}^{2}{ }^{2} \mathrm{D}_{3 / 2}$ & 385.023 & 6.00 & 7.0 & 2.0 & 12.8 & 8.4 & 12.4 & 7.3 \\
\hline $\mathrm{Al}$ IX & $392.398^{\mathrm{E}}$ & $2 \mathrm{~s}^{2} 2 \mathrm{p}^{2} \mathrm{P}_{3 / 2}^{0}-2 \mathrm{~s} 2 \mathrm{p}^{2}{ }^{2} \mathrm{D}_{3 / 2}$ & & 6.00 & & & 1.9 & & 1.8 & \\
\hline $\mathrm{Al}$ IX & $392.432^{\mathrm{E}}$ & $2 \mathrm{~s}^{2} 2 \mathrm{p}^{2} \mathrm{P}_{3 / 2}^{0}-2 \mathrm{~s} 2 \mathrm{p}^{2}{ }^{2} \mathrm{D}_{5 / 2}$ & 392.414 & 6.00 & 15.3 & 2.7 & 18.9 & 1.8 & 19.1 & 2.0 \\
\hline
\end{tabular}

b: Blended.

E Wavelength from Edlén (1983b).

and the blend of the $3 / 2-5 / 2$ and $3 / 2-3 / 2$ components at $356.027 \AA$. The agreement of the former is very good while the latter is overestimated by $18-22 \%$.

The S XII $2 \mathrm{~s}^{2} 2 \mathrm{p}^{2} \mathrm{P}-2 \mathrm{~s} 2 \mathrm{p}^{2}{ }^{2} \mathrm{P}$ quartet falls within the SERTS-89 wavelength range. The $3 / 2-3 / 2$ and $3 / 2-1 / 2$ predicted intensities are above the sensitivity level of the instrument, but are not detected. Further work is required to solve this issue.

The S XII $2 \mathrm{~s}^{2} 2 \mathrm{p}^{2} \mathrm{P}-2 \mathrm{~s} 2 \mathrm{p}^{2} 2 \mathrm{D}$ multiplet is used to select the most likely uniform $P_{\mathrm{e}}$ or $N_{\mathrm{e}}$ approximation (see Sect. 4.1). S XII (288.420 $\AA$ ) is used in the integral inversion and is in good agreement with observations. Good agreement is found for $\mathrm{S}$ XII $(299.540 \AA)$ also, while the
S XII (299.778 $\AA$ ) intensity is found below the instrumental sensitivity limit at these wavelengths. The formation temperature of this ion $\left(\log \left(T_{\mathrm{p}}\right)=6.30\right)$ overlaps with Fe XV.

\subsubsection{C-like lines}

In Table 6 we report the comparison of the C-like lines with observations.

The wavelength region around the observed O III line has plenty of weak lines, most of them just at or below the instrumental sensitivity limit. Assuming photospheric abundances for $\mathrm{O}$ (see Sect.4.3), the line observed at $374.051 \AA$ (blend of $0-1$ and $2-2$ components) 
Table 5. continued.

\begin{tabular}{|c|c|c|c|c|c|c|c|c|c|c|}
\hline Ion & $\lambda^{\text {ad. }}$ & Transition & $\lambda^{\text {obs. }}$ & $\log \left(T_{\mathrm{p}}\right)$ & $I^{\mathrm{obs}}$ & $e^{\mathrm{obs}}$ & $\begin{array}{c}I^{\mathrm{th}} \\
\log (\Lambda\end{array}$ & $\begin{array}{l}\left(\sigma_{0} \chi_{i}\right)^{2} \\
=9.5\end{array}$ & $\begin{array}{c}I^{\mathrm{th}} \\
\log \left(P_{\mathrm{e}}\right.\end{array}$ & $\begin{array}{l}\left(\sigma_{0} \chi_{i}\right)^{2} \\
=15.8\end{array}$ \\
\hline Six & $253.787^{\mathrm{E}}$ & $2 \mathrm{~s}^{2} 2 \mathrm{p}^{2} \mathrm{P}_{1 / 2}^{0}-2 \mathrm{~s} 2 \mathrm{p}^{2}{ }^{2} \mathrm{P}_{3 / 2}$ & 253.808 & 6.15 & 207.0 & 55.0 & 95.1 & 4.1 & 97.2 & 4.0 \\
\hline $\operatorname{Six}$ & $256.366^{\mathrm{E}}$ & $2 \mathrm{~s}^{2} 2 \mathrm{p}^{2} \mathrm{P}_{1 / 2}^{0}-2 \mathrm{~s} 2 \mathrm{p}^{2}{ }^{2} \mathrm{P}_{1 / 2}$ & 256.323 & 6.15 & 1580.0 & 185.0 & 189.8 & $\mathrm{~b}$ & 185.1 & $\mathrm{~b}$ \\
\hline Six & $258.371^{\mathrm{E}}$ & $2 \mathrm{~s}^{2} 2 \mathrm{p}^{2} \mathrm{P}_{3 / 2}^{0}-2 \mathrm{~s} 2 \mathrm{p}^{2}{ }^{2} \mathrm{P}_{3 / 2}$ & 258.368 & 6.15 & 377.0 & 58.0 & 481.8 & 3.3 & 492.5 & 4.0 \\
\hline Six & $261.043^{\mathrm{E}}$ & $2 \mathrm{~s}^{2} 2 \mathrm{p}^{2} \mathrm{P}_{3 / 2}^{0}-2 \mathrm{~s} 2 \mathrm{p}^{2}{ }^{2} \mathrm{P}_{1 / 2}$ & 261.049 & 6.15 & 140.0 & 27.0 & 151.0 & $1.7(-1)$ & 147.2 & $7.1(-2)$ \\
\hline $\operatorname{Six}$ & $272.005^{\mathrm{E}}$ & $2 \mathrm{~s}^{2} 2 \mathrm{p}^{2} \mathrm{P}_{1 / 2}^{0}-2 \mathrm{~s} 2 \mathrm{p}^{2}{ }^{2} \mathrm{~S}_{1 / 2}$ & 271.992 & 6.15 & 131.0 & 25.0 & 122.4 & $1.2(-1)$ & 119.5 & $2.1(-1)$ \\
\hline Six & $277.277^{\mathrm{E}}$ & $2 \mathrm{~s}^{2} 2 \mathrm{p}^{2} \mathrm{P}_{3 / 2}^{0}-2 \mathrm{~s} 2 \mathrm{p}^{2}{ }^{2} \mathrm{~S}_{1 / 2}$ & 277.268 & 6.15 & 114.0 & 25.0 & 97.6 & $4.3(-1)$ & 95.2 & $5.7(-1)$ \\
\hline Six & $287.098^{\mathrm{E}}$ & $2 \mathrm{~s} 2 \mathrm{p}^{2}{ }^{4} \mathrm{P}_{1 / 2}-2 \mathrm{p}^{3}{ }^{4} \mathrm{~S}_{3 / 2}^{0}$ & & 6.10 & & & 0.1 & & 0.1 & \\
\hline Six & $289.153^{\mathrm{E}}$ & $2 \mathrm{~s} 2 \mathrm{p}^{2}{ }^{4} \mathrm{P}_{3 / 2}-2 \mathrm{p}^{3}{ }^{4} \mathrm{~S}_{3 / 2}^{0}$ & & 6.10 & & & 0.1 & & 0.1 & \\
\hline $\operatorname{Six}$ & $292.170^{\mathrm{E}}$ & $2 \mathrm{~s} 2 \mathrm{p}^{2}{ }^{4} \mathrm{P}_{5 / 2}-2 \mathrm{p}^{3}{ }^{4} \mathrm{~S}_{3 / 2}^{0}$ & 292.251 & 6.10 & 43.7 & 13.0 & 0.2 & $1.1(+1)$ & 0.2 & $1.1(+1)$ \\
\hline Six & $347.408^{\mathrm{E}}$ & $2 \mathrm{~s}^{2} 2 \mathrm{p}^{2} \mathrm{P}_{1 / 2}^{0}-2 \mathrm{~s} 2 \mathrm{p}^{2}{ }^{2} \mathrm{D}_{3 / 2}$ & 347.406 & 6.15 & 210.0 & 48.0 & 203.9 & $1.6(-2)$ & 193.8 & $1.1(-1)$ \\
\hline Six & $356.029^{\mathrm{E}}$ & $2 \mathrm{~s}^{2} 2 \mathrm{p}^{2} \mathrm{P}_{3 / 2}^{0}-2 \mathrm{~s} 2 \mathrm{p}^{2}{ }^{2} \mathrm{D}_{5 / 2}$ & & 6.10 & & & 231.6 & & 242.4 & \\
\hline Six & $356.054^{\mathrm{E}}$ & $2 \mathrm{~s}^{2} 2 \mathrm{p}^{2} \mathrm{P}_{3 / 2}^{0}-2 \mathrm{~s} 2 \mathrm{p}^{2}{ }^{2} \mathrm{D}_{3 / 2}$ & & 6.15 & & & 27.6 & & 26.2 & \\
\hline \multicolumn{2}{|c|}{ - SUM - } & & 356.027 & & 218.0 & 25.0 & 259.2 & 2.7 & 268.7 & 4.1 \\
\hline S XII & $212.120^{\mathrm{E}}$ & $2 \mathrm{~s}^{2} 2 \mathrm{p}^{2} \mathrm{P}_{1 / 2}^{0}-2 \mathrm{~s} 2 \mathrm{p}^{2}{ }^{2} \mathrm{P}_{3 / 2}$ & & 6.30 & & & 31.8 & & 33.0 & \\
\hline S XII & $215.143^{\mathrm{E}}$ & $2 \mathrm{~s}^{2} 2 \mathrm{p}^{2} \mathrm{P}_{1 / 2}^{0}-2 \mathrm{~s} 2 \mathrm{p}^{2}{ }^{2} \mathrm{P}_{1 / 2}$ & & 6.30 & & & 77.4 & & 78.0 & \\
\hline S XII & $218.200^{\mathrm{E}}$ & $2 \mathrm{~s}^{2} 2 \mathrm{p}^{2} \mathrm{P}_{3 / 2}^{0}-2 \mathrm{~s} 2 \mathrm{p}^{2}{ }^{2} \mathrm{P}_{3 / 2}$ & & 6.00 & & & 162.7 & & 169.1 & \\
\hline S XII & $221.400^{\mathrm{E}}$ & $2 \mathrm{~s}^{2} 2 \mathrm{p}^{2} \mathrm{P}_{3 / 2}^{0}-2 \mathrm{~s} 2 \mathrm{p}^{2}{ }^{2} \mathrm{P}_{1 / 2}$ & & 6.30 & & & 88.1 & & 88.7 & \\
\hline S XII & $288.420^{\mathrm{E}}$ & $2 \mathrm{~s}^{2} 2 \mathrm{p}^{2} \mathrm{P}_{1 / 2}^{0}-2 \mathrm{~s} 2 \mathrm{p}^{2}{ }^{2} \mathrm{D}_{3 / 2}$ & 288.401 & 6.35 & 135.0 & 21.0 & 143.8 & $1.8(-1)$ & 142.6 & $1.3(-1)$ \\
\hline S XII & $299.540^{\mathrm{E}}$ & $2 \mathrm{~s}^{2} 2 \mathrm{p}^{2} \mathrm{P}_{3 / 2}^{0}-2 \mathrm{~s} 2 \mathrm{p}^{2}{ }^{2} \mathrm{D}_{5 / 2}$ & 299.534 & 6.30 & 47.2 & 18.3 & 46.3 & $2.4(-3)$ & 50.9 & $4.1(-2)$ \\
\hline S XII & $299.778^{\mathrm{E}}$ & $2 \mathrm{~s}^{2} 2 \mathrm{p}^{2} \mathrm{P}_{3 / 2}^{0}-2 \mathrm{~s} 2 \mathrm{p}^{2}{ }^{2} \mathrm{D}_{3 / 2}$ & & 6.30 & & & 15.3 & & 15.2 & \\
\hline
\end{tabular}

b: Blended.

E Wavelength from Edlén (1983b).

is in excellent agreement with the observations. The O III $(374.164 \AA)$ theoretical intensity is about half that observed, but still within the observational uncertainties. Note that O III $(374.330 \AA)$ and O III $(374.435 \AA)$ are expected to have slightly higher intensities than O III (374.164 $\AA)$, but these are not reported. A blend with N III $(374.20 \AA)$ contributing about $50 \%$ of the intensity of the O III $(374.164 \AA)$ is also compatible with our analysis.

Ne V $(359.375 \AA)$ is used in the integral inversion to sample the temperature region around $\log \left(T_{\mathrm{p}}\right)=5.50$ and is in excellent agreement with the observations. The other observed line of the $2 \mathrm{~s}^{2} 2 \mathrm{p}^{2}{ }^{3} \mathrm{P}-2 \mathrm{~s} 2 \mathrm{p}^{3}{ }^{3} \mathrm{~S}$ triplet at $358.476 \AA$ is also in excellent agreement. The $\mathrm{NeV}(357.946 \AA)$ has an expected intensity of $5 \mathrm{erg} \mathrm{cm} \mathrm{cm}^{-2} \mathrm{~s}^{-1} \mathrm{sr}^{-1}$ and a blend with Ne IV (357.825 ̊), as suggested by Young et al. (1998), seems unlikely both because the unblended Ne IV line is in good agreement with observation (Ne V $(357.946 \AA)$ would contribute $70 \%$ of the total intensity if blended with it) and because our adopted laboratory wavelengths indicate a separation of $121 \mathrm{~mA}$, above the resolution of the instrument. Ne V $(365.603 \AA)$ is predicted to have an intensity of $25 \mathrm{erg} \mathrm{cm}^{-2} \mathrm{~s}^{-1} \mathrm{sr}^{-1}$, but lies close to the Fex line observed at $365.565 \AA$ and may not be resolved from it. Assuming a blend of these two lines we obtain an excellent agreement with observations (see Sect. 4.5.2). The Ne V (416.209 $\AA$ ) theoretical intensity is about twice that observed, consistent with the aforementioned instrumental calibration inaccuracy at these wavelengths.

$\operatorname{Mg}$ VII $(276.993 \AA)$ is blended with Si VIII, contributing $54 \%$ of the observed intensity at $277.045 \AA$.

Mg VII $(278.393 \AA)$ is found discrepant with observations and Young et al. (1998) explained this by means of a blend with Si viI. Our analysis indicates that Mg VII contributes by up to $70.2 \mathrm{erg} \mathrm{cm}^{-2} \mathrm{~s}^{-1} \mathrm{sr}^{-1}$ and Si VII by up to $10.2 \mathrm{erg} \mathrm{cm}^{-2} \mathrm{~s}^{-1} \mathrm{sr}^{-1}$ leaving more than $10 \mathrm{erg} \mathrm{cm}^{-2} \mathrm{~s}^{-1} \mathrm{sr}^{-1}$ unaccounted for, suggesting the presence of a further blend component. 
Table 6. As for Table 3 for the C-like iso-electronic sequence.

\begin{tabular}{|c|c|c|c|c|c|c|c|c|c|c|}
\hline Ion & $\lambda^{\text {ad. }}$ & Transition & $\lambda^{\text {obs. }}$ & $\log \left(T_{\mathrm{p}}\right)$ & $I^{\mathrm{obs}}$ & $e^{\mathrm{obs}}$ & $\begin{array}{l}I^{\text {th }} \\
\log (\end{array}$ & $\begin{array}{c}\left(\sigma_{0} \chi_{i}\right)^{2} \\
\mathrm{e})=9.5\end{array}$ & $\begin{array}{c}I^{\text {th }} \\
\log \left(P_{\mathrm{e}}\right.\end{array}$ & $\begin{array}{l}\left(\sigma_{0} \chi_{i}\right)^{2} \\
=15.8\end{array}$ \\
\hline O III & $373.805^{\mathrm{N}}$ & $2 \mathrm{~s}^{2} 2 \mathrm{p}^{2}{ }^{3} \mathrm{P}_{1}-2 \mathrm{~s}^{2} 2 \mathrm{p} 3 \mathrm{~s}^{3} \mathrm{P}_{0}^{0}$ & & 5.00 & & & 3.8 & & 3.9 & \\
\hline O III & $374.006^{\mathrm{N}}$ & $2 \mathrm{~s}^{2} 2 \mathrm{p}^{2}{ }^{3} \mathrm{P}_{0}-2 \mathrm{~s}^{2} 2 \mathrm{p} 3 \mathrm{~s}^{3} \mathrm{P}_{1}^{0}$ & & 5.00 & & & 2.9 & & 3.0 & \\
\hline O III & $374.075^{\mathrm{N}}$ & $2 \mathrm{~s}^{2} 2 \mathrm{p}^{2}{ }^{3} \mathrm{P}_{2}-2 \mathrm{~s}^{2} 2 \mathrm{p} 3 \mathrm{~s}^{3} \mathrm{P}_{2}^{0}$ & & 5.00 & & & 11.5 & & 11.8 & \\
\hline \multicolumn{2}{|c|}{ - SUM - } & & 374.051 & & 14.4 & 4.4 & 14.4 & 0.0 & 14.9 & $1.3(-2)$ \\
\hline O III & $374.164^{\mathrm{N}}$ & $2 \mathrm{~s}^{2} 2 \mathrm{p}^{2}{ }^{3} \mathrm{P}_{1}-2 \mathrm{~s}^{2} 2 \mathrm{p} 3 \mathrm{~s}^{3} \mathrm{P}_{1}^{0}$ & 374.160 & 5.00 & 4.9 & 3.1 & 2.2 & $7.6(-1)$ & 2.3 & $7.0(-1)$ \\
\hline O III & $374.330^{\mathrm{N}}$ & $2 \mathrm{~s}^{2} 2 \mathrm{p}^{2}{ }^{3} \mathrm{P}_{1}-2 \mathrm{~s}^{2} 2 \mathrm{p} 3 \mathrm{~s}^{3} \mathrm{P}_{0}^{0}$ & & 5.00 & & & 3.1 & & 3.2 & \\
\hline O III & $374.435^{\mathrm{N}}$ & $2 \mathrm{~s}^{2} 2 \mathrm{p}^{2}{ }^{3} \mathrm{P}_{2}-2 \mathrm{~s}^{2} 2 \mathrm{p} 3 \mathrm{~s}^{3} \mathrm{P}_{1}^{0}$ & & 5.00 & & & 3.7 & & 3.8 & \\
\hline $\mathrm{NeV}$ & $357.946^{\mathrm{E}}$ & $2 \mathrm{~s}^{2} 2 \mathrm{p}^{2}{ }^{3} \mathrm{P}_{0}-2 \mathrm{~s} 2 \mathrm{p}^{3}{ }^{3} \mathrm{~S}_{1}^{0}$ & & 5.45 & & & 5.3 & & 5.3 & \\
\hline $\mathrm{NeV}$ & $358.476^{\mathrm{E}}$ & $2 \mathrm{~s}^{2} 2 \mathrm{p}^{2}{ }^{3} \mathrm{P}_{1}-2 \mathrm{~s} 2 \mathrm{p}^{3}{ }^{3} \mathrm{~S}_{1}^{0}$ & 358.455 & 5.45 & 15.2 & 3.7 & 15.7 & $1.8(-2)$ & 15.8 & $2.6(-2)$ \\
\hline $\mathrm{NeV}$ & $359.375^{\mathrm{E}}$ & $2 \mathrm{~s}^{2} 2 \mathrm{p}^{2}{ }^{3} \mathrm{P}_{2}-2 \mathrm{~s} 2 \mathrm{p}^{3}{ }^{3} \mathrm{~S}_{1}^{0}$ & 359.378 & 5.50 & 26.3 & 4.3 & 26.3 & 0.0 & 26.5 & $2.2(-3)$ \\
\hline $\mathrm{Ne} V$ & $365.603^{\mathrm{N}}$ & $2 \mathrm{~s}^{2} 2 \mathrm{p}^{2}{ }^{1} \mathrm{D}_{2}-2 \mathrm{~s} 2 \mathrm{p}^{3}{ }^{1} \mathrm{P}_{1}^{0}$ & & 5.45 & & & 25.2 & & 26.6 & \\
\hline $\mathrm{NeV}$ & $416.209^{\mathrm{E}}$ & $2 \mathrm{~s}^{2} 2 \mathrm{p}^{2}{ }^{1} \mathrm{D}_{2}-2 \mathrm{~s} 2 \mathrm{p}^{3}{ }^{1} \mathrm{D}_{2}^{0}$ & 416.208 & 5.45 & 24.2 & 3.4 & 45.6 & $4.0(+1)$ & 47.5 & $4.7(+1)$ \\
\hline Mg VII & $276.138^{\mathrm{E}}$ & $2 \mathrm{~s}^{2} 2 \mathrm{p}^{2}{ }^{3} \mathrm{P}_{0}-2 \mathrm{~s} 2 \mathrm{p}^{3}{ }^{3} \mathrm{~S}_{1}^{0}$ & & 5.80 & & & 14.0 & & 12.5 & \\
\hline Mg VII & $276.993^{\mathrm{E}}$ & $2 \mathrm{~s}^{2} 2 \mathrm{p}^{2}{ }^{3} \mathrm{P}_{1}-2 \mathrm{~s} 2 \mathrm{p}^{3}{ }^{3} \mathrm{~S}_{1}^{0}$ & 277.045 & 5.80 & 85.1 & 23.0 & 41.8 & $\mathrm{~b}$ & 37.4 & $\mathrm{~b}$ \\
\hline Mg VII & $278.393^{\mathrm{E}}$ & $2 \mathrm{~s}^{2} 2 \mathrm{p}^{2}{ }^{3} \mathrm{P}_{2}-2 \mathrm{~s} 2 \mathrm{p}^{3}{ }^{3} \mathrm{~S}_{1}^{0}$ & 278.407 & 5.80 & 114.0 & 24.0 & 70.2 & $\mathrm{~b}$ & 62.8 & $\mathrm{~b}$ \\
\hline Mg VII & $280.722^{\mathrm{E}}$ & $2 \mathrm{~s}^{2} 2 \mathrm{p}^{2}{ }^{1} \mathrm{D}_{2}-2 \mathrm{~s} 2 \mathrm{p}^{3}{ }^{1} \mathrm{P}_{1}^{0}$ & $280.749^{\mathrm{D}}$ & 5.80 & 9.4 & 7.5 & 29.4 & 7.1 & 41.3 & $1.8(+1)$ \\
\hline Mg VII & $319.018^{\mathrm{E}}$ & $2 \mathrm{~s}^{2} 2 \mathrm{p}^{2}{ }^{1} \mathrm{D}_{2}-2 \mathrm{~s} 2 \mathrm{p}^{3}{ }^{1} \mathrm{D}_{2}^{0}$ & 319.023 & 5.80 & 76.4 & 11.0 & 56.5 & $\mathrm{~b}$ & 74.6 & $\mathrm{~b}$ \\
\hline Mg VII & $320.513^{\mathrm{N}}$ & $2 \mathrm{~s}^{2} 2 \mathrm{p}^{2}{ }^{1} \mathrm{~S}_{0}-2 \mathrm{~s} 2 \mathrm{p}^{3}{ }^{1} \mathrm{P}_{1}^{0}$ & & 5.80 & & & 5.8 & & 8.1 & \\
\hline Mg VII & $363.749^{\mathrm{E}}$ & $2 \mathrm{~s}^{2} 2 \mathrm{p}^{2}{ }^{3} \mathrm{P}_{0}-2 \mathrm{~s} 2 \mathrm{p}^{3}{ }^{3} \mathrm{P}_{1}^{0}$ & 363.753 & 5.80 & 11.2 & 3.0 & 17.4 & 4.3 & 15.8 & 2.3 \\
\hline Mg VII & $365.162^{\mathrm{E}}$ & $2 \mathrm{~s}^{2} 2 \mathrm{p}^{2}{ }^{3} \mathrm{P}_{1}-2 \mathrm{~s} 2 \mathrm{p}^{3}{ }^{3} \mathrm{P}_{0}^{0}$ & & 5.80 & & & 18.6 & & 16.6 & \\
\hline $\mathrm{Mg}$ VII & $365.221^{\mathrm{E}}$ & $2 \mathrm{~s}^{2} 2 \mathrm{p}^{2}{ }^{3} \mathrm{P}_{1}-2 \mathrm{~s} 2 \mathrm{p}^{3}{ }^{3} \mathrm{P}_{2}^{0}$ & & 5.80 & & & 20.3 & & 18.4 & \\
\hline Mg VII & $365.234^{\mathrm{E}}$ & $2 \mathrm{~s}^{2} 2 \mathrm{p}^{2}{ }^{3} \mathrm{P}_{1}-2 \mathrm{~s} 2 \mathrm{p}^{3}{ }^{3} \mathrm{P}_{1}^{0}$ & & 5.80 & & & 14.9 & & 13.5 & \\
\hline \multicolumn{2}{|c|}{ - SUM - } & & 365.210 & & 23.2 & 4.3 & 53.9 & $5.1(+1)$ & 48.5 & $3.5(+1)$ \\
\hline Mg VII & $367.658^{\mathrm{E}}$ & $2 \mathrm{~s}^{2} 2 \mathrm{p}^{2}{ }^{3} \mathrm{P}_{2}-2 \mathrm{~s} 2 \mathrm{p}^{3}{ }^{3} \mathrm{P}_{2}^{0}$ & & 5.80 & & & 69.5 & & 62.6 & \\
\hline Mg VII & $367.671^{\mathrm{E}}$ & $2 \mathrm{~s}^{2} 2 \mathrm{p}^{2}{ }^{3} \mathrm{P}_{2}-2 \mathrm{~s} 2 \mathrm{p}^{3}{ }^{3} \mathrm{P}_{1}^{0}$ & & 5.80 & & & 21.1 & & 19.1 & \\
\hline \multicolumn{2}{|c|}{ - SUM - } & & 367.675 & & 46.2 & 5.6 & 90.6 & $6.3(+1)$ & 81.7 & $4.0(+1)$ \\
\hline Mg VII & $429.122^{\mathrm{E}}$ & $2 \mathrm{~s}^{2} 2 \mathrm{p}^{2}{ }^{3} \mathrm{P}_{0}-2 \mathrm{~s} 2 \mathrm{p}^{3}{ }^{3} \mathrm{D}_{1}^{0}$ & 429.132 & 5.80 & 10.9 & 2.5 & 18.7 & 9.7 & 17.1 & 6.1 \\
\hline Mg VII & $431.191^{\mathrm{E}}$ & $2 \mathrm{~s}^{2} 2 \mathrm{p}^{2}{ }^{3} \mathrm{P}_{1}-2 \mathrm{~s} 2 \mathrm{p}^{3}{ }^{3} \mathrm{D}_{1}^{0}$ & 431.141 & 5.80 & 9.2 & 3.0 & 12.0 & $8.7(-1)$ & 10.9 & $3.2(-1)$ \\
\hline Mg VII & $431.304^{\mathrm{E}}$ & $2 \mathrm{~s}^{2} 2 \mathrm{p}^{2}{ }^{3} \mathrm{P}_{1}-2 \mathrm{~s} 2 \mathrm{p}^{3}{ }^{3} \mathrm{D}_{2}^{0}$ & 431.288 & 5.80 & 17.6 & 3.4 & 43.0 & $5.6(+1)$ & 38.8 & $3.9(+1)$ \\
\hline Mg VII & $434.592^{\mathrm{E}}$ & $2 \mathrm{~s}^{2} 2 \mathrm{p}^{2}{ }^{3} \mathrm{P}_{2}-2 \mathrm{~s} 2 \mathrm{p}^{3}{ }^{3} \mathrm{D}_{1}^{0}$ & & 5.80 & & & 0.6 & & 0.5 & \\
\hline Mg VII & $434.707^{\mathrm{E}}$ & $2 \mathrm{~s}^{2} 2 \mathrm{p}^{2}{ }^{3} \mathrm{P}_{1}-2 \mathrm{~s} 2 \mathrm{p}^{3}{ }^{3} \mathrm{D}_{2}^{0}$ & & 5.80 & & & 10.5 & & 9.4 & \\
\hline Mg VII & $434.906^{\mathrm{E}}$ & $2 \mathrm{~s}^{2} 2 \mathrm{p}^{2}{ }^{3} \mathrm{P}_{2}-2 \mathrm{~s} 2 \mathrm{p}^{3}{ }^{3} \mathrm{D}_{3}^{0}$ & 434.917 & 5.80 & 27.9 & 3.9 & 72.5 & $1.3(+2)$ & 65.7 & $9.4(+1)$ \\
\hline
\end{tabular}

b: Blended.

D New fit by Dwivedi et al. (1998).

E Wavelength from Edlén (1985a).

$\mathrm{N}$ Wavelength from NIST standard reference database.

Dwivedi et al. (1998) give a fit to a line at $280.749 \AA$ and suggest that it is the $\mathrm{Mg}$ VII $2 \mathrm{~s}^{2} 2 \mathrm{p}^{2}{ }^{1} \mathrm{D}_{2}-2 \mathrm{~s} 2 \mathrm{p}^{31} \mathrm{P}_{1}$ transition. According to our analysis, this line is expected to be at least 3 times more intense than measured.
$\operatorname{Mg}$ VII $(319.018 \AA)$ is blended with Ni XV. An estimate of the relative contribution to this blend is made difficult by the high density sensitivity of the Mg VII transition. Note that in the uniform $P_{\mathrm{e}}$ approximation Mg VII 
Table 6. continued.

\begin{tabular}{|c|c|c|c|c|c|c|c|c|c|c|}
\hline Ion & $\lambda^{\text {ad. }}$ & Transition & $\lambda^{\text {obs. }}$ & $\log \left(T_{\mathrm{p}}\right)$ & $I^{\text {obs }}$ & $e^{\text {obs }}$ & $\log \left(N_{\mathrm{e}}\right)=9.5$ & $\begin{array}{l}\left(\sigma_{0} \chi_{i}\right)^{2} \\
=9.5\end{array}$ & \multicolumn{2}{|c|}{$\log \left(P_{\mathrm{e}}\right)=15.8$} \\
\hline Al VIII & $285.47^{\mathrm{N}}$ & $2 \mathrm{~s}^{2} 2 \mathrm{p}^{2}{ }^{1} \mathrm{D}_{2}-2 \mathrm{~s} 2 \mathrm{p}^{3}{ }^{1} \mathrm{D}_{2}^{0}$ & 285.449 & 5.90 & 27.8 & 12.4 & 4.0 & 3.7 & 6.2 & 3.0 \\
\hline Si IX & $258.082^{\mathrm{E}}$ & $2 \mathrm{~s}^{2} 2 \mathrm{p}^{2}{ }^{1} \mathrm{D}_{2}-2 \mathrm{~s} 2 \mathrm{p}^{3}{ }^{1} \mathrm{D}_{2}^{0}$ & 258.095 & 6.05 & 49.7 & 19.4 & 17.3 & 2.8 & 24.4 & 1.7 \\
\hline Si ix & $259.770^{\mathrm{E}}$ & $2 \mathrm{~s}^{2} 2 \mathrm{p}^{2}{ }^{1} \mathrm{~S}_{0}-2 \mathrm{~s} 2 \mathrm{p}^{3}{ }^{1} \mathrm{P}_{1}^{0}$ & & 6.05 & & & 1.7 & & 2.5 & \\
\hline Si ix & $290.687^{\mathrm{E}}$ & $2 \mathrm{~s}^{2} 2 \mathrm{p}^{2}{ }^{3} \mathrm{P}_{0}-2 \mathrm{~s} 2 \mathrm{p}^{3}{ }^{3} \mathrm{P}_{1}^{0}$ & 290.693 & 6.05 & 33.2 & 15.1 & 30.0 & $4.5(-2)$ & 29.3 & $6.7(-2)$ \\
\hline Si IX & $292.759^{\mathrm{E}}$ & $2 \mathrm{~s}^{2} 2 \mathrm{p}^{2}{ }^{3} \mathrm{P}_{1}-2 \mathrm{~s} 2 \mathrm{p}^{3}{ }^{3} \mathrm{P}_{2}^{0}$ & & 6.05 & & & 31.9 & & 31.7 & \\
\hline Si IX & $292.809^{\mathrm{E}}$ & $2 \mathrm{~s}^{2} 2 \mathrm{p}^{2}{ }^{3} \mathrm{P}_{1}-2 \mathrm{~s} 2 \mathrm{p}^{3}{ }^{3} \mathrm{P}_{0}^{0}$ & & 6.05 & & & 32.6 & & 31.4 & \\
\hline Si IX & $\begin{array}{l}\mathrm{UM}- \\
292.854^{\mathrm{E}}\end{array}$ & $2 \mathrm{~s}^{2} 2 \mathrm{p}^{2}{ }^{3} \mathrm{P}_{1}-2 \mathrm{~s} 2 \mathrm{p}^{3}{ }^{3} \mathrm{P}_{1}^{0}$ & 292.801 & 6.05 & 70.6 & 16.3 & $\begin{array}{l}64.6 \\
28.2\end{array}$ & $1.4(-2)$ & $\begin{array}{l}63.2 \\
27.6\end{array}$ & $2.1(-2)$ \\
\hline Si IX & $296.113^{\mathrm{E}}$ & $2 \mathrm{~s}^{2} 2 \mathrm{p}^{2}{ }^{3} \mathrm{P}_{2}-2 \mathrm{~s} 2 \mathrm{p}^{3}{ }^{3} \mathrm{P}_{2}^{0}$ & $296.128^{\mathrm{Y}}$ & 6.05 & 146.0 & 31 & 121.6 & $6.2(-1)$ & 120.7 & $6.7(-1)$ \\
\hline Si ix & $296.210^{\mathrm{E}}$ & $2 \mathrm{~s}^{2} 2 \mathrm{p}^{2}{ }^{3} \mathrm{P}_{2}-2 \mathrm{~s} 2 \mathrm{p}^{3}{ }^{3} \mathrm{P}_{1}^{0}$ & $296.228^{\mathrm{Y}}$ & 6.05 & 34.0 & 26 & 35.3 & $2.5(-3)$ & 34.5 & $3.7(-4)$ \\
\hline Si IX & $341.950^{\mathrm{E}}$ & $2 \mathrm{~s}^{2} 2 \mathrm{p}^{2}{ }^{3} \mathrm{P}_{0}-2 \mathrm{~s} 2 \mathrm{p}^{3}{ }^{3} \mathrm{D}_{1}^{0}$ & 341.974 & 6.05 & 29.4 & 4.9 & 34.3 & 1.0 & 33.0 & $5.5(-1)$ \\
\hline Si IX & $344.954^{\mathrm{E}}$ & $2 \mathrm{~s}^{2} 2 \mathrm{p}^{2}{ }^{3} \mathrm{P}_{1}-2 \mathrm{~s} 2 \mathrm{p}^{3}{ }^{3} \mathrm{D}_{1}^{0}$ & 344.958 & 6.05 & 17.3 & 4.2 & 19.6 & $3.0(-1)$ & 18.8 & $1.3(-1)$ \\
\hline Si IX & $345.120^{\mathrm{E}}$ & $2 \mathrm{~s}^{2} 2 \mathrm{p}^{2}{ }^{3} \mathrm{P}_{1}-2 \mathrm{~s} 2 \mathrm{p}^{3}{ }^{3} \mathrm{D}_{2}^{0}$ & 345.130 & 6.05 & 70.9 & 9.9 & 77.6 & $4.6(-1)$ & 75.4 & $2.1(-1)$ \\
\hline Si IX & $349.620^{\mathrm{E}}$ & $2 \mathrm{~s}^{2} 2 \mathrm{p}^{2}{ }^{3} \mathrm{P}_{2}-2 \mathrm{~s} 2 \mathrm{p}^{3}{ }^{3} \mathrm{D}_{1}^{0}$ & & 6.05 & & & 0.8 & & 0.7 & \\
\hline Si IX & $349.791^{\mathrm{E}}$ & $2 \mathrm{~s}^{2} 2 \mathrm{p}^{2}{ }^{3} \mathrm{P}_{2}-2 \mathrm{~s} 2 \mathrm{p}^{3}{ }^{3} \mathrm{D}_{2}^{0}$ & & 6.05 & & & 15.0 & & 14.5 & \\
\hline Si IX & $349.860^{\mathrm{E}}$ & $2 \mathrm{~s}^{2} 2 \mathrm{p}^{2}{ }^{3} \mathrm{P}_{2}-2 \mathrm{~s} 2 \mathrm{p}^{3}{ }^{3} \mathrm{D}_{3}^{0}$ & & 6.05 & & & 119.6 & & 119.8 & \\
\hline & JM - & & 349.872 & & 140.0 & 16.3 & 134.6 & $1.1(-1)$ & 134.4 & $1.2(-1)$ \\
\hline S XI & $186.839^{\mathrm{E}}$ & $2 \mathrm{~s}^{2} 2 \mathrm{p}^{2}{ }^{3} \mathrm{P}_{0}-2 \mathrm{~s} 2 \mathrm{p}^{3}{ }^{3} \mathrm{~S}_{1}^{0}$ & 186.883 & 6.25 & 1330.0 & 330.0 & 30.8 & $\mathrm{~b}$ & 31.3 & $\mathrm{~b}$ \\
\hline S XI & $188.675^{\mathrm{E}}$ & $2 \mathrm{~s}^{2} 2 \mathrm{p}^{2}{ }^{3} \mathrm{P}_{1}-2 \mathrm{~s} 2 \mathrm{p}^{3}{ }^{3} \mathrm{~S}_{1}^{0}$ & & 6.25 & & & 90.7 & & 92.3 & \\
\hline S XI & $191.266^{\mathrm{E}}$ & $2 \mathrm{~s}^{2} 2 \mathrm{p}^{2}{ }^{3} \mathrm{P}_{2}-2 \mathrm{~s} 2 \mathrm{p}^{3}{ }^{3} \mathrm{~S}_{1}^{0}$ & 191.234 & 6.25 & 286.0 & 135.0 & 156.2 & $\mathrm{~b}$ & 158.9 & $\mathrm{~b}$ \\
\hline S XI & $239.816^{\mathrm{E}}$ & $2 \mathrm{~s}^{2} 2 \mathrm{p}^{2}{ }^{3} \mathrm{P}_{0}-2 \mathrm{~s} 2 \mathrm{p}^{3}{ }^{3} \mathrm{P}_{1}^{0}$ & 239.834 & 6.25 & 130.0 & 56.0 & 42.8 & 2.4 & 41.6 & 2.5 \\
\hline S XI & $242.594^{\mathrm{E}}$ & $2 \mathrm{~s}^{2} 2 \mathrm{p}^{2}{ }^{3} \mathrm{P}_{1}-2 \mathrm{~s} 2 \mathrm{p}^{3}{ }^{3} \mathrm{P}_{2}^{0}$ & & 6.25 & & & 24.5 & & 26.4 & \\
\hline S XI & $242.849^{\mathrm{E}}$ & $2 \mathrm{~s}^{2} 2 \mathrm{p}^{2}{ }^{3} \mathrm{P}_{1}-2 \mathrm{~s} 2 \mathrm{p}^{3}{ }^{3} \mathrm{P}_{1}^{0}$ & & 6.25 & & & 46.3 & & 45.0 & \\
\hline S XI & $242.872^{\mathrm{E}}$ & $2 \mathrm{~s}^{2} 2 \mathrm{p}^{2}{ }^{3} \mathrm{P}_{1}-2 \mathrm{~s} 2 \mathrm{p}^{3}{ }^{3} \mathrm{P}_{0}^{0}$ & & 6.25 & & & 47.9 & & 47.7 & \\
\hline S XI & $246.895^{\mathrm{E}}$ & $2 \mathrm{~s}^{2} 2 \mathrm{p}^{2}{ }^{3} \mathrm{P}_{2}-2 \mathrm{~s} 2 \mathrm{p}^{3}{ }^{3} \mathrm{P}_{2}^{0}$ & 246.887 & 6.25 & 104.0 & 44.0 & 108.6 & $1.1(-2)$ & 116.7 & $8.3(-2)$ \\
\hline S XI & $247.159^{\mathrm{E}}$ & $2 \mathrm{~s}^{2} 2 \mathrm{p}^{2}{ }^{3} \mathrm{P}_{2}-2 \mathrm{~s} 2 \mathrm{p}^{3}{ }^{3} \mathrm{P}_{1}^{0}$ & $247.159^{\mathrm{Y}}$ & 6.25 & 85.0 & 41.0 & 48.3 & $8.0(-1)$ & 46.9 & $8.6(-1)$ \\
\hline $\mathrm{S}$ XI & $281.402^{\mathrm{E}}$ & $2 \mathrm{~s}^{2} 2 \mathrm{p}^{2}{ }^{3} \mathrm{P}_{0}-2 \mathrm{~s} 2 \mathrm{p}^{3}{ }^{3} \mathrm{D}_{1}^{0}$ & 281.440 & 6.25 & 36.3 & 16.0 & 79.1 & 7.2 & 73.1 & 5.3 \\
\hline S XI & $285.587^{\mathrm{E}}$ & $2 \mathrm{~s}^{2} 2 \mathrm{p}^{2}{ }^{3} \mathrm{P}_{1}-2 \mathrm{~s} 2 \mathrm{p}^{3}{ }^{3} \mathrm{D}_{1}^{0}$ & 285.578 & 6.25 & 53.4 & 17.8 & 38.4 & $7.1(-1)$ & 35.5 & 1.0 \\
\hline S XI & $285.822^{\mathrm{E}}$ & $2 \mathrm{~s}^{2} 2 \mathrm{p}^{2}{ }^{3} \mathrm{P}_{1}-2 \mathrm{~s} 2 \mathrm{p}^{3}{ }^{3} \mathrm{D}_{2}^{0}$ & 285.830 & 6.25 & 68.4 & 16.5 & 117.8 & 9.0 & 118.3 & 9.1 \\
\hline S XI & $291.566^{\mathrm{E}}$ & $2 \mathrm{~s}^{2} 2 \mathrm{p}^{2}{ }^{3} \mathrm{P}_{2}-2 \mathrm{~s} 2 \mathrm{p}^{3}{ }^{3} \mathrm{D}_{1}^{0}$ & & 6.25 & & & 1.1 & & 1.0 & \\
\hline S XI & $291.577^{\mathrm{E}}$ & $2 \mathrm{~s}^{2} 2 \mathrm{p}^{2}{ }^{3} \mathrm{P}_{2}-2 \mathrm{~s} 2 \mathrm{p}^{3}{ }^{3} \mathrm{D}_{3}^{0}$ & & 6.25 & & & 91.8 & & 101.7 & \\
\hline S XI & $291.811^{\mathrm{E}}$ & $2 \mathrm{~s}^{2} 2 \mathrm{p}^{2}{ }^{3} \mathrm{P}_{2}-2 \mathrm{~s} 2 \mathrm{p}^{3}{ }^{3} \mathrm{D}_{2}^{0}$ & & 6.25 & & & 16.1 & & 16.2 & \\
\hline
\end{tabular}

b: Blended.

E Wavelength from Edlén (1985a).

$\mathrm{N}$ Wavelength from NIST standard reference database.

Y New fit by Young et al. (1998).

alone gives the entire measured intensity, while in the uniform $N_{\mathrm{e}}$ approximation it contributes $74 \%$ of the observed intensity.

Our analysis overestimates the observed Mg VII lines of the $2 \mathrm{~s}^{2} 2 \mathrm{p}^{2} \mathrm{P}-2 \mathrm{~s} 2 \mathrm{p}^{3}{ }^{3} \mathrm{P}$ multiplet by factors of 1.5 to 2.3. It is likely that this discrepancy is due to inaccuracy in the atomic data involving these transitions.
Lines of the $2 \mathrm{~s}^{2} 2 \mathrm{p}^{23} \mathrm{P}-2 \mathrm{~s} 2 \mathrm{p}^{33} \mathrm{D}$ multiplet are found weaker than predicted by theory, consistent with the instrumental calibration inaccuracy found at these wavelengths (Young et al. 1998).

The Al VIII (285.470 $\AA$ ) theoretical intensity is only 0.2 of that observed. If the observed feature at $285.449 \AA$ is due to Al VIII then the other stronger Al VIII lines should 
be detected (and are observed in other C-like ions), but they are not. Thus this identification is doubtful.

The Si IX (341.950 $\AA)$ line is used for the integral inversion and is reproduced within the observational uncertainties. All other lines of the $2 \mathrm{~s}^{2} 2 \mathrm{p}^{2}{ }^{3} \mathrm{P}-2 \mathrm{~s} 2 \mathrm{p}^{3}{ }^{3} \mathrm{D}$ multiplet are also in good agreement with the observations.

The Si IX $(258.082 \AA)$ theoretical intensity is about $50 \%$ and $30 \%$ of that observed in the uniform- $P_{\mathrm{e}}$ and in the uniform- $N_{\mathrm{e}}$ approximation, respectively. This line is used as a density diagnostic together with $\operatorname{Si}$ IX $(296.113 \AA)$, whose theoretical intensity is in good agreement with the new estimate of Young et al. (1998). Although it gives an electron density compatible with other diagnostics, this ratio should, therefore, be treated with caution, since Si IX $(258.082 \AA)$ may be blended or affected by inaccuracies in intensity calibration at the low wavelength bandpass of the instrument. Note that we included this ratio in estimating the electron density for the evaluation of the kernels (see Sect.4.1 and Table 1), but the discrepancies found for Si IX $(258.082 \AA)$ do not affect our choice of the most likely electron density or electron pressure.

Si IX $(290.687 \AA)$ is reproduced within the observational uncertainties, but the line observed at $292.801 \AA$ is not. However, the discrepancy is not severe since its theoretical intensity only slightly exceeds the observational uncertainties. Note that the latter is a blend of $1-0,1-1$ and 1-2 components whose centroids embrace a wavelength region about $100 \mathrm{~m} \AA$ wide. Thomas \& Neupert (1994) report a FWHM of $100 \mathrm{~m} \AA$, which suggests that not all three components are included in their measurement. We suggest that only the 1-0 and 1-2 components are actually measured, which brings the comparison with theory into good agreement (see Table 6).

The line reported in the Thomas \& Neupert (1994) catalogue at $296.137 \AA$ has been subsequently fitted by Young et al. (1998) as two components at 296.128 and $296.228 \AA$ which are in excellent agreement with our DEM prediction (Table 6$)$.

S XI $(246.895 \AA)$ is used for the integral inversion to sample the temperature region around $\log \left(T_{\mathrm{p}}\right)=6.25 \mathrm{~K}$ and is well reproduced.

S XI (186.839 $\AA)$ is reported as blended with FeXII and our analysis indicates that the S XI contribution is $2 \%$ of the observed intensity. S XI (191.266 $\AA)$ is reported as blended with FeXIII, but our results indicate that the FeXIII contribution is negligible (see Sect. 4.5.5 and Table 11); the S XI theoretical intensity alone, despite being half the total observed intensity, is just within the error bars.

The S XI (239.816 $\AA$ ) theoretical intensity is 0.3 of that observed and outside the observational uncertainties. On the other hand, the new Young et al. (1998) identification of S XI $(247.159 \AA)$, the intensity of which is somewhat below the $3-\sigma$ sensitivity level of the intrument at that wavelength, is reproduced within the observational uncertainties; other lines of the $2 \mathrm{~s}^{2} 2 \mathrm{p}^{2}{ }^{3} \mathrm{P}-2 \mathrm{~s} 2 \mathrm{p}^{3}{ }^{3} \mathrm{P}$ multiplet are predicted to have intensities slightly weaker than S XI $(247.159 \AA)$, which could make their identification very difficult. It is therefore reasonable that S XI $(239.816 \AA)$ is blended with an unknown line.

We find discrepancies with observations for S XI lines of the $2 \mathrm{~s}^{2} 2 \mathrm{p}^{2}{ }^{3} \mathrm{P}-2 \mathrm{~s} 2 \mathrm{p}^{3}{ }^{3} \mathrm{D}$ multiplet, which could not be explained by assuming blends. Keenan et al. (2000b), using effective collision strengths interpolated from R-matrix calulations by Conlon et al. (1992) and A-values from Aggarwal (1998) and Froese Fischer \& Saha (1983), found the $246.895 / 285.822 \AA$ and $281.402 / 285.822 \AA$ observed ratios in agreement with theory while the $285.587 / 285.822 \AA$ ratio suggested the presence of a blend affecting S XI (285.587 $\AA)$. Note, however, that the atomic data adopted in this work are not significantly different from those used by Keenan et al. (2000b), and that our predicted ratios are also in agreement with observations, but our predicted absolute intensities are not. We therefore suggest that atomic data available for such transitions are affected by larger inaccuracies and that further work is required to solve this issue.

\subsubsection{N-like lines}

The comparison for the N-like ions is reported in Table 7.

Ne IV $(357.825 \AA)$ is used for the integral inversion to sample the temperature region around $\log \left(T_{\mathrm{p}}\right)=5.30 \mathrm{~K}$, and is well reproduced. Ne IV $(358.688 \AA)$ is reported as blended with Fe XI, Si XI and Fe XIV by Young et al. (1998), and our analysis indicates that NeIV contributes $20 \%$ to the total blend intensity (see Sects.4.4.2 and 4.5.3). Ne IV $(358.746 \AA)$ is predicted to be below the sensitivity limit of the instrument. The NeIV feature measured at $421.592 \AA$ is a self-blend of $1 / 2-1 / 2$ and $3 / 2-1 / 2$ components of the $2 \mathrm{~s}^{2} 2 \mathrm{p}^{3}{ }^{2} \mathrm{P}-2 \mathrm{~s} 2 \mathrm{p}^{4}{ }^{2} \mathrm{~S}$ doublet and its theoretical intensity is $60 \%$ higher than observed, consistent with the inaccuracy in the calibration at these wavelengths suggested by Young et al. (1998).

$\mathrm{Mg}$ VI lines of the $2 \mathrm{~s}^{2} 2 \mathrm{p}^{3}{ }^{2} \mathrm{D}-2 \mathrm{~s} 2 \mathrm{p}^{4}{ }^{2} \mathrm{P}$ multiplet are in good agreement with observations. Lines of the $2 \mathrm{~s}^{2} 2 \mathrm{p}^{3}{ }^{2} \mathrm{P}-2 \mathrm{~s} 2 \mathrm{p}^{42} \mathrm{P}$ and $2 \mathrm{~s}^{2} 2 \mathrm{p}^{3}{ }^{2} \mathrm{P}-2 \mathrm{~s} 2 \mathrm{p}^{4}{ }^{2} \mathrm{~S}$ multiplets are found to be below the instrument sensitivity limit and are not reported in Table 7 . We confirm the misidentification of the $319.80 \AA$ line as due to the $\mathrm{MgVI}$ $2 \mathrm{~s} 2 \mathrm{p}^{4}{ }^{2} \mathrm{D}_{3 / 2}-2 \mathrm{p}^{5}{ }^{2} \mathrm{P}_{1 / 2}$ transition since our analysis predicts a negligible intensity for this.

The feature measured at $349.162 \AA$ was identified as a self blend of the $5 / 2-3 / 2,3 / 2-3 / 2,5 / 2-5 / 2$ and $3 / 2-5 / 2$ components of the Mg VI $2 \mathrm{~s}^{2} 2 \mathrm{p}^{3}{ }^{2} \mathrm{D}-2 \mathrm{~s} 2 \mathrm{p}^{4}{ }^{2} \mathrm{D}$ multiplet. We find discrepancies with theory and suggest that, because of fitting problems, only the latter two components were actually measured, which brings the theoretical intensity down to $54-61 \mathrm{erg} \mathrm{cm}^{-2} \mathrm{~s}^{-1} \mathrm{sr}^{-1}$, in good agreement with observations. Note that Young et al. (1998) also found the $349.16 \AA$ self-blend too low in intensity by comparing the observed $270.401 / 349.162 \AA$ ratio with theory.

Despite the observed ratio of the Mgvi $2 \mathrm{~s}^{2} 2 \mathrm{p}^{3}{ }^{4} \mathrm{~S}-$ $2 \mathrm{~s} 2 \mathrm{p}^{4}{ }^{4} \mathrm{P}$ components being consistent with theory, the absolute intensities predicted by the DEM are a factor 4 
Table 7. As for Table 3 for the N-like iso-electronic sequence.

\begin{tabular}{|c|c|c|c|c|c|c|c|c|c|c|}
\hline Ion & $\lambda^{\mathrm{ad}}$ & Transition & $\lambda^{\text {obs. }}$ & $\log \left(T_{\mathrm{p}}\right)$ & $I^{\mathrm{obs}}$ & $e^{\mathrm{obs}}$ & $\begin{array}{c}I^{\mathrm{th}} \\
\log (\Lambda\end{array}$ & $\begin{array}{l}\left(\sigma_{0} \chi_{i}\right)^{2} \\
=9.5\end{array}$ & $\begin{array}{c}I^{\mathrm{th}} \\
\log \left(P_{\mathrm{e}}\right.\end{array}$ & $\begin{array}{r}\left(\sigma_{0} \chi_{i}\right)^{2} \\
=15.8\end{array}$ \\
\hline Ne IV & $357.825^{\mathrm{E}}$ & $2 \mathrm{~s}^{2} 2 \mathrm{p}^{3}{ }^{2} \mathrm{D}_{3 / 2}^{0}-2 \mathrm{~s} 2 \mathrm{p}^{4}{ }^{2} \mathrm{P}_{1 / 2}$ & 357.889 & 5.30 & 7.8 & 3.9 & 8.6 & $4.2(-2)$ & 8.4 & $2.4(-2)$ \\
\hline NeIV & $358.688^{\mathrm{E}}$ & $2 \mathrm{~s}^{2} 2 \mathrm{p}^{3}{ }^{2} \mathrm{D}_{5 / 2}^{0}-2 \mathrm{~s} 2 \mathrm{p}^{4}{ }^{2} \mathrm{P}_{3 / 2}$ & & 5.25 & & & 15.8 & $\mathrm{~b}$ & 15.6 & $\mathrm{~b}$ \\
\hline Ne IV & $358.746^{\mathrm{E}}$ & $2 \mathrm{~s}^{2} 2 \mathrm{p}^{3}{ }^{2} \mathrm{D}_{3 / 2}^{0}-2 \mathrm{~s} 2 \mathrm{p}^{4}{ }^{2} \mathrm{P}_{3 / 2}$ & & 5.25 & & & 1.9 & & 1.9 & \\
\hline NeIV & $421.599^{\mathrm{E}}$ & $2 \mathrm{~s}^{2} 2 \mathrm{p}^{3}{ }^{2} \mathrm{P}_{1 / 2}^{0}-2 \mathrm{~s} 2 \mathrm{p}^{4}{ }^{2} \mathrm{~S}_{1 / 2}$ & & 5.25 & & & 2.4 & & 2.5 & \\
\hline Ne IV & $421.610^{\mathrm{E}}$ & $2 \mathrm{~s}^{2} 2 \mathrm{p}^{3}{ }^{2} \mathrm{P}_{3 / 2}^{0}-2 \mathrm{~s} 2 \mathrm{p}^{4}{ }^{2} \mathrm{~S}_{1 / 2}$ & & 5.25 & & & 4.6 & & 4.7 & \\
\hline \multicolumn{2}{|c|}{ - SUM - } & & 421.592 & & 4.3 & 1.4 & 7.0 & 3.7 & 7.2 & 4.3 \\
\hline $\mathrm{Mg}$ VI & $268.991^{\mathrm{E}}$ & $2 \mathrm{~s}^{2} 2 \mathrm{p}^{3}{ }^{2} \mathrm{D}_{3 / 2}^{0}-2 \mathrm{~s} 2 \mathrm{p}^{4}{ }^{2} \mathrm{P}_{1 / 2}$ & 269.038 & 5.65 & 37.1 & 17.3 & 24.0 & $5.7(-1)$ & 26.4 & $3.8(-1)$ \\
\hline $\mathrm{Mg}$ VI & $270.390^{\mathrm{E}}$ & $2 \mathrm{~s}^{2} 2 \mathrm{p}^{3}{ }^{2} \mathrm{D}_{5 / 2}^{0}-2 \mathrm{~s} 2 \mathrm{p}^{4}{ }^{2} \mathrm{P}_{3 / 2}$ & & 5.65 & & & 44.5 & & 50.4 & \\
\hline $\mathrm{Mg}$ VI & $270.400^{\mathrm{E}}$ & $2 \mathrm{~s}^{2} 2 \mathrm{p}^{3}{ }^{2} \mathrm{D}_{3 / 2}^{0}-2 \mathrm{~s} 2 \mathrm{p}^{4}{ }^{2} \mathrm{P}_{3 / 2}$ & & 5.64 & & & 6.0 & & 6.8 & \\
\hline \multicolumn{2}{|c|}{ - SUM - } & & 270.401 & & 59.1 & 16.9 & 50.6 & $2.5(-1)$ & 57.2 & $1.1(-2)$ \\
\hline Mg VI & $319.80^{\mathrm{K}}$ & $2 \mathrm{~s} 2 \mathrm{p}^{4}{ }^{2} \mathrm{D}_{3 / 2}-2 \mathrm{p}^{5}{ }^{2} \mathrm{P}_{1 / 2}^{0}$ & 319.726 & 5.65 & 7.8 & 4.2 & 0.1 & 3.4 & 0.2 & 3.3 \\
\hline Mg VI & $349.108^{\mathrm{E}}$ & $2 \mathrm{~s}^{2} 2 \mathrm{p}^{3}{ }^{2} \mathrm{D}_{5 / 2}^{0}-2 \mathrm{~s} 2 \mathrm{p}^{4}{ }^{2} \mathrm{D}_{3 / 2}$ & & 5.65 & & & 3.6 & & 3.9 & \\
\hline Mg VI & $349.124^{\mathrm{E}}$ & $2 \mathrm{~s}^{2} 2 \mathrm{p}^{3}{ }^{2} \mathrm{D}_{3 / 2}^{0}-2 \mathrm{~s} 2 \mathrm{p}^{4}{ }^{2} \mathrm{D}_{3 / 2}$ & & 5.65 & & & 37.7 & & 40.0 & \\
\hline Mg VI & $349.163^{\mathrm{E}}$ & $2 \mathrm{~s}^{2} 2 \mathrm{p}^{3}{ }^{2} \mathrm{D}_{5 / 2}^{0}-2 \mathrm{~s} 2 \mathrm{p}^{4}{ }^{2} \mathrm{D}_{5 / 2}$ & & 5.65 & & & 51.3 & & 58.3 & \\
\hline Mg VI & $349.179^{\mathrm{E}}$ & $2 \mathrm{~s}^{2} 2 \mathrm{p}^{3}{ }^{2} \mathrm{D}_{3 / 2}^{0}-2 \mathrm{~s} 2 \mathrm{p}^{4}{ }^{2} \mathrm{D}_{5 / 2}$ & & 5.65 & & & 2.7 & & 3.0 & \\
\hline \multicolumn{2}{|c|}{ - SUM - } & & 349.162 & & 55.2 & 8.6 & 54.0 & $1.9(-2)$ & 61.4 & $5.2(-1)$ \\
\hline $\mathrm{Mg}$ VI & $387.788^{\mathrm{N}}$ & $2 \mathrm{~s}^{2} 2 \mathrm{p}^{3}{ }^{2} \mathrm{P}_{1 / 2}^{0}-2 \mathrm{~s} 2 \mathrm{p}^{4}{ }^{2} \mathrm{D}_{3 / 2}$ & $387.769^{\mathrm{Y}}$ & 5.65 & 3.8 & 1.5 & 4.1 & $4.0(-2)$ & 4.4 & $1.6(-1)$ \\
\hline $\mathrm{Mg}$ VI & $387.951^{\mathrm{N}}$ & $2 \mathrm{~s}^{2} 2 \mathrm{p}^{3}{ }^{2} \mathrm{P}_{3 / 2}^{0}-2 \mathrm{~s} 2 \mathrm{p}^{4}{ }^{2} \mathrm{D}_{3 / 2}$ & & 5.65 & & & 0.3 & & 0.3 & \\
\hline $\mathrm{Mg}$ VI & $388.014^{\mathrm{N}}$ & $2 \mathrm{~s}^{2} 2 \mathrm{p}^{3}{ }^{2} \mathrm{P}_{3 / 2}^{0}-2 \mathrm{~s} 2 \mathrm{p}^{4}{ }^{2} \mathrm{D}_{5 / 2}$ & $387.966^{\mathrm{Y}}$ & 5.65 & 6.2 & 2.3 & 7.5 & $3.2(-1)$ & 8.5 & 1.0 \\
\hline $\mathrm{Mg}$ VI & $399.281^{\mathrm{E}}$ & $2 \mathrm{~s}^{2} 2 \mathrm{p}^{3}{ }^{4} \mathrm{~S}_{3 / 2}^{0}-2 \mathrm{~s} 2 \mathrm{p}^{4}{ }^{4} \mathrm{P}_{1 / 2}$ & 399.275 & 5.65 & 9.3 & 1.8 & 32.3 & $1.6(+2)$ & 27.2 & $9.9(+1)$ \\
\hline Mg VI & $400.662^{\mathrm{E}}$ & $2 \mathrm{~s}^{2} 2 \mathrm{p}^{3}{ }^{4} \mathrm{~S}_{3 / 2}^{0}-2 \mathrm{~s} 2 \mathrm{p}^{4}{ }^{4} \mathrm{P}_{3 / 2}$ & 400.668 & 5.65 & 16.2 & 2.5 & 65.4 & $3.9(+2)$ & 55.0 & $2.4(+2)$ \\
\hline $\mathrm{Mg}$ VI & $403.307^{\mathrm{E}}$ & $2 \mathrm{~s}^{2} 2 \mathrm{p}^{3}{ }^{4} \mathrm{~S}_{3 / 2}^{0}-2 \mathrm{~s} 2 \mathrm{p}^{4}{ }^{4} \mathrm{P}_{5 / 2}$ & 403.296 & 5.65 & 45.6 & 5.6 & 96.6 & $\mathrm{~b}$ & 81.2 & $\mathrm{~b}$ \\
\hline Si VIII & $276.850^{\mathrm{E}}$ & $2 \mathrm{~s}^{2} 2 \mathrm{p}^{3}{ }^{2} \mathrm{D}_{3 / 2}^{0}-2 \mathrm{~s} 2 \mathrm{p}^{4}{ }^{2} \mathrm{D}_{3 / 2}$ & & 5.90 & & & 22.4 & & 25.6 & \\
\hline Si VIII & $276.865^{\mathrm{E}}$ & $2 \mathrm{~s}^{2} 2 \mathrm{p}^{3}{ }^{2} \mathrm{D}_{3 / 2}^{0}-2 \mathrm{~s} 2 \mathrm{p}^{4}{ }^{2} \mathrm{D}_{5 / 2}$ & & 5.90 & & & 1.2 & & 1.3 & \\
\hline \multicolumn{2}{|c|}{ - SUM - } & & 276.850 & & 65.6 & 17.7 & 23.5 & $\mathrm{~b}$ & 26.8 & $\mathrm{~b}$ \\
\hline Si VIII & $277.042^{\mathrm{E}}$ & $2 \mathrm{~s}^{2} 2 \mathrm{p}^{3}{ }^{2} \mathrm{D}_{5 / 2}^{0}-2 \mathrm{~s} 2 \mathrm{p}^{4}{ }^{2} \mathrm{D}_{3 / 2}$ & & 5.90 & & & 1.9 & & 2.2 & \\
\hline Si VIII & $277.057^{\mathrm{E}}$ & $2 \mathrm{~s}^{2} 2 \mathrm{p}^{3}{ }^{2} \mathrm{D}_{5 / 2}^{0}-2 \mathrm{~s} 2 \mathrm{p}^{4}{ }^{2} \mathrm{D}_{5 / 2}$ & & 5.90 & & & 29.3 & & 32.1 & \\
\hline \multicolumn{2}{|c|}{ - SUM - } & & 277.045 & & 85.1 & 23.0 & 31.3 & $\mathrm{~b}$ & 34.3 & $\mathrm{~b}$ \\
\hline Si VIII & $314.356^{\mathrm{E}}$ & $2 \mathrm{~s}^{2} 2 \mathrm{p}^{3}{ }^{4} \mathrm{~S}_{3 / 2}^{0}-2 \mathrm{~s} 2 \mathrm{p}^{4}{ }^{4} \mathrm{P}_{1 / 2}$ & 314.345 & 5.90 & 54.1 & 10.3 & 35.5 & 3.3 & 32.5 & 4.4 \\
\hline Si VIII & $316.218^{\mathrm{E}}$ & $2 \mathrm{~s}^{2} 2 \mathrm{p}^{3}{ }^{4} \mathrm{~S}_{3 / 2}^{0}-2 \mathrm{~s} 2 \mathrm{p}^{4}{ }^{4} \mathrm{P}_{3 / 2}$ & 316.220 & 5.90 & 88.7 & 12.9 & 67.2 & 2.8 & 61.6 & 4.4 \\
\hline Si VIII & $319.839^{\mathrm{E}}$ & $2 \mathrm{~s}^{2} 2 \mathrm{p}^{3}{ }^{4} \mathrm{~S}_{3 / 2}^{0}-2 \mathrm{~s} 2 \mathrm{p}^{4}{ }^{4} \mathrm{P}_{5 / 2}$ & 319.839 & 5.90 & 113.0 & 13.9 & 101.6 & $6.7(-1)$ & 93.0 & 2.0 \\
\hline $\mathrm{Sx}$ & $257.147^{\mathrm{E}}$ & $2 \mathrm{~s}^{2} 2 \mathrm{p}^{3}{ }^{4} \mathrm{~S}_{3 / 2}^{0}-2 \mathrm{~s} 2 \mathrm{p}^{4}{ }^{4} \mathrm{P}_{1 / 2}$ & $257.144^{\mathrm{D}}$ & 6.15 & 28.8 & 17.8 & 108.2 & $2.0(+1)$ & 106.1 & $1.9(+1)$ \\
\hline $\mathrm{Sx}$ & $259.496^{\mathrm{E}}$ & $2 \mathrm{~s}^{2} 2 \mathrm{p}^{3}{ }^{4} \mathrm{~S}_{3 / 2}^{0}-2 \mathrm{~s} 2 \mathrm{p}^{4}{ }^{4} \mathrm{P}_{3 / 2}$ & 259.495 & 6.15 & 123.0 & 44.0 & 206.7 & 3.6 & 202.8 & 3.3 \\
\hline $\mathrm{Sx}$ & $264.230^{\mathrm{E}}$ & $2 \mathrm{~s}^{2} 2 \mathrm{p}^{3}{ }^{4} \mathrm{~S}_{3 / 2}^{0}-2 \mathrm{~s} 2 \mathrm{p}^{4}{ }^{4} \mathrm{P}_{5 / 2}$ & 264.221 & 6.15 & 96.3 & 32.0 & 309.7 & $4.4(+1)$ & 303.7 & $4.2(+1)$ \\
\hline
\end{tabular}

b: Blended.

D New fit by Dwivedi et al. (1998).

K Wavelength from Kelly (1987).

$\mathrm{N}$ Wavelength from NIST standard reference database.

E Wavelength from Edlén (1984).

Y New fit by Young et al. (1998). 
higher than observed, which suggests inaccuracies in the atomic data. As a consequence, the expected Mg VI contribution to the $403.307 \AA$ blend with Ne VI (see Sect.4.4.3) cannot be confirmed by the Mg VI analysis.

Lines of the Si VIII $2 \mathrm{~s}^{2} 2 \mathrm{p}^{3}{ }^{2} \mathrm{P}-2 \mathrm{~s} 2 \mathrm{p}^{4}{ }^{2} \mathrm{~S}$ multiplet are found to be below the instrument sensitivity, consistent with the lack of detection, and are not reported in Table 7.

Si VIII $(276.850 \AA)$ is reported as blended with Si VII by Young et al. (1998). According to our analysis, this leaves more than 16 erg $\mathrm{cm}^{-2} \mathrm{~s}^{-1} \mathrm{sr}^{-1}$ unaccounted for, which may indicate the presence of a further blend.

The Si VIII feature at $277.045 \AA$ is blended with Mg VII and we reproduce such a blend within the observational uncertainties.

Of the SiviII $2 \mathrm{~s}^{2} 2 \mathrm{p}^{3}{ }^{4} \mathrm{~S}-2 \mathrm{~s} 2 \mathrm{p}^{4}{ }^{4} \mathrm{P}$ multiplet, only Si VIII $(319.839 \AA)$ is reproduced within the observational uncertainties in the uniform $N_{\mathrm{e}}$ approximation, suggesting possible inaccuracy in the atomic data involving such transitions.

The theoretical intensities of all three S x lines are considerably higher than observed. Line ratios also do not agree with observations.

\subsubsection{O-like lines}

The comparison for O-like ions is reported in Table 8.

Ne III $(379.308 \AA)$ is used in the integral inversion to sample the temperature region around $\log \left(T_{\mathrm{p}}\right)=5.05 \mathrm{~K}$, which is the lowest temperature in the DEM evaluation (see Table 2 ). The Ne III (427.847 $\AA$ ) theoretical intensity is well below the sensitivity limit of the instrument, which confirms the misidentification of this line as reported in Young et al. (1998).

$\operatorname{MgV}(351.085 \AA)$ is used in the integral inversion to sample the temperature region around $\log \left(T_{\mathrm{p}}\right)=$ $5.45 \mathrm{~K}$ and is in excellent agreement with observations. Mg V (276.581 ^) was identified by Dwivedi et al. (1998) and the theoretical intensity is in agreement with observations. They identified another $\mathrm{Mg} \mathrm{V}$ line at $352.200 \AA$ but the observed intensity is lower than predicted by the DEM. The observed intensity of $\mathrm{MgV}(353.092 \AA)$ is also too low compared with the DEM prediction. The other $\mathrm{Mg} \mathrm{V}$ lines of the $2 \mathrm{~s}^{2} 2 \mathrm{p}^{43} \mathrm{P}-2 \mathrm{~s} 2 \mathrm{p}^{53} \mathrm{P}$ multiplet are in good agreement with observations. Note that $\mathrm{MgV}(353.297 \AA)$ is blended with $\mathrm{Na}$ VI and is expected to contribute $75-80 \%$ of the blend intensity.

All Sivil $2 \mathrm{~s}^{2} 2 \mathrm{p}^{43} \mathrm{P}-2 \mathrm{~s} 2 \mathrm{p}^{53} \mathrm{P}$ transitions are found well below the sensitivity limit of the instrument, except the line identified at $275.377 \AA$ whose predicted intensity is, however, only $30 \%$ of that observed, suggesting the presence of a blend. Si viI (276.850 $)$ is blended with Si VIII (see Sect. 4.4.5), but the sum of their theoretical intensities is about half that observed. Si VII (278.449 $\AA$ ) is blended with Mg VII (see Sect. 4.4.4) producing a total theoretical intensity about $30 \%$ lower than observed.

\subsection{The iron ions}

\subsubsection{FeIX}

Lines of Fe IX have theoretical to observed intensity ratios (or quality fit ratio - QFR) between 0.1 and 0.7. Marginal agreement is found for Fe IX $(171.073 \AA)$ in the uniform- $N_{\mathrm{e}}$ approximation, but the $244.909 / 241.739 \AA$ ratio is closer to the observations in the uniform- $P_{\mathrm{e}}$ approximation. Note that Fe IX (241.739 $\AA$ ) is sensitive to the model adopted in computing the $G$-functions.

Fe IX $(171.073 \AA)$ and Fe IX $(217.101 \AA)$ are close to the end of the SERTS-89 second order bandpass and Fe IX $(241.739 \AA)$ and Fe IX $(244.909 \AA)$ close to the low wavelength end of the first order bandpass, creating uncertainties in the line intensities. However, the difference in QFR between the intersystem lines and allowed transition at $171.061 \AA$ suggests that excitation/de-excitation rate coefficients need to be substantially revised.

\subsubsection{FeX}

Fex $(174.534 \AA)$ is blended with the first-order line Fe XI $(349.035 \AA)$. The predicted intensity of each of these lines is close to the observed intensity of the whole blend, which is therefore overestimated by a factor 2 . Young et al. (1998) suggested that Fex (365.543 $\AA$ ) may be blended with $\mathrm{Ne} \mathrm{V}(365.60 \AA)$. Indeed, our results indicate that the feature at $365.565 \AA$ is not due solely to Fex, but that by assuming a blend with $\mathrm{Ne} \mathrm{V}$ we found excellent agreement with observations.

Invoking the self-blend of $3 \mathrm{p}^{5}{ }^{2} \mathrm{P}_{3 / 2}-3 \mathrm{p}^{4} 3 \mathrm{~d}^{4} \mathrm{D}_{7 / 2}$ and $3 \mathrm{p}^{5}{ }^{2} \mathrm{P}_{3 / 2}-3 \mathrm{p}^{4} 3 \mathrm{~d}^{4} \mathrm{D}_{5 / 2}$ is not sufficient to account for the feature observed at $257.257 \AA$, suggesting the presence of an unknown blend.

A blend could be invoked also for Fex (345.723 $\AA)$. A close lying line is $\mathrm{Alx}(345.66 \AA)$, but our results indicate that its intensity is negligible and cannot explain the discrepancy.

\subsubsection{FeXI}

Fe XI $(356.519 \AA)$ is in excellent agreement with observations. We also confirm the Brickhouse et al. (1995) identification of the feature at $406.791 \AA$ as due to the Fe XI $3 \mathrm{~s}^{2} 3 \mathrm{p}^{4}{ }^{1} \mathrm{D}_{2}-3 \mathrm{~s} 3 \mathrm{p}^{5}{ }^{3} \mathrm{P}_{2}$ transition. Fe XI $(349.046 \AA)$ and Fe XI (369.153 $\AA$ ) are reproduced within the observational uncertainties in the uniform- $N_{\mathrm{e}}$ approximation and in marginal agreement in the uniform- $P_{\mathrm{e}}$ approximation. Large discrepancies are found for the features at 188.219, 308.548 and $358.621 \AA$.

FexI $(358.621 \AA)$ is reported as blended with Si XI (358.656 $\AA)$, Ne IV (358.688 $)$ ) and with a Fe XIV line by Young et al. (1998). The Fe XIV line was studied by Bhatia et al. (1994) and is not in our database. Our results essentially confirm this blending provided Fe XIV contributes by $26 \pm 9.4 \mathrm{erg} \mathrm{cm}^{-2} \mathrm{~s}^{-1} \mathrm{sr}^{-1}$. 
Table 8. Same as Table 1 for the O-like iso-electronic sequence.

\begin{tabular}{|c|c|c|c|c|c|c|c|c|c|c|}
\hline Ion & $\lambda^{\text {ad. }}$ & Transition & $\lambda^{\text {obs. }}$ & $\log \left(T_{\mathrm{p}}\right)$ & $I^{\mathrm{obs}}$ & $e^{\text {obs }}$ & \multicolumn{2}{|c|}{$\log \left(N_{\mathrm{e}}\right)=9.5$} & \multicolumn{2}{|c|}{$\log \left(P_{\mathrm{e}}\right)=15.8$} \\
\hline NeIII & $379.308^{\mathrm{N}}$ & $2 \mathrm{~s}^{2} 2 \mathrm{p}^{4}{ }^{1} \mathrm{D}_{2}-2 \mathrm{~s} 2 \mathrm{p}^{5}{ }^{1} \mathrm{P}_{1}^{0}$ & 379.306 & 5.05 & 7.6 & 2.2 & 7.4 & $8.3(-3)$ & 7.4 & $8.3(-3)$ \\
\hline Ne III & $427.847^{\mathrm{N}}$ & $2 \mathrm{~s}^{2} 2 \mathrm{p}^{4}{ }^{1} \mathrm{~S}_{0}-2 \mathrm{~s} 2 \mathrm{p}^{5}{ }^{1} \mathrm{P}_{1}^{0}$ & 427.843 & 5.05 & 3.9 & 1.8 & 0.4 & 3.8 & 0.4 & 3.8 \\
\hline $\mathrm{Mg} \mathrm{V}$ & $276.581^{\mathrm{F}}$ & $2 \mathrm{~s}^{2} 2 \mathrm{p}^{4}{ }^{1} \mathrm{D}_{2}-2 \mathrm{~s} 2 \mathrm{p}^{5}{ }^{1} \mathrm{P}_{1}^{0}$ & $276.582^{\mathrm{D}}$ & 5.45 & 22.4 & 12.3 & 23.2 & $4.2(-3)$ & 27.7 & $1.9(-2)$ \\
\hline Mg V & $351.085^{\mathrm{E}}$ & $2 \mathrm{~s}^{2} 2 \mathrm{p}^{4}{ }^{3} \mathrm{P}_{2}-2 \mathrm{~s} 2 \mathrm{p}^{5}{ }^{3} \mathrm{P}_{1}^{0}$ & 351.117 & 5.45 & 13.1 & 4.6 & 13.4 & $4.3(-3)$ & 12.8 & $4.3(-3)$ \\
\hline $\mathrm{Mg} \mathrm{V}$ & $352.197^{\mathrm{E}}$ & $2 \mathrm{~s}^{2} 2 \mathrm{p}^{4}{ }^{3} \mathrm{P}_{1}-2 \mathrm{~s} 2 \mathrm{p}^{5}{ }^{3} \mathrm{P}_{0}^{0}$ & $352.200^{\mathrm{D}}$ & 5.45 & 4.3 & 3.1 & 11.0 & 4.7 & 10.3 & 3.7 \\
\hline $\mathrm{Mg} \mathrm{V}$ & $353.092^{\mathrm{E}}$ & $2 \mathrm{~s}^{2} 2 \mathrm{p}^{4}{ }^{3} \mathrm{P}_{2}-2 \mathrm{~s} 2 \mathrm{p}^{5}{ }^{3} \mathrm{P}_{2}^{0}$ & 353.084 & 5.45 & 10.4 & 3.8 & 40.8 & $6.4(+1)$ & 38.6 & $5.5(+1)$ \\
\hline $\mathrm{Mg} \mathrm{V}$ & $353.297^{\mathrm{E}}$ & $2 \mathrm{~s}^{2} 2 \mathrm{p}^{4}{ }^{3} \mathrm{P}_{1}-2 \mathrm{~s} 2 \mathrm{p}^{5}{ }^{3} \mathrm{P}_{1}^{0}$ & 353.290 & 5.45 & 10.1 & 3.1 & 7.9 & $5.0(-1)$ & 7.5 & $7.0(-1)$ \\
\hline $\mathrm{Mg} \mathrm{V}$ & $354.221^{\mathrm{E}}$ & $2 \mathrm{~s}^{2} 2 \mathrm{p}^{4}{ }^{3} \mathrm{P}_{0}-2 \mathrm{~s} 2 \mathrm{p}^{5}{ }^{3} \mathrm{P}_{1}^{0}$ & 354.162 & 5.45 & 9.0 & 4.6 & 10.4 & $9.3(-2)$ & 9.9 & $3.8(-2)$ \\
\hline $\mathrm{Mg} \mathrm{V}$ & $355.329^{\mathrm{E}}$ & $2 \mathrm{~s}^{2} 2 \mathrm{p}^{4}{ }^{3} \mathrm{P}_{1}-2 \mathrm{~s} 2 \mathrm{p}^{5}{ }^{3} \mathrm{P}_{2}^{0}$ & 355.339 & 5.45 & 11.3 & 6.2 & 13.3 & $1.0(-2)$ & 12.5 & $3.7(-2)$ \\
\hline Si VII & $272.647^{\mathrm{E}}$ & $2 \mathrm{~s}^{2} 2 \mathrm{p}^{4}{ }^{3} \mathrm{P}_{2}-2 \mathrm{~s} 2 \mathrm{p}^{5}{ }^{3} \mathrm{P}_{1}^{0}$ & & 5.75 & & & 8.6 & & 8.0 & \\
\hline Si VII & $274.180^{\mathrm{E}}$ & $2 \mathrm{~s}^{2} 2 \mathrm{p}^{4}{ }^{3} \mathrm{P}_{1}-2 \mathrm{~s} 2 \mathrm{p}^{5}{ }^{3} \mathrm{P}_{0}^{0}$ & & 5.75 & & & 6.9 & & 6.9 & \\
\hline Si VII & $275.361^{\mathrm{E}}$ & $2 \mathrm{~s}^{2} 2 \mathrm{p}^{4}{ }^{3} \mathrm{P}_{2}-2 \mathrm{~s} 2 \mathrm{p}^{5}{ }^{3} \mathrm{P}_{2}^{0}$ & 275.377 & 5.75 & 105.0 & 28.0 & 32.1 & 6.8 & 28.4 & 7.5 \\
\hline Si VII & $275.675^{\mathrm{E}}$ & $2 \mathrm{~s}^{2} 2 \mathrm{p}^{4}{ }^{3} \mathrm{P}_{1}-2 \mathrm{~s} 2 \mathrm{p}^{5}{ }^{3} \mathrm{P}_{1}^{0}$ & & 5.75 & & & 4.9 & & 4.6 & \\
\hline Si VII & $276.850^{\mathrm{E}}$ & $2 \mathrm{~s}^{2} 2 \mathrm{p}^{4}{ }^{3} \mathrm{P}_{0}-2 \mathrm{~s} 2 \mathrm{p}^{5}{ }^{3} \mathrm{P}_{1}^{0}$ & & 5.75 & & & 6.5 & $\mathrm{~b}$ & 6.0 & $\mathrm{~b}$ \\
\hline Si VII & $278.449^{\mathrm{E}}$ & $2 \mathrm{~s}^{2} 2 \mathrm{p}^{4}{ }^{3} \mathrm{P}_{1}-2 \mathrm{~s} 2 \mathrm{p}^{5}{ }^{3} \mathrm{P}_{2}^{0}$ & & 5.75 & & & 10.2 & $\mathrm{~b}$ & 9.1 & $\mathrm{~b}$ \\
\hline
\end{tabular}

b: Blended.

D New fit by Dwivedi et al. (1998).

E Wavelength from Edlén (1983a).

F Wavelength from Fawcett (1975).

$\mathrm{N}$ Wavelength from NIST standard reference database.

The theoretical-to-observed ratios of Fe XI (188.219 $\AA)$ and FeXI $(308.548 \AA)$ are 0.4 and 0.2 respectively, which suggests blending as the cause of the discrepancy.

\subsubsection{FeXII}

We reproduce Fe XII (196.640 $\AA)$, Fe XII $(219.438 \AA)$ and Fe XII $(283.64 \AA)$ within the observational uncertainties. We therefore confirm the Keenan et al. (1996) identification of the features at $196.619 \AA$ and $283.70 \AA$ as FeXII $3 \mathrm{p}^{3}{ }^{2} \mathrm{D}_{5 / 2}-3 \mathrm{p}^{2} 3 \mathrm{~d}^{2} \mathrm{D}_{5 / 2}$ and Fe XII $3 \mathrm{~s}^{2} 3 \mathrm{p}^{3}{ }^{2} \mathrm{D}_{3 / 2^{-}}$ $3 \mathrm{~s} 3 \mathrm{p}^{4} \mathrm{P}_{1 / 2}$ transitions, respectively (see also Young et al. 1998). Fe XII (193.509 $\AA$ ) is reproduced in the uniform- $P_{\mathrm{e}}$ approximation and marginally in the uniform- $N_{\mathrm{e}}$ approximation This line is better reproduced assuming a uniform $\log \left(N_{\mathrm{e}}\right)=10 \mathrm{~cm}^{-3}$.

The FexiI $3 \mathrm{p}^{32} \mathrm{D}_{5 / 2}-3 \mathrm{p}^{2} 3 \mathrm{~d}^{2} \mathrm{~F}_{7 / 2}$ and $3 \mathrm{p}^{32} \mathrm{D}_{3 / 2^{-}}$ $3 \mathrm{p}^{2} 3 \mathrm{~d}^{2} \mathrm{~F}_{5 / 2}$ transitions cannot account for the full line intensity at $186.883 \AA$, as already found by Young et al. (1998), although the theoretical intensity in the uniform- $P_{\mathrm{e}}$ approximation is just inside the error bars. We estimate that SXI contributes by approximately $30 \mathrm{erg} \mathrm{cm}^{-2} \mathrm{~s}^{-1} \mathrm{sr}^{-1}$, and therefore is not sufficient to fully account for the discrepancy. Young et al. (1998) invoke a weak first order $\mathrm{O}$ III line which we estimate to have an intensity of $3 \mathrm{erg} \mathrm{cm}^{-2} \mathrm{~s}^{-1} \mathrm{sr}^{-1}$ that would produce a response equivalent to a second order line of $300 \mathrm{erg} \mathrm{cm}^{-2} \mathrm{~s}^{-1} \mathrm{sr}^{-1}$. This produces a blend total flux very close to the observed value.

Fe XII $(192.394 \AA)$ is reported as blended with Mn XV (384.75 $\AA$ ), contributing, according to our results, about $20 \%$ of the total intensity, in contrast with the Young et al. (1998) estimate of $5 \mathrm{erg} \mathrm{cm} \mathrm{cm}^{-1} \mathrm{sr}^{-1}$ based on the 192.394/195.119 $\AA$ density insensitive ratio. Note, however, that our estimate of Fe XII (195.119 $\AA)$ is approximately twice that observed and it reduces to the observed intensity only assuming $\log \left(N_{\mathrm{e}}\right) \sim 11$, which is somewhat larger than estimates by other density diagnostics.

According to Keenan et al. (1996), the discrepancy seen in Fe XII (200.356 $\AA$ ) may be due to a blend with first order Ca vi $(400.83 \AA)$.

Fe XII $(201.121 \AA)$ is reported as blended with Fe XIII, but our results indicate that the Fe XII contribution is negligible. The Fe XIII theoretical intensity is, on the other hand, about $50 \%$ higher than observed and to reproduce it within the observational uncertainties we must assume $\log \left(N_{\mathrm{e}}\right)=11$. This result disagrees with Young et al. (1998), who found a weak Fe XIII contribution to this blend.

Fe XII $(291.010 \AA)$ is $30-40 \%$ weaker than observed. This discrepancy reduces by increasing the electron density and disappears when $\log \left(N_{\mathrm{e}}\right)=11$. 
Table 9. Comparison of the observed intensities with those derived from the DEM for the Fe IX-XI ions. Wavelengths are in $\AA$. Intensities in erg $\mathrm{cm}^{-2} \mathrm{~s}^{-1} \mathrm{sr}^{-1}$. See text and Table 3 for description.

\begin{tabular}{|c|c|c|c|c|c|c|c|c|c|c|}
\hline \multirow[t]{2}{*}{ Ion } & \multirow[t]{2}{*}{$\lambda^{\text {ad. }}$} & \multirow[t]{2}{*}{ Transition } & \multirow[t]{2}{*}{$\lambda^{\text {obs. }}$} & \multirow[t]{2}{*}{$\log \left(T_{\mathrm{p}}\right)$} & \multirow[t]{2}{*}{$I^{\text {obs }}$} & \multirow[t]{2}{*}{$e^{\text {obs }}$} & \multirow{2}{*}{\multicolumn{2}{|c|}{$\begin{array}{c}I^{\text {th }} \quad\left(\sigma_{0} \chi_{i}\right)^{2} \\
\log \left(N_{\mathrm{e}}\right)=9.5\end{array}$}} & \multirow{2}{*}{$\begin{array}{c}I^{\text {th }} \\
\log \left(P_{\mathrm{e}}\right)\end{array}$} & \multirow{2}{*}{$\begin{array}{l}\left(\sigma_{0} \chi_{i}\right)^{2} \\
=15.8\end{array}$} \\
\hline & & & & & & & & & & \\
\hline Fe IX & $171.073^{\mathrm{N}}$ & $3 \mathrm{p}^{6}{ }^{1} \mathrm{~S}_{0}-3 \mathrm{p}^{5} 3 \mathrm{~d}{ }^{1} \mathrm{P}_{1}^{0}$ & 171.061 & 5.80 & 1510.0 & 470.0 & 1034.5 & 1.0 & 911.3 & 1.6 \\
\hline Fe IX & $217.101^{\mathrm{N}}$ & $3 \mathrm{p}^{6}{ }^{1} \mathrm{~S}_{0}-3 \mathrm{p}^{5} 3 \mathrm{~d}^{3} \mathrm{D}_{1}^{0}$ & 217.102 & 5.80 & 70.5 & 34.0 & 14.0 & 2.8 & 15.5 & 2.6 \\
\hline Fe IX & $241.739^{\mathrm{K}}$ & $3 \mathrm{p}^{6}{ }^{1} \mathrm{~S}_{0}-3 \mathrm{p}^{5} 3 \mathrm{~d}^{3} \mathrm{P}_{2}^{0}$ & 241.747 & 5.80 & 195.0 & 70.0 & 41.1 & 4.8 & 29.4 & 5.6 \\
\hline Fe IX & $244.909^{\mathrm{N}}$ & $3 \mathrm{p}^{6}{ }^{1} \mathrm{~S}_{0}-3 \mathrm{p}^{5} 3 \mathrm{~d}^{3} \mathrm{P}_{1}^{0}$ & 244.916 & 5.80 & 162.0 & 48.0 & 21.3 & 8.6 & 21.1 & 8.6 \\
\hline Fex & $174.534^{\mathrm{N}}$ & $3 \mathrm{p}^{5}{ }^{2} \mathrm{P}_{3 / 2}^{0}-3 \mathrm{p}^{4} 3 \mathrm{~d}^{2} \mathrm{D}_{5 / 2}$ & 174.517 & 6.00 & 764.0 & 360.0 & 768.1 & $\mathrm{~b}$ & 706.6 & $\mathrm{~b}$ \\
\hline $\mathrm{Fex}$ & $257.262^{\mathrm{N}}$ & $3 \mathrm{p}^{5}{ }^{2} \mathrm{P}_{3 / 2}^{0}-3 \mathrm{p}^{4} 3 \mathrm{~d}^{4} \mathrm{D}_{7 / 2}$ & & 6.00 & & & 32.6 & & 22.3 & \\
\hline Fex & $257.308^{\mathrm{T}}$ & $3 \mathrm{p}^{5}{ }^{2} \mathrm{P}_{3 / 2}^{0}-3 \mathrm{p}^{4} 3 \mathrm{~d}^{4} \mathrm{D}_{5 / 2}$ & & 6.00 & & & 16.2 & & 16.6 & \\
\hline- & UM - & & 257.257 & & 132.0 & 34.0 & 48.8 & 6.0 & 38.9 & 7.5 \\
\hline $\mathrm{Fex}$ & $345.723^{\mathrm{N}}$ & $3 \mathrm{~s}^{2} 3 \mathrm{p}^{5}{ }^{2} \mathrm{P}_{3 / 2}^{0}-3 \mathrm{~s} 3 \mathrm{p}^{6}{ }^{2} \mathrm{~S}_{1 / 2}$ & 345.735 & 6.00 & 75.8 & 9.7 & 41.6 & $1.2(+1)$ & 40.1 & $1.3(+1)$ \\
\hline Fex & $365.543^{\mathrm{N}}$ & $3 s^{2} 3 p^{5}{ }^{2} \mathrm{P}_{1 / 2}^{0}-3 \mathrm{~s} 3 \mathrm{p}^{6}{ }^{2} \mathrm{~S}_{1 / 2}$ & 365.565 & 6.00 & 43.0 & 6.0 & 17.5 & $\mathrm{~b}$ & 16.8 & $\mathrm{~b}$ \\
\hline Fe XI & $188.219^{\mathrm{N}}$ & $3 \mathrm{p}^{4}{ }^{3} \mathrm{P}_{2}-3 \mathrm{p}^{3} 3 \mathrm{~d}^{3} \mathrm{P}_{2}^{0}$ & 188.209 & 6.05 & 1140.0 & 270.0 & 520.2 & 5.3 & 492.9 & 5.7 \\
\hline Fe XI & $308.548^{\mathrm{N}}$ & $3 \mathrm{~s}^{2} 3 \mathrm{p}^{4}{ }^{1} \mathrm{D}_{2}-3 \mathrm{~s} 3 \mathrm{p}^{5}{ }^{1} \mathrm{P}_{1}^{0}$ & 308.575 & 6.05 & 84.4 & 15.9 & 14.5 & $1.9(+1)$ & 18.4 & $1.7(+1)$ \\
\hline FexI & $341.113^{\mathrm{N}}$ & $3 \mathrm{~s}^{2} 3 \mathrm{p}^{4}{ }^{3} \mathrm{P}_{2}-3 \mathrm{~s} 3 \mathrm{p}^{5}{ }^{3} \mathrm{P}_{1}^{0}$ & 341.114 & 6.05 & 37.3 & 5.7 & 30.1 & 1.6 & 29.7 & 1.8 \\
\hline FexI & $349.046^{\mathrm{N}}$ & $3 \mathrm{~s}^{2} 3 \mathrm{p}^{4}{ }^{3} \mathrm{P}_{1}-3 \mathrm{~s} 3 \mathrm{p}^{5}{ }^{3} \mathrm{P}_{0}^{0}$ & 349.035 & 6.05 & 7.2 & 3.4 & 9.0 & $\mathrm{~b}$ & 11.0 & $\mathrm{~b}$ \\
\hline Fe XI & $352.662^{\mathrm{N}}$ & $3 \mathrm{~s}^{2} 3 \mathrm{p}^{4}{ }^{3} \mathrm{P}_{2}-3 \mathrm{~s} 3 \mathrm{p}^{5}{ }^{3} \mathrm{P}_{2}^{0}$ & 352.672 & 6.05 & 130.0 & 15.3 & 110.0 & 1.7 & 104.7 & 2.7 \\
\hline FexI & $356.519^{\mathrm{N}}$ & $3 \mathrm{~s}^{2} 3 \mathrm{p}^{4}{ }^{3} \mathrm{P}_{1}-3 \mathrm{~s} 3 \mathrm{p}^{5}{ }^{3} \mathrm{P}_{1}^{0}$ & 356.530 & 6.05 & 15.0 & 4.9 & 15.1 & $4.2(-4)$ & 14.9 & $4.2(-4)$ \\
\hline FexI & $358.621^{\mathrm{N}}$ & $3 \mathrm{~s}^{2} 3 \mathrm{p}^{4}{ }^{3} \mathrm{P}_{0}-3 \mathrm{~s} 3 \mathrm{p}^{5}{ }^{3} \mathrm{P}_{1}^{0}$ & 358.667 & 6.05 & 72.6 & 9.4 & 19.2 & $\mathrm{~b}$ & 19.0 & $\mathrm{~b}$ \\
\hline Fe XI & $369.153^{\mathrm{N}}$ & $3 \mathrm{~s}^{2} 3 \mathrm{p}^{4}{ }^{3} \mathrm{P}_{1}-3 \mathrm{~s} 3 \mathrm{p}^{5}{ }^{3} \mathrm{P}_{2}^{0}$ & 369.163 & 6.05 & 37.9 & 5.2 & 33.1 & $8.5(-1)$ & 31.5 & 1.5 \\
\hline FexI & $406.811^{\mathrm{N}}$ & $3 \mathrm{~s}^{2} 3 \mathrm{p}^{4}{ }^{1} \mathrm{D}_{2}-3 \mathrm{~s} 3 \mathrm{p}^{5}{ }^{3} \mathrm{P}_{2}^{0}$ & $406.791^{\mathrm{B}}$ & 6.05 & 3.3 & 1.8 & 3.0 & $2.8(-2)$ & 2.8 & $7.7(-2)$ \\
\hline
\end{tabular}

b: Blended.

B New identification by Brickhouse et al. (1995).

K Wavelength from Kelly (1987).

$\mathrm{N}$ Wavelength from NIST standard reference database.

$\mathrm{T}$ Theoretical wavelength.

On the other hand, FexII $(335.060 \AA)$ is too strong compared with observations and, unlike the cases discussed above, the discrepancy increases when increasing the density. Note that from the $335.060 / 364.467 \AA$ ratio Keenan et al. (1996) derive $\log \left(N_{\mathrm{e}}\right)=9.0 \pm 0.4$, a value considerably lower than obtained with other line ratios.

Looking at the branching ratio with $382.866 \AA$, Young et al. (1998) suggested a possible blend affecting FexiI (338.263 $\mathrm{A}$ ), which is supported by our results indicating a theoretical intensity $20-30 \%$ lower than observed. The Fe XII (338.263 $\AA)$ theoretical intensity increases rapidly with electron density, making it difficult to evaluate the intensity of the blended line.
Fe XII $(382.866 \AA)$ is itself marginally higher than observed, and the comparison gets worse by increasing $N_{\mathrm{e}}$.

Excellent agreement is found by Young et al. (1998) and Keenan et al. (1996) for the density insensitive ratios $346.852 / 364.467 \AA$ and $352.106 / 364.467 \AA$, but we find their theoretical intensity higher than observed for $\log \left(N_{\mathrm{e}}\right)=9.5$ and to get agreement with observations we need to assume $\log \left(N_{\mathrm{e}}\right)=10.5$.

In summary, the density sensitivity of Fe XII makes it a very important ion for diagnostic purposes. However, comparison of absolute intensity of lines with the observations leads to contradictory results, which indicate that a substantial improvement to the atomic modelling is necessary. 
Table 10. Comparison of the observed intensities with those derived from the DEM for the FexII ions. Wavelengths are in $\AA$. Intensities in erg $\mathrm{cm}^{-2} \mathrm{~s}^{-1} \mathrm{sr}^{-1}$. See text and Table 3 for description.

\begin{tabular}{|c|c|c|c|c|c|c|c|c|c|c|}
\hline Ion & $\lambda^{\text {ad. }}$ & Transition & $\lambda^{\text {obs. }}$ & $\log \left(T_{\mathrm{p}}\right)$ & $I^{\mathrm{obs}}$ & $e^{\text {obs }}$ & $\begin{array}{c}I^{\text {th }} \\
\log (N\end{array}$ & $\begin{array}{l}\left(\sigma_{0} \chi_{i}\right)^{2} \\
=9.5\end{array}$ & $\begin{array}{c}I^{\text {th }} \\
\log \left(P_{\mathrm{e}}\right)\end{array}$ & $\begin{array}{l}\left(\sigma_{0} \chi_{i}\right)^{2} \\
=15.8\end{array}$ \\
\hline Fe XII & $186.880^{\mathrm{N}}$ & $3 \mathrm{p}^{3}{ }^{2} \mathrm{D}_{5 / 2}^{0}-3 \mathrm{p}^{2} 3 \mathrm{~d}^{2} \mathrm{~F}_{7 / 2}$ & & 6.15 & & & 555.1 & & 607.5 & \\
\hline Fe XII & $186.9^{\mathrm{T}}$ & $3 \mathrm{p}^{3}{ }^{2} \mathrm{D}_{3 / 2}^{0}-3 \mathrm{p}^{2} 3 \mathrm{~d}^{2} \mathrm{~F}_{5 / 2}$ & & 6.15 & & & 319.4 & & 396.2 & \\
\hline \multicolumn{2}{|c|}{ - SUM - } & & 186.883 & & 1330.0 & 330.0 & 874.5 & $\mathrm{~b}$ & 1003.8 & $\mathrm{~b}$ \\
\hline Fe XII & $192.394^{\mathrm{N}}$ & $3 \mathrm{p}^{3}{ }^{4} \mathrm{~S}_{3 / 2}^{0}-3 \mathrm{p}^{2} 3 \mathrm{~d}{ }^{4} \mathrm{P}_{1 / 2}$ & 192.373 & 6.15 & 2370.0 & 340.0 & 575.5 & $2.8(+1)$ & 554.7 & $2.8(+1)$ \\
\hline Fe XII & $193.509^{\mathrm{N}}$ & $3 \mathrm{p}^{3}{ }^{4} \mathrm{~S}_{3 / 2}^{0}-3 \mathrm{p}^{2} 3 \mathrm{~d}{ }^{4} \mathrm{P}_{3 / 2}$ & 193.511 & 6.15 & 1280.0 & 230.0 & 1564.6 & 1.5 & 1488.3 & $8.2(-1)$ \\
\hline Fe XII & $195.119^{\mathrm{N}}$ & $3 \mathrm{p}^{3}{ }^{4} \mathrm{~S}_{3 / 2}^{0}-3 \mathrm{p}^{2} 3 \mathrm{~d}{ }^{4} \mathrm{P}_{5 / 2}$ & 195.115 & 6.15 & 1220.0 & 210.0 & 2575.8 & $4.2(+1)$ & 2447.4 & $3.4(+1)$ \\
\hline Fe XII & $195.640^{\mathrm{N}}$ & $3 \mathrm{p}^{3}{ }^{2} \mathrm{D}_{5 / 2}^{0}-3 \mathrm{p}^{2} 3 \mathrm{~d}^{2} \mathrm{D}_{5 / 2}$ & $196.618^{\mathrm{a}}$ & 6.15 & 279.0 & 139.0 & 235.1 & $1.0(-1)$ & 260.5 & $1.8(-2)$ \\
\hline Fe XII & $200.356^{\mathrm{K}}$ & $3 \mathrm{p}^{3}{ }^{2} \mathrm{P}_{3 / 2}^{0}-3 \mathrm{p}^{2} 3 \mathrm{~d}^{2} \mathrm{~S}_{1 / 2}$ & 200.408 & 6.15 & 365.0 & 96.0 & 11.9 & $1.3(+1)$ & 17.1 & $1.3(+1)$ \\
\hline Fe XII & $201.121^{\mathrm{N}}$ & $3 \mathrm{p}^{3}{ }^{2} \mathrm{P}_{3 / 2}^{0}-3 \mathrm{p}^{2} 3 \mathrm{~d}^{2} \mathrm{P}_{3 / 2}$ & 201.121 & 6.15 & 394.0 & 137.0 & 25.4 & $\mathrm{~b}$ & 33.6 & $\mathrm{~b}$ \\
\hline Fe XII & $219.438^{\mathrm{K}}$ & $3 \mathrm{p}^{3}{ }^{2} \mathrm{D}_{5 / 2}^{0}-3 \mathrm{p}^{2} 3 \mathrm{~d}{ }^{2} \mathrm{P}_{3 / 2}$ & 219.428 & 6.15 & 136.0 & 60.0 & 172.9 & $3.8(-1)$ & 192.1 & $8.7(-1)$ \\
\hline Fe XII & $283.64^{\mathrm{K}}$ & $3 \mathrm{~s}^{2} 3 \mathrm{p}^{3}{ }^{2} \mathrm{D}_{3 / 2}^{0}-3 \mathrm{~s} 3 \mathrm{p}^{4}{ }^{2} \mathrm{P}_{1 / 2}$ & $283.700^{\mathrm{a}}$ & 6.15 & 18.2 & 9.2 & 22.4 & $2.1(-1)$ & 27.4 & 1.0 \\
\hline Fe XII & $291.010^{\mathrm{K}}$ & $3 \mathrm{~s}^{2} 3 \mathrm{p}^{3}{ }^{2} \mathrm{D}_{5 / 2}^{0}-3 \mathrm{~s} 3 \mathrm{p}^{4}{ }^{2} \mathrm{P}_{3 / 2}$ & 291.007 & 6.15 & 109.0 & 19.4 & 67.9 & 4.5 & 73.4 & 3.4 \\
\hline FexiI & $335.060^{\mathrm{N}}$ & $3 \mathrm{~s}^{2} 3 \mathrm{p}^{3}{ }^{2} \mathrm{D}_{3 / 2}^{0}-3 \mathrm{~s} 3 \mathrm{p}^{4}{ }^{2} \mathrm{D}_{3 / 2}$ & 335.043 & 6.15 & 13.0 & 6.2 & 34.3 & $1.2(+1)$ & 43.2 & $2.4(+1)$ \\
\hline Fe XII & $338.263^{\mathrm{N}}$ & $3 \mathrm{~s}^{2} 3 \mathrm{p}^{3}{ }^{2} \mathrm{D}_{5 / 2}^{0}-3 \mathrm{~s} 3 \mathrm{p}^{4}{ }^{2} \mathrm{D}_{5 / 2}$ & 338.273 & 6.10 & 76.6 & 10.3 & 54.2 & 4.7 & 60.0 & 2.6 \\
\hline Fe XII & $346.852^{\mathrm{N}}$ & $3 s^{2} 3 p^{3}{ }^{4} S_{3 / 2}^{0}-3 s 3 p^{4}{ }^{4} P_{1 / 2}$ & 346.857 & 6.15 & 66.9 & 8.6 & 106.3 & $2.1(+1)$ & 101.0 & $1.6(+1)$ \\
\hline FexiI & $352.106^{\mathrm{N}}$ & $3 s^{2} 3 p^{3}{ }^{4} S_{3 / 2}^{0}-3 s 3 p^{4}{ }^{4} P_{3 / 2}$ & 352.106 & 6.15 & 144.0 & 17.0 & 205.3 & $1.3(+1)$ & 195.2 & 9.1 \\
\hline Fe XII & $364.467^{\mathrm{N}}$ & $3 \mathrm{~s}^{2} 3 \mathrm{p}^{3}{ }^{4} \mathrm{~S}_{3 / 2}^{0}-3 \mathrm{~s} 3 \mathrm{p}^{4}{ }^{4} \mathrm{P}_{5 / 2}$ & 364.468 & 6.15 & 233.0 & 26.0 & 305.4 & 7.7 & 291.1 & 5.0 \\
\hline Fe XII & $382.866^{\mathrm{N}}$ & $3 \mathrm{~s}^{2} 3 \mathrm{p}^{3}{ }^{2} \mathrm{P}_{3 / 2}^{0}-3 \mathrm{~s} 3 \mathrm{p}^{4}{ }^{2} \mathrm{D}_{5 / 2}$ & 382.854 & 6.15 & 7.1 & 2.1 & 9.3 & 1.1 & 10.3 & 2.3 \\
\hline
\end{tabular}

b: Blended.

a New identification by Keenan et al. (1996).

K Wavelength from Kelly (1987).

$\mathrm{N}$ Wavelength from NIST standard reference database.

$\mathrm{T}$ Theoretical wavelength.

\subsubsection{FeXIII}

Assuming $\log \left(N_{\mathrm{e}}\right)=9.5$ or $\log \left(P_{\mathrm{e}}\right)=15.8$, Fe XIII lines have theoretical intensities systematically higher than observed except those at 191.255, 204.942, 311.552, and $318.21 \AA$. Such discrepancies reduce for some lines at increasing plasma density, but, as we shall see below, in a contradictory manner so that one cannot infer, from Fe XıII lines, a reliable electron density at the temperature of formation of this ion.

Fe XIII (191.255 $\AA$ ) is reported as blended with S XI, but we confirm the Young et al. (1998) conclusion that the Fe XIII contribution is negligible.

Fe XIII $(312.880 \AA)$ was identified by Brickhouse et al. (1995) and excellent agreement was found by
Young et al. (1998) for the density insensitive ratio $312.880 / 359.638 \AA$. We find this line about $50 \%$ higher than observed at $\log \left(N_{\mathrm{e}}\right)=9.5$ or $\log \left(P_{\mathrm{e}}\right)=15.8$, and we get agreement with observations by increasing the electron density up to $\log \left(N_{\mathrm{e}}\right)=10.5 \mathrm{~cm}^{-3}$. Fe XIII $(359.638 \AA)$, on the other hand, is in agreement with observations only if we assume $\log \left(N_{\mathrm{e}}\right)=11.0$. This despite the fact that the ratio $359.638 / 348.183 \AA$ gives $\log \left(N_{\mathrm{e}}\right)=9.6_{-0.2}^{+0.2}$ (Young et al. 1998). At $\log \left(N_{\mathrm{e}}\right)=9.5$ we find, in fact, that Fe XIII (359.638 $\AA$ ) and Fe XIII $(348.183 \AA)$ are $30 \%$ and $60 \%$ higher than observed, respectively. Assuming $\log \left(P_{\mathrm{e}}\right)=15.8$, these lines are $30 \%$ and $38 \%$ higher than observed. Therefore, the ratio combines to give a density close to that obtained using other lines, but the absolute 
Table 11. Comparison of the observed intensities with those derived from the DEM for the Fe XIII ions. Wavelengths are in $\AA$. Intensities in erg $\mathrm{cm}^{-2} \mathrm{~s}^{-1} \mathrm{sr}^{-1}$. See text and Table 3 for description.

\begin{tabular}{|c|c|c|c|c|c|c|c|c|c|c|}
\hline Ion & $\lambda^{\text {ad. }}$ & Transition & $\lambda^{\text {obs. }}$ & $\log \left(T_{\mathrm{p}}\right)$ & $I^{\mathrm{obs}}$ & $e^{\text {obs }}$ & $\begin{array}{c}I^{\text {th }} \\
\log (N\end{array}$ & $\begin{array}{l}\left(\sigma_{0} \chi_{i}\right)^{2} \\
=9.5\end{array}$ & $\begin{array}{c}I^{\mathrm{th}} \\
\log \left(P_{\mathrm{e}}\right)\end{array}$ & $\begin{array}{l}\left(\sigma_{0} \chi_{i}\right)^{2} \\
=15.8\end{array}$ \\
\hline Fe XIII & $191.255^{\mathrm{B}}$ & $3 \mathrm{p}^{2}{ }^{1} \mathrm{D}_{2}-3 \mathrm{p} 3 \mathrm{~d}^{1} \mathrm{P}_{1}^{0}$ & 191.234 & 6.20 & 286.0 & 135.0 & 0.0 & $\mathrm{~b}$ & 0.0 & $\mathrm{~b}$ \\
\hline Fexini & $201.121^{\mathrm{B}}$ & $3 \mathrm{p}^{2}{ }^{3} \mathrm{P}_{1}-3 \mathrm{p} 3 \mathrm{~d}^{3} \mathrm{D}_{1}^{0}$ & 201.121 & 6.20 & 394.0 & 137.0 & 573.8 & $\mathrm{~b}$ & 580.8 & $\mathrm{~b}$ \\
\hline Fe XIII & $202.044^{\mathrm{K}}$ & $3 \mathrm{p}^{2}{ }^{3} \mathrm{P}_{0}-3 \mathrm{p} 3 \mathrm{~d}^{3} \mathrm{P}_{1}^{0}$ & 202.043 & 6.20 & 646.0 & 109.0 & 1751.7 & $1.0(+2)$ & 1528.6 & $6.6(+1)$ \\
\hline Fe XiıI & $203.821^{\mathrm{K}}$ & $3 \mathrm{p}^{2}{ }^{3} \mathrm{P}_{2}-3 \mathrm{p} 3 \mathrm{~d}^{3} \mathrm{D}_{2}^{0}$ & & 6.20 & & & 611.8 & & 646.3 & \\
\hline Fe XiıI & $203.826^{\mathrm{N}}$ & $3 \mathrm{p}^{2}{ }^{3} \mathrm{P}_{2}-3 \mathrm{p} 3 \mathrm{~d}^{3} \mathrm{D}_{3}^{0}$ & & 6.20 & & & 1875.8 & & 1997.5 & \\
\hline \multicolumn{2}{|c|}{ - SUM - } & & 203.824 & & 1060.0 & 158.0 & 2487.6 & $8.2(+1)$ & 2643.8 & $1.0(+2)$ \\
\hline Fe XIII & $204.263^{\mathrm{K}}$ & $3 \mathrm{p}^{2}{ }^{3} \mathrm{P}_{1}-3 \mathrm{p} 3 \mathrm{~d}{ }^{1} \mathrm{D}_{2}^{0}$ & 204.251 & 6.20 & 141.0 & 41.0 & 270.4 & $1.0(+1)$ & 287.9 & $1.3(+1)$ \\
\hline Fe XIII & $204.942^{\mathrm{K}}$ & $3 \mathrm{p}^{2}{ }^{3} \mathrm{P}_{2}-3 \mathrm{p} 3 \mathrm{~d}{ }^{3} \mathrm{D}_{1}^{0}$ & 204.952 & 6.20 & 348.0 & 93.0 & 168.0 & 3.8 & 170.0 & 3.7 \\
\hline Fe XIII & $209.617^{\mathrm{K}}$ & $3 p^{2}{ }^{3} \mathrm{P}_{1}-3 \mathrm{p} 3 \mathrm{~d}^{3} \mathrm{P}_{2}^{0}$ & 209.615 & 6.20 & 93.7 & 51.0 & 329.9 & $2.1(+1)$ & 350.4 & $2.5(+1)$ \\
\hline Fe XIII & $213.770^{\mathrm{K}}$ & $3 \mathrm{p}^{2}{ }^{3} \mathrm{P}_{2}-3 \mathrm{p} 3 \mathrm{~d}{ }^{3} \mathrm{P}_{2}^{0}$ & 213.774 & 6.20 & 58.3 & 28.0 & 325.3 & $9.1(+1)$ & 345.5 & $1.0(+2)$ \\
\hline Fe XIII & $221.822^{\mathrm{K}}$ & $3 \mathrm{p}^{2}{ }^{1} \mathrm{D}_{2}-3 \mathrm{p} 3 \mathrm{~d}{ }^{1} \mathrm{D}_{2}^{0}$ & 221.830 & 6.20 & 152.0 & 47.0 & 490.2 & $5.2(+1)$ & 522.1 & $6.2(+1)$ \\
\hline Fe XIII & $240.713^{\mathrm{K}}$ & $3 \mathrm{~s}^{2} 3 \mathrm{p}^{2}{ }^{3} \mathrm{P}_{0}-3 \mathrm{~s} 3 \mathrm{p}^{3}{ }^{3} \mathrm{~S}_{1}^{0}$ & 240.723 & 6.20 & 148.0 & 61.0 & 200.5 & $7.4(-1)$ & 200.5 & $7.4(-1)$ \\
\hline Fe XiıI & $246.208^{\mathrm{K}}$ & $3 \mathrm{~s}^{2} 3 \mathrm{p}^{2}{ }^{3} \mathrm{P}_{1}-3 \mathrm{~s} 3 \mathrm{p}^{3}{ }^{3} \mathrm{~S}_{1}^{0}$ & 246.195 & 6.20 & 160.0 & 48.0 & 488.6 & $4.7(+1)$ & 488.7 & $4.7(+1)$ \\
\hline Fe XIII & $251.953^{\mathrm{K}}$ & $3 \mathrm{~s}^{2} 3 \mathrm{p}^{2}{ }^{3} \mathrm{P}_{2}-3 \mathrm{~s} 3 \mathrm{p}^{3}{ }^{3} \mathrm{~S}_{1}^{0}$ & 251.943 & 6.20 & 364.0 & 55.0 & 916.9 & $1.0(+2)$ & 917.3 & $1.0(+2)$ \\
\hline Fe XIII & $256.42^{\mathrm{K}}$ & $3 \mathrm{~s}^{2} 3 \mathrm{p}^{2}{ }^{1} \mathrm{D} 2-3 \mathrm{~s} 3 \mathrm{p}^{3}{ }^{1} \mathrm{P}_{1}^{0}$ & 256.430 & 6.20 & 133.0 & 51.0 & 181.4 & $9.0(-1)$ & 198.4 & 1.6 \\
\hline Fe XIII & $303.320^{\mathrm{J}}$ & $3 \mathrm{~s}^{2} 3 \mathrm{p}^{2}{ }^{3} \mathrm{P}_{0}-3 \mathrm{~s} 3 \mathrm{p}^{3}{ }^{3} \mathrm{P}_{1}^{0}$ & & 6.20 & & & 93.5 & & 88.6 & \\
\hline Fe XiıI & $311.552^{\mathrm{O}}$ & $3 \mathrm{~s}^{2} 3 \mathrm{p}^{2}{ }^{3} \mathrm{P}_{1}-3 \mathrm{~s} 3 \mathrm{p}^{3}{ }^{3} \mathrm{P}_{2}^{0}$ & 311.555 & 6.20 & 40.8 & 10.9 & 35.6 & $2.3(-1)$ & 37.6 & $8.6(-2)$ \\
\hline Fe XiıI & $312.095^{\mathrm{J}}$ & $3 \mathrm{~s}^{2} 3 \mathrm{p}^{2}{ }^{3} \mathrm{P}_{1}-3 \mathrm{~s} 3 \mathrm{p}^{3}{ }^{3} \mathrm{P}_{1}^{0}$ & 312.174 & 6.20 & 85.9 & 12.3 & 135.3 & $1.6(+1)$ & 128.1 & $1.2(+1)$ \\
\hline Fe XIII & $312.880^{\mathrm{J}}$ & $3 \mathrm{~s}^{2} 3 \mathrm{p}^{2}{ }^{3} \mathrm{P}_{2}-3 \mathrm{~s} 3 \mathrm{p}^{3}{ }^{3} \mathrm{P}_{2}^{0}$ & $312.868^{\mathrm{a}}$ & 6.20 & 50.4 & 16.5 & 72.5 & 1.8 & 74.3 & 2.1 \\
\hline Fe XIII & $318.21^{\mathrm{K}}$ & $3 \mathrm{~s}^{2} 3 \mathrm{p}^{2}{ }^{1} \mathrm{D}_{2}-3 \mathrm{~s} 3 \mathrm{p}^{3}{ }^{1} \mathrm{D}_{2}^{0}$ & 318.120 & 6.20 & 96.0 & 13.9 & 60.1 & 6.7 & 74.2 & 2.5 \\
\hline Fe XIII & $320.800^{\mathrm{O}}$ & $3 \mathrm{~s}^{2} 3 \mathrm{p}^{2}{ }^{3} \mathrm{P}_{2}-3 \mathrm{~s} 3 \mathrm{p}^{3}{ }^{3} \mathrm{P}_{2}^{0}$ & 320.800 & 6.20 & 172.0 & 22.0 & 257.0 & $1.5(+1)$ & 272.0 & $2.1(+1)$ \\
\hline Fe XIII & $321.455^{\mathrm{N}}$ & $3 \mathrm{~s}^{2} 3 \mathrm{p}^{2}{ }^{3} \mathrm{P}_{2}-3 \mathrm{~s} 3 \mathrm{p}^{3}{ }^{3} \mathrm{P}_{1}^{0}$ & 321.463 & 6.20 & 32.9 & 7.4 & 68.0 & $2.3(+1)$ & 64.4 & $1.8(+1)$ \\
\hline Fe XIII & $348.183^{\mathrm{N}}$ & $3 \mathrm{~s}^{2} 3 \mathrm{p}^{2}{ }^{3} \mathrm{P}_{0}-3 \mathrm{~s} 3 \mathrm{p}^{3}{ }^{3} \mathrm{D}_{1}^{0}$ & 348.182 & 6.20 & 128.0 & 15.3 & 201.3 & $2.3(+1)$ & 177.0 & $1.0(+1)$ \\
\hline Fe XiıI & $359.638^{\mathrm{N}}$ & $3 \mathrm{~s}^{2} 3 \mathrm{p}^{2}{ }^{3} \mathrm{P}_{1}-3 \mathrm{~s} 3 \mathrm{p}^{3}{ }^{3} \mathrm{D}_{2}^{0}$ & 359.644 & 6.20 & 147.0 & 16.9 & 189.1 & 6.2 & 193.6 & 7.6 \\
\hline FexiıI & $359.838^{\mathrm{N}}$ & $3 \mathrm{~s}^{2} 3 \mathrm{p}^{2}{ }^{3} \mathrm{P}_{1}-3 \mathrm{~s} 3 \mathrm{p}^{3}{ }^{3} \mathrm{D}_{1}^{0}$ & 359.830 & 6.20 & 22.4 & 4.4 & 53.1 & $4.9(+1)$ & 46.7 & $3.0(+1)$ \\
\hline Fe XiıI & $368.122^{\mathrm{N}}$ & $3 \mathrm{~s}^{2} 3 \mathrm{p}^{2}{ }^{3} \mathrm{P}_{2}-3 \mathrm{~s} 3 \mathrm{p}^{3}{ }^{3} \mathrm{D}_{3}^{0}$ & 368.163 & 6.20 & 128.0 & 24.0 & 185.4 & 5.7 & 198.0 & 8.5 \\
\hline Fe XiıI & $412.981^{\mathrm{N}}$ & $3 \mathrm{~s}^{2} 3 \mathrm{p}^{2}{ }^{1} \mathrm{D}_{2}-3 \mathrm{~s} 3 \mathrm{p}^{3}{ }^{3} \mathrm{D}_{3}^{0}$ & 412.997 & 6.20 & 6.9 & 1.8 & 10.8 & 4.7 & 11.6 & 6.8 \\
\hline
\end{tabular}

b: Blended.

a New identification by Brickhouse et al. (1995).

B Wavelength from Behring et al. (1976).

J Wavelength from Jupén et al. (1993).

K Wavelength from Kelly (1987).

$\mathrm{N}$ Wavelength from NIST standard reference database.

O Wavelength from ORNL (1995).

intensities are higher than observed at that density. The ratio itself is sensitive to the model assumed in computing the $G$-functions.

Young et al. (1998) suggested that Fe XIII (204.942 $\AA$ ) could be blended with a first order line around $409.90 \AA$.
They also found a discrepancy in the $311.552 / 320.800 \AA$ ratio due probably to a blend with CrXII affecting Fe XIII (311.552 $\AA$ ). Examining the $3 \mathrm{~s}^{2} 3 \mathrm{p}^{2}{ }^{3} \mathrm{P}-3 \mathrm{~s} 3 \mathrm{p}^{3}{ }^{3} \mathrm{~S}$ triplet we note that FexIII $(240.713 \AA)$ is reproduced within the error bars and that FexIII $(246.208 \AA)$ and 
Fe XIII (251.953 $\AA$ ) are a factor 3 and 2.5 higher than observed, respectively. The $240.713 / 251.953 \AA$ branching ratio was found inconsistent with observations by Malinovsky \& Heroux (1973) and Flower \& Nussbaumer (1974), and the discrepancy is evident in the SERTS-89 spectrum as noted by Young et al. (1998). The agreement of Fe XIII (240.713 $\AA$ ), therefore, is to be considered fortuitous.

The observed 412.981/368.122 $\AA$ value reproduces its branching ratio within the observational uncertainties, but we find the theoretical intensities of both lines around $50 \%$ higher than observed. From the difference in the QFR we infer that there is a blend affecting FexIII (368.122 $\AA$ ) and providing around $12 \%$ of the observed intensity. Similarly, from the QFR of Fe XIII (359.638 $\AA$ ) and Fe XII (318.21 $\AA$ ), which have the same upper level, we infer that FexIII $(318.21 \AA)$ is blended with a line contributing approximately $66 \%$ of the intensity.

Fe XIII (201.121 $\AA$ ) is blended with Fe XII (201.121 $\AA$ ), but the theoretical intensity of the FexIII alone is $45 \%$ higher than the total observed blend intensity. Therefore, it is not possible to quantify the relative contributions to the blend. However, the results indicate that the FeXII contribution must be very weak.

Summing up, Fe XIII lines show systematic discrepancies that are likely to be due to lack of accuracy in the atomic modelling. Comparing with other ions, this ionisation stage looks overestimated by the Arnaud \& Raymond (1992) data or by the density scaling procedure applied. Further work is required to solve this issue.

\subsubsection{FeXIV}

A striking behaviour of FexIV lines in the SERTS-89 range is that $3 \mathrm{~s}^{2} 3 \mathrm{p}^{2} \mathrm{P}-3 \mathrm{~s}^{2} 3 \mathrm{~d}^{2} \mathrm{D}$ and $3 \mathrm{~s}^{2} 3 \mathrm{p}^{2} \mathrm{P}-3 \mathrm{~s} 3 \mathrm{p}^{2} \mathrm{P}$ transitions (except Fe XIV (257.394 $\AA$ )) are $30-40 \%$ higher than observed, while the others are 50-60\% lower than observed, with a trend to lower QFR at the long end of the wavelength bandpass due to the calibration problems outlined by Young et al. (1998). This situation is likely to be due to inaccuracies in the collision strengths for this ion. The $A$ value of FexIV (257.394 $\AA$ ) is also likely to be in error, since the theoretical intensity stands out at almost a factor 3 greater than observed.

Collision strengths being unreliable, it is not possible to check whether the ionisation/recombination data give a satisfactory comparison with observations.

By looking at line ratios, Young et al. (1998) came to the equivalent conclusion that a distinction exists between those lines found above $274 \AA$ and those found below $274 \AA$. They also found a discrepancy in the $257.394 / 270.521 \AA$ ratio, which was, however, interpreted as a blend affecting FeXIV $(270.521 \AA)$, while the estimate of the absolute intensity allows us to realise that the problem is with Fe XIV (257.394 $\AA)$ instead. We agree with Young et al. (1998) that any Fe XIV contribution to the feature observed at $429.540 \AA$ must be negligible.

\subsubsection{FeXV}

Unlike Fexiı,, Fexv lines are systematically underestimated, the QFR ranging from 0.1 to 0.85 . The line closest to its observed value is $\operatorname{Fexv}(284.147 \AA)$, with $\mathrm{QFR}=0.85$ and $\chi_{i}=1.8$, and the highest discrep-

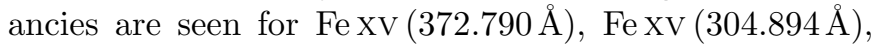
which is known to be significantly affected by blends, and Fe XV $(417.258 \AA)$, whose ratio to $\operatorname{FeXV}(284.147 \AA)$ has long been acknowledged as discrepant with theory (see Young et al. 1998 and references therein).

Fe XV (243.783 $\AA$ ) was identified as blend with Ar XIV by Dere (1978), but Thomas \& Neupert (1994) found that the wavelength and intensity match better with Fexv alone. In the present analysis $\operatorname{FexV}(243.783 \AA)$ is predicted to have an intensity approximately $70 \%$ of that observed. This suggests, in comparison with the other Fe XV lines, that the Ar XIV contribution must be less than $10 \%$ of the observed intensity.

Fe XV (292.36 $\AA$ ) was identified by Thomas \& Neupert (1994) as Six, but subsequently attributed to FexV by Young et al. (1998). We find such an identification to be compatible with the other Fe XV lines, although the predicted intensity is $40 \%$ of that observed.

Fe XV (304.894 $\AA$ ) is blended with Fe XVII and Mn XIV, and FexV (312.55 $\AA$ ) with Co XVII (see Young et al. 1998).

Fe XV (321.78 $\AA$ ) is not reported as blended, but we find its theoretical intensity only 0.3 of that observed, which suggests that blends may affect this line as well.

The feature at $393.969 \AA$ was reported as unidentified by Thomas \& Neupert (1994) and subsequently identified as due to the Fexv $3 \mathrm{~s}^{2}{ }^{1} \mathrm{~S}_{0}-3 \mathrm{~s} 3 \mathrm{p}^{3} \mathrm{P}_{2}$ transition by Brickhouse et al. (1995). We find such an identification to be compatible with the other Fe XV lines, although the predicted intensity is $50 \%$ of that observed.

Therefore, the only Fexv lines for which we may reasonably exclude the presence of blends (apart from the line at $417.258 \AA$ which may be affected by errors in the atomic data) are those at 284.147 and $327.04 \AA$. However, the comparison of such lines with observations suggests that the FeXV ion abundance may be underestimated by $15-25 \%$.

\subsubsection{FeXVI}

All Fe XVI lines are a factor 3.5 lower in intensity than observed. Multiplying all intensities by this factor, we obtain excellent agreement with observations. Note that we have adopted the new fit reported by Young et al. (1998) for Fe XVI (265.014 $\AA$ ).

Around the temperature of formation of FeXVI, the DEM is determined mainly by SXII and SxIV. At higher temperatures, the DEM is constrained by ArXVI and CaXviII (see also Sect.4.5.9). We have therefore 
Table 12. Comparison of the observed intensities with those derived from the DEM for the Fe XIV-XV ions. Wavelengths are in $\AA$. Intensities in erg $\mathrm{cm}^{-2} \mathrm{~s}^{-1} \mathrm{sr}^{-1}$. See text and Table 3 for description.

\begin{tabular}{|c|c|c|c|c|c|c|c|c|c|c|}
\hline Ion & $\lambda^{\text {ad. }}$ & Transition & $\lambda^{\text {obs. }}$ & $\log \left(T_{\mathrm{p}}\right)$ & $I^{\text {obs }}$ & $e^{\text {obs }}$ & $\begin{array}{c}I^{\mathrm{th}} \\
\log \left(N_{\mathrm{e}}\right.\end{array}$ & $\begin{array}{l}\left(\sigma_{0} \chi_{i}\right)^{2} \\
=9.5\end{array}$ & $\begin{array}{c}I^{\text {th }} \\
\log \left(P_{\mathrm{e}}\right)\end{array}$ & $\begin{array}{l}\left(\sigma_{0} \chi_{i}\right)^{2} \\
=15.8\end{array}$ \\
\hline FexIV & $211.315^{\mathrm{N}}$ & $3 \mathrm{~s}^{2} 3 \mathrm{p}^{2} \mathrm{P}_{1 / 2}^{0}-3 \mathrm{~s}^{2} 3 \mathrm{~d}^{2} \mathrm{D}_{3 / 2}$ & 211.315 & 6.25 & 1020.0 & 136.0 & 1625.3 & $2.0(+1)$ & 1587.9 & $1.7(+1)$ \\
\hline Fexiv & $219.123^{\mathrm{N}}$ & $3 \mathrm{~s}^{2} 3 \mathrm{p}^{2} \mathrm{P}_{3 / 2}^{0}-3 \mathrm{~s}^{2} 3 \mathrm{~d}^{2} \mathrm{D}_{5 / 2}$ & 219.117 & 6.25 & 412.0 & 63.0 & 585.9 & 7.6 & 673.4 & $1.7(+1)$ \\
\hline Fe XIV & $220.083^{\mathrm{N}}$ & $3 \mathrm{~s}^{2} 3 \mathrm{p}^{2} \mathrm{P}_{3 / 2}^{0}-3 \mathrm{~s}^{2} 3 \mathrm{~d}^{2} \mathrm{D}_{3 / 2}$ & 220.072 & 6.25 & 253.0 & 49.0 & 342.9 & 3.4 & 335.0 & 2.8 \\
\hline Fe XIV & $252.197^{\mathrm{N}}$ & $3 \mathrm{~s}^{2} 3 \mathrm{p}^{2} \mathrm{P}_{1 / 2}^{0}-3 \mathrm{~s} 3 \mathrm{p}^{2}{ }^{2} \mathrm{P}_{3 / 2}$ & 252.201 & 6.25 & 190.0 & 59.0 & 236.8 & $6.3(-1)$ & 250.0 & 1.0 \\
\hline FexIV & $257.394^{\mathrm{N}}$ & $3 \mathrm{~s}^{2} 3 \mathrm{p}^{2} \mathrm{P}_{1 / 2}^{0}-3 \mathrm{~s} 3 \mathrm{p}^{2}{ }^{2} \mathrm{P}_{1 / 2}$ & 257.395 & 6.25 & 187.0 & 36.0 & 511.5 & $8.1(+1)$ & 507.2 & $7.9(+1)$ \\
\hline FexIV & $264.787^{\mathrm{N}}$ & $3 \mathrm{~s}^{2} 3 \mathrm{p}^{2} \mathrm{P}_{3 / 2}^{0}-3 \mathrm{~s} 3 \mathrm{p}^{2}{ }^{2} \mathrm{P}_{3 / 2}$ & 264.783 & 6.25 & 1040.0 & 124.0 & 979.1 & $2.4(-1)$ & 1033.5 & $2.7(-3)$ \\
\hline Fe XIV & $270.521^{\mathrm{N}}$ & $3 \mathrm{~s}^{2} 3 \mathrm{p}^{2} \mathrm{P}_{3 / 2}^{0}-3 \mathrm{~s} 3 \mathrm{p}^{2}{ }^{2} \mathrm{P}_{1 / 2}$ & 270.522 & 6.25 & 489.0 & 64.0 & 683.3 & 9.2 & 677.6 & 8.7 \\
\hline Fe XIV & $274.203^{\mathrm{O}}$ & $3 \mathrm{~s}^{2} 3 \mathrm{p}^{2} \mathrm{P}_{1 / 2}^{0}-3 \mathrm{~s} 3 \mathrm{p}^{2}{ }^{2} \mathrm{~S}_{1 / 2}$ & 274.209 & 6.25 & 1030.0 & 120.0 & 552.7 & $1.6(+1)$ & 546.1 & $1.6(+1)$ \\
\hline Fe XIV & $289.160^{\mathrm{O}}$ & $3 \mathrm{~s}^{2} 3 \mathrm{p}^{2} \mathrm{P}_{3 / 2}^{0}-3 \mathrm{~s} 3 \mathrm{p}^{2}{ }^{2} \mathrm{~S}_{1 / 2}$ & 289.171 & 6.25 & 74.3 & 23.0 & 49.0 & 1.2 & 48.5 & 1.3 \\
\hline Fe XIV & $334.178^{\mathrm{O}}$ & $3 \mathrm{~s}^{2} 3 \mathrm{p}^{2} \mathrm{P}_{1 / 2}^{0}-3 \mathrm{~s} 3 \mathrm{p}^{2}{ }^{2} \mathrm{D}_{3 / 2}$ & 334.171 & 6.25 & 642.0 & 73.0 & 392.7 & 1.2 & 382.4 & 1.3 \\
\hline Fexiv & $353.838^{\mathrm{O}}$ & $3 \mathrm{~s}^{2} 3 \mathrm{p}^{2} \mathrm{P}_{3 / 2}^{0}-3 \mathrm{~s} 3 \mathrm{p}^{2}{ }^{2} \mathrm{D}_{5 / 2}$ & 353.833 & 6.25 & 291.0 & 33.0 & 119.8 & $2.7(+1)$ & 135.6 & $2.2(+1)$ \\
\hline Fe XIV & $356.59^{\mathrm{O}}$ & $3 \mathrm{~s}^{2} 3 \mathrm{p}^{2} \mathrm{P}_{3 / 2}^{0}-3 \mathrm{~s} 3 \mathrm{p}^{2}{ }^{2} \mathrm{D}_{3 / 2}$ & 356.649 & 6.25 & 18.0 & 5.8 & 14.0 & $4.8(-1)$ & 13.6 & $5.7(-1)$ \\
\hline Fe XIV & $429.540^{\mathrm{T}}$ & $3 \mathrm{~s}^{2} 3 \mathrm{p}^{2} \mathrm{P}_{1 / 2}^{0}-3 \mathrm{~s} 3 \mathrm{p}^{2}{ }^{4} \mathrm{P}_{3 / 2}$ & 429.540 & 6.25 & 3.1 & 1.0 & 0.0 & 9.6 & 0.0 & 9.6 \\
\hline Fexiv & $444.25^{\mathrm{D}}$ & $3 \mathrm{~s}^{2} 3 \mathrm{p}^{2} \mathrm{P}_{1 / 2}^{0}-3 \mathrm{~s} 3 \mathrm{p}^{2}{ }^{4} \mathrm{P}_{1 / 2}$ & 444.241 & 6.25 & 11.9 & 11.9 & 5.2 & 6.2 & 5.1 & 6.4 \\
\hline Fe XIV & $447.36^{\mathrm{D}}$ & $3 \mathrm{~s}^{2} 3 \mathrm{p}{ }^{2} \mathrm{P}_{3 / 2}^{0}-3 \mathrm{~s} 3 \mathrm{p}^{2}{ }^{4} \mathrm{P}_{5 / 2}$ & 447.343 & 6.25 & 34.3 & 4.2 & 8.5 & $3.8(+1)$ & 9.0 & $3.6(+1)$ \\
\hline Fexv & $243.783^{\mathrm{O}}$ & $2 p^{6} 3 \mathrm{~s} 3 \mathrm{p}^{1} \mathrm{P}_{1}^{0}-2 \mathrm{p}^{6} 3 \mathrm{~s} 3 \mathrm{~d}^{1} \mathrm{D}_{2}$ & 243.780 & 6.30 & 545.0 & 92.0 & 363.2 & 3.9 & 367.8 & 3.7 \\
\hline Fexv & $284.147^{\mathrm{O}}$ & $2 \mathrm{p}^{6} 3 \mathrm{~s}^{2}{ }^{1} \mathrm{~S}_{0}-2 \mathrm{p}^{6} 3 \mathrm{~s} 3 \mathrm{p}^{1} \mathrm{P}_{1}^{0}$ & 284.158 & 6.30 & 7560.0 & 850.0 & 6428.7 & 1.8 & 6513.0 & 1.5 \\
\hline Fexv & $292.36^{\mathrm{O}}$ & $2 \mathrm{p}^{6} 3 \mathrm{~s} 3 \mathrm{p}^{3} \mathrm{P}_{1}^{0}-2 \mathrm{p}^{6} 3 \mathrm{p}^{2}{ }^{3} \mathrm{P}_{2}$ & $292.251^{\mathrm{Y}}$ & 6.30 & 43.7 & 13.0 & 18.4 & 3.8 & 19.6 & 3.4 \\
\hline Fexv & $302.45^{\mathrm{O}}$ & $2 p^{6} 3 \mathrm{~s} 3 \mathrm{p}^{3} \mathrm{P}_{0}^{0}-2 \mathrm{p}^{6} 3 \mathrm{p}^{2}{ }^{3} \mathrm{P}_{1}$ & & 6.30 & & & 12.1 & & 13.1 & \\
\hline Fexv & $304.894^{\mathrm{S}}$ & $2 p^{6} 3 \mathrm{~s} 3 \mathrm{p}^{3} \mathrm{P}_{2}^{0}-2 \mathrm{p}^{6} 3 \mathrm{p}^{2}{ }^{3} \mathrm{P}_{2}$ & 304.874 & 6.30 & 206.0 & 29.0 & 50.0 & $\mathrm{~b}$ & 53.4 & $\mathrm{~b}$ \\
\hline Fexv & $307.78^{\mathrm{O}}$ & $2 p^{6} 3 \mathrm{~s} 3 \mathrm{p}^{3} \mathrm{P}_{1}^{0}-2 \mathrm{p}^{6} 3 \mathrm{p}^{2}{ }^{3} \mathrm{P}_{1}$ & & 6.30 & & & 8.4 & & 9.1 & \\
\hline Fexv & $317.61^{\mathrm{O}}$ & $2 p^{6} 3 \mathrm{~s} 3 \mathrm{p}^{3} \mathrm{P}_{1}^{0}-2 \mathrm{p}^{6} 3 \mathrm{p}^{2}{ }^{3} \mathrm{P}_{0}$ & & 6.30 & & & 0.1 & & 0.1 & \\
\hline Fexv & $321.78^{\mathrm{O}}$ & $2 p^{6} 3 \mathrm{~s} 3 \mathrm{p}^{3} \mathrm{P}_{2}^{0}-2 \mathrm{p}^{6} 3 \mathrm{p}^{2}{ }^{3} \mathrm{P}_{1}$ & 321.782 & 6.30 & 35.4 & 7.9 & 11.8 & 8.9 & 12.7 & 8.3 \\
\hline Fexv & $312.57^{\mathrm{N}}$ & $2 \mathrm{p}^{6} 3 \mathrm{~s} 3 \mathrm{p}^{3} \mathrm{P}_{1}^{0}-2 \mathrm{p}^{6} 3 \mathrm{p}^{2}{ }^{1} \mathrm{D}_{2}$ & 312.554 & 6.30 & 66.2 & 14.1 & 38.6 & 3.8 & 39.2 & 3.7 \\
\hline Fexv & $327.04^{\mathrm{N}}$ & $2 \mathrm{p}^{6} 3 \mathrm{~s} 3 \mathrm{p}^{3} \mathrm{P}_{2}^{0}-2 \mathrm{p}^{6} 3 \mathrm{p}^{2}{ }^{1} \mathrm{D}_{2}$ & 327.030 & 6.30 & 87.5 & 12.5 & 65.3 & 3.1 & 66.4 & 2.8 \\
\hline Fexv & $372.79^{\mathrm{N}}$ & $2 \mathrm{p}^{6} 3 \mathrm{~s} 3 \mathrm{~d}^{3} \mathrm{D}_{3}-2 \mathrm{p}^{6} 3 \mathrm{p} 3 \mathrm{~d}^{3} \mathrm{~F}_{4}^{0}$ & 372.758 & 6.30 & 16.2 & 4.2 & 2.1 & $1.1(+1)$ & 2.3 & $1.1(+1)$ \\
\hline Fexv & $393.98^{\mathrm{N}}$ & $2 \mathrm{p}^{6} 3 \mathrm{~s}^{2}{ }^{1} \mathrm{~S}_{0}-2 \mathrm{p}^{6} 3 \mathrm{~s} 3 \mathrm{p}^{3} \mathrm{P}_{2}^{0}$ & $393.969^{\mathrm{B}}$ & 6.30 & 16.1 & 2.8 & 7.9 & 8.6 & 7.8 & 8.7 \\
\hline Fexv & $417.258^{\mathrm{N}}$ & $2 p^{6} 3 s^{2}{ }^{1} S_{0}-2 p^{6} 3 s 3 p{ }^{3} P_{1}^{0}$ & 417.245 & 6.30 & 339.0 & 38.0 & 197.2 & $1.4(+1)$ & 199.7 & $1.3(+1)$ \\
\hline
\end{tabular}

b: Blended.

B New identification by Brickhouse et al. (1995).

D Wavelength from Dere (1978).

$\mathrm{N}$ Wavelength from NIST standard reference database.

O Wavelength from ORNL (1995).

S Wavelength from Shirai et al. (1990).

$\mathrm{T}$ Theoretical wavelength.

Y New fit by Young et al. (1998). 
Table 13. Comparison of the observed intensities with those derived from the DEM for the Fe XVI-XVII ions. Wavelengths are in $\AA$. Intensities in erg $\mathrm{cm}^{-2} \mathrm{~s}^{-1} \mathrm{sr}^{-1}$. See text and Table 3 for description.

\begin{tabular}{|c|c|c|c|c|c|c|c|c|c|c|}
\hline Ion & $\lambda^{\text {ad. }}$ & Transition & $\lambda^{\text {obs. }}$ & $\log \left(T_{\mathrm{p}}\right)$ & $I^{\mathrm{obs}}$ & $e^{\mathrm{obs}}$ & $\begin{array}{c}I^{\mathrm{th}} \\
\log \left(N_{\mathrm{e}}\right.\end{array}$ & $\begin{array}{l}\left(\sigma_{0} \chi_{i}\right)^{2} \\
=9.5\end{array}$ & $\begin{array}{c}I^{\mathrm{th}} \\
\log \left(P_{\mathrm{e}}\right)\end{array}$ & $\begin{array}{l}\left(\sigma_{0} \chi_{i}\right)^{2} \\
=15.8\end{array}$ \\
\hline Fe XVI & $251.069^{\mathrm{E}}$ & $3 \mathrm{p}^{2} \mathrm{P}_{1 / 2}^{0}-3 \mathrm{~d}^{2} \mathrm{D}_{3 / 2}$ & 251.067 & 6.40 & 445.0 & 77.0 & 117.3 & $1.8(+1)$ & 117.2 & $1.8(+1)$ \\
\hline Fe XVI & $262.980^{\mathrm{E}}$ & $3 \mathrm{p}^{2} \mathrm{P}_{3 / 2}^{0}-3 \mathrm{~d}^{2} \mathrm{D}_{5 / 2}$ & 262.978 & 6.40 & 654.0 & 81.0 & 196.5 & $3.2(+1)$ & 196.3 & $3.2(+1)$ \\
\hline Fe XVI & $265.014^{\mathrm{E}}$ & $3 \mathrm{p}^{2} \mathrm{P}_{3 / 2}^{0}-3 \mathrm{~d}{ }^{2} \mathrm{D}_{3 / 2}$ & $265.003^{\mathrm{Y}}$ & 6.40 & 84.0 & 25.0 & 18.9 & 6.8 & 18.9 & 6.8 \\
\hline FexvI & $335.396^{\mathrm{E}}$ & $3 \mathrm{~s}{ }^{2} \mathrm{~S}_{1 / 2}-3 \mathrm{p}{ }^{2} \mathrm{P}_{3 / 2}^{0}$ & 335.401 & 6.40 & 10400.0 & 5000.0 & 2707.0 & 2.4 & 2708.5 & 2.4 \\
\hline Fe XVI & $360.743^{\mathrm{E}}$ & $3 \mathrm{~s}^{2} \mathrm{~S}_{1 / 2}-3 \mathrm{p}{ }^{2} \mathrm{P}_{1 / 2}^{0}$ & 360.754 & 6.40 & 4320.0 & 690.0 & 1303.4 & $1.9(+1)$ & 1304.3 & $1.9(+1)$ \\
\hline Fe XVII & $254.87^{\mathrm{D}}$ & $2 \mathrm{p}^{5} 3 \mathrm{~s}^{3} \mathrm{P}_{1}^{0}-2 \mathrm{p}^{5} 3 \mathrm{p}^{1} \mathrm{~S}_{0}$ & 254.892 & 6.75 & 53.7 & 26.0 & 5.1 & 3.5 & 5.1 & 3.5 \\
\hline Fe XVII & $347.85^{\mathrm{D}}$ & $2 \mathrm{p}^{5} 3 \mathrm{~s}^{3} \mathrm{P}_{1}^{0}-2 \mathrm{p}^{5} 3 \mathrm{p}{ }^{1} \mathrm{D}_{2}$ & 347.814 & 6.75 & 14.4 & 3.8 & 1.4 & $1.2(+1)$ & 1.4 & $1.2(+1)$ \\
\hline Fe XVII & $350.50^{\mathrm{D}}$ & $2 \mathrm{p}^{5} 3 \mathrm{~s}^{3} \mathrm{P}_{2}^{0}-2 \mathrm{p}^{5} 3 \mathrm{p}^{3} \mathrm{D}_{3}$ & 350.477 & 6.70 & 21.1 & 4.9 & 2.1 & $1.5(+1)$ & 2.0 & $1.5(+1)$ \\
\hline Fe XVII & $358.24^{\mathrm{D}}$ & $2 \mathrm{p}^{5} 3 \mathrm{~s}^{1} \mathrm{P}_{1}^{0}-2 \mathrm{p}^{5} 3 \mathrm{p}^{3} \mathrm{P}_{1}$ & 358.247 & 6.70 & 7.0 & 3.1 & 0.6 & 4.3 & 0.6 & 4.3 \\
\hline Fe XVII & $367.287^{\mathrm{T}}$ & $2 \mathrm{p}^{5} 3 \mathrm{~s}^{3} \mathrm{P}_{2}^{0}-2 \mathrm{p}^{5} 3 \mathrm{p}^{3} \mathrm{D}_{2}$ & $367.287^{\mathrm{B}}$ & 6.70 & 7.6 & 4.4 & 0.8 & 2.4 & 0.8 & 2.4 \\
\hline Fe XVII & $389.08^{\mathrm{D}}$ & $2 \mathrm{p}^{5} 3 \mathrm{~s}^{1} \mathrm{P}_{1}^{0}-2 \mathrm{p}^{5} 3 \mathrm{p}{ }^{3} \mathrm{D}_{2}$ & 389.075 & 6.70 & 12.8 & 2.2 & 0.7 & $3.0(+1)$ & 0.7 & $3.0(+1)$ \\
\hline Fe XVII & $409.69^{\mathrm{D}}$ & $2 \mathrm{p}^{5} 3 \mathrm{~s}^{3} \mathrm{P}_{2}^{0}-2 \mathrm{p}^{5} 3 \mathrm{p}^{3} \mathrm{~S}_{1}$ & 409.705 & 6.70 & 6.7 & 2.0 & 1.2 & 7.6 & 1.2 & 7.6 \\
\hline
\end{tabular}

B New identification by Brickhouse et al. (1995).

D Wavelength from Dere (1978).

E Wavelength from Edlén (1985b).

T Wavelength from Thomas \& Neupert (1994).

Y New fit by Young et al. (1998).

attempted further to adjust the abundance of such elements to obtain a better agreement for all ions forming between $\log \left(T_{\mathrm{e}}\right)=6.4$ and 6.8 , but this was not possible for any of the current estimates of the $\mathrm{S} / \mathrm{Ne}, \mathrm{Ar} / \mathrm{Ne}$ and $\mathrm{Ca} / \mathrm{Ne}$ abundance ratios.

This situation leads to the conclusion that the Fe XVI ion abundance is underestimated by a factor 3.5. Such a discrepancy may derive either from inaccuracy in the Arnaud \& Raymond (1992) ionisation/recombination data for the low density limit, or by the density scaling applied following Summers (1974). Further work is required to solve this issue.

\subsubsection{FeXVII}

FeXVII lines are predicted to be a factor 10 lower than observed. Applying such a correction, most likely due to inaccuracies in the ionisation/recombination rates, only Fe XVII (389.08 $\AA$ ) and Fe XVII (409.69 $)$ are not reproduced within the observational uncertainties. FeXVII $(389.08 \AA)$ is reported as blended with ArXVI which should contribute $5 \mathrm{erg} \mathrm{cm}^{-2} \mathrm{~s}^{-1} \mathrm{sr}^{-1}$. Note that in this case the agreement with Young et al. (1998) is extremely close. The Fe XVII (409.69 $\AA$ ) theoretical intensity, on the other hand, is twice that observed, so that blending cannot be the cause of the discrepancy.

\subsection{Test for ionisation equilibrium}

A lack of ionisation equilibrium is expected to a greater or lesser degree in the manifestly dynamic and inhomogeneous solar upper atmosphere and its presence gives an error in DEM analysis. The issue for the present paper is whether non-equilibrium can be shown to be unambiguously present as revealed by significant systematic discrepancies in the emission measure analysis. From a theoretical point of view, non-equilibrium occurs when either the plasma electron temperature or density changes on a time scale, $\tau_{\mathrm{p}}$, shorter than the atomic ionisation stage fractional abundance relaxation, $\tau_{\mathrm{a}}^{(z, \text { elem })}$, or if the time for plasma transport across a temperature or density scale length, $L_{T_{\mathrm{e}}, N_{\mathrm{e}}} / \nu$, is shorter than this value. $\nu$ is the convective or diffusive speed. As well as the normal $\tau_{\mathrm{a}}^{(z, \text { elem })}$ variation iso-nuclearly due to the $z$-scaling of the recombination and ionisation coefficients, $\tau_{\mathrm{a}}^{(z, \text { elem })}$ 


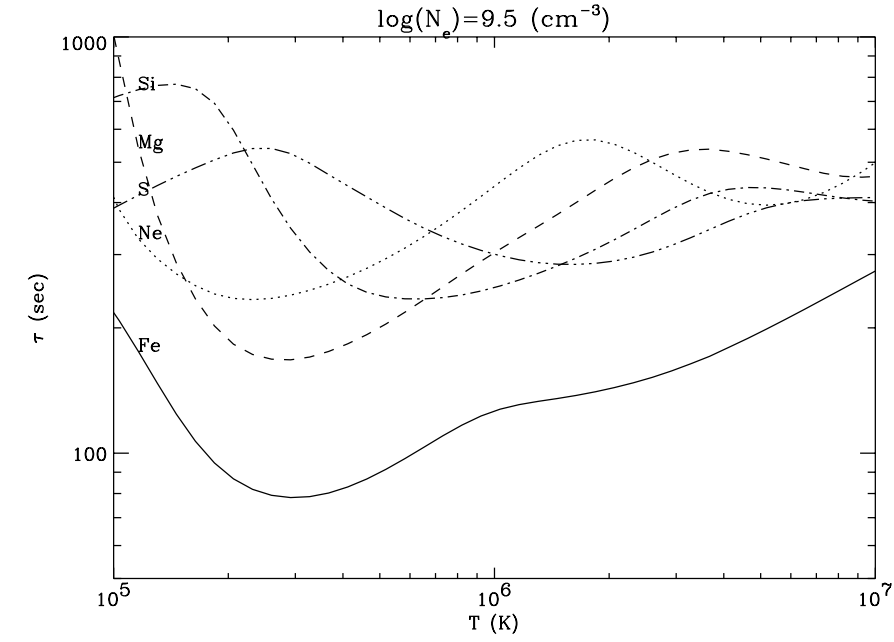

Fig. 4. Relaxation time-scales for the ground states of $\mathrm{Ne}, \mathrm{Mg}$, $\mathrm{Si}, \mathrm{S}$, and $\mathrm{Fe}$ as a function of temperature in the uniform electron density approximation $\left(\log \left(N_{\mathrm{e}}\right)=9.5 \mathrm{~cm}^{-3}\right)$.

curves as a function of $z$ show characteristic jumps between iso-electronic sequences. As already pointed out by Judge et al. (1995), this is particularly the case for the Li-like sequence in recombination (low $\tau_{\mathrm{a}}^{(z, \text { elem })}$ ) and the He-like sequence in ionisation and arises from the larger than average temperature increase required to excite from the $n=1$ shell of atoms. The effect is also present, but to a lesser degree in the Na-like sequence. So spectrum lines of the Li-like and Na-like sequences are the appropriate targets for the detection of a systematic discrepancy which would be most clearly revealed if the DEM could be derived separately from each iso-electronic sequence.

The data set available to us here is insufficiently complete to sustain such an analysis. In particular, we are obliged to include Li-like lines (which are also of high spectroscopic accuracy) in the main analysis to reach sufficient temperature coverage. We note that in the SERTS89 spectrum, there is no possibility of comparing Li-like ions with other iso-electronic sequences, thereby avoiding ambiguities in the elemental abundance. Only sulphur is observed in both its Li-like transitions and in a sufficient number of other ions to make an abundance independent comparison. In fact, we do observe a discrepancy in the Belike sulphur line S XIII (256.685 $\AA$ ) and a satisfactory agreement in the Li-like sulphur lines, but we cannot exclude the possibility that other factors affect S XIII $(256.685 \AA)$ (see Sect.4.4.2). A simpler procedure is merely to seek discrepancies between ions with markedly different atomic relaxation times. For an atom close to ionisation balance, we summarise the individual ion ground state relaxation times in the single function

$\tau_{\mathrm{a}}^{\text {elem }}\left(T_{\mathrm{e}}, N_{\mathrm{e}}\right)=\frac{1}{N_{\mathrm{e}}} \sum_{z} \frac{1}{S^{(z \rightarrow z+1)}+\alpha^{(z+1 \rightarrow z)}}$

for the element (see Brooks 1997). $S^{(z \rightarrow z+1)}$ denotes the effective ionisation coefficient and $\alpha^{(z+1 \rightarrow z)}$ the effective recombination coefficient. Figures 4 and 5 show $\tau_{\mathrm{a}}^{\text {elem }}$ for

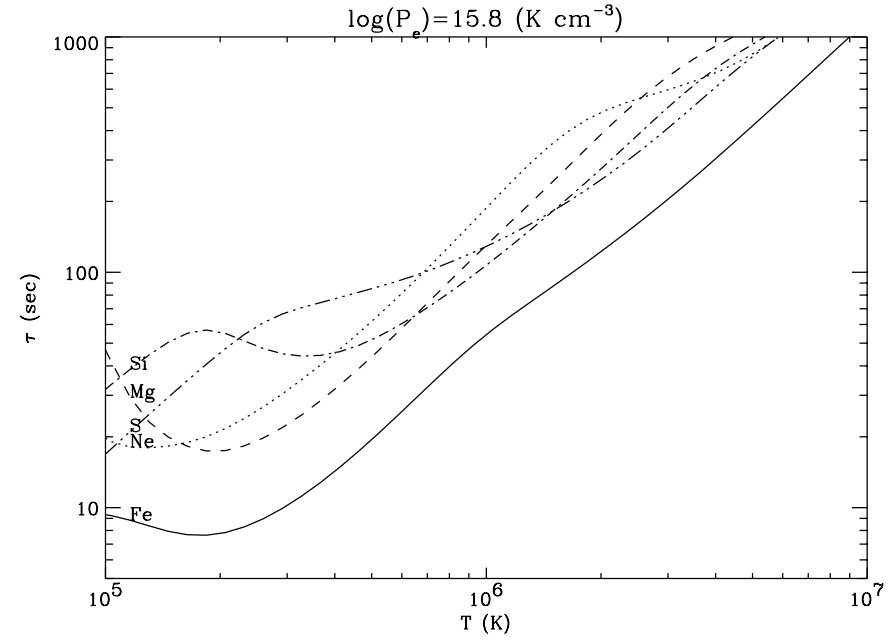

Fig. 5. Relaxation time-scales for the ground states of $\mathrm{Ne}, \mathrm{Mg}$, $\mathrm{Si}, \mathrm{S}$, and $\mathrm{Fe}$ as a function of temperature in the uniform electron pressure approximation $\left(\log \left(P_{\mathrm{e}}\right)=15.8 \mathrm{~K} \mathrm{~cm}^{-3}\right)$.

a selection of elements in the SERTS-89 spectrum in the constant density $\left(\log \left(N_{\mathrm{e}}\right)=9.5 \mathrm{~cm}^{-3}\right)$ and constant pressure $\left(\log \left(P_{\mathrm{e}}\right)=15.8 \mathrm{~cm}^{-3} \mathrm{~K}\right)$ cases respectively. The difference in the two cases derives principally from the explicit dependence on the reciprocal of the electron density. Note the significantly lower values for iron with respect to the other elements. The discrepancies observed (see Tables 3-13) do not obviously mimic the variation of $\tau_{\mathrm{a}}^{\text {(elem) }}$. We conclude that our observational data do not show a clear non-equilibrium based discrepancy and in this respect they confirm and extend the findings of Judge et al. (1995) in the corona.

It is possible from the above that phenomena in which plasma transport across a scale height in less than $\sim 100 \mathrm{~s}$ above $\log \left(T_{\mathrm{e}}\right)=6$ in the constant density model or in less than $\sim 10 \mathrm{~s}$ below $\log \left(T_{\mathrm{e}}\right)=6$ in the constant pressure model are infrequent and/or non-pervasive. However, we are unable to state unambiguously from the observations that such non-equilibrium effects are absent. This is because the regions of strong transport or transient behaviour in the solar atmosphere are probably localised in temperature, for example in the transition zone, and so the influence of the variation of $\tau_{\mathrm{a}}^{\text {(elem) }}$ may be masked. Also the actual electron density distribution may be different from that in our two models. From a theoretical point of view, for convective events, such as spicules, with speeds $\sim 20 \mathrm{~km} \mathrm{~s}^{-1}$, the transit time across a temperature scale length varies from $\sim 8 \mathrm{~s}$ at $T_{\mathrm{e}} \sim 3 \times 10^{5} \mathrm{~K}$ through $30 \mathrm{~s}$ at $T_{\mathrm{e}} \sim 5 \times 10^{5} \mathrm{~K}$ to $100 \mathrm{~s}$ at $T_{\mathrm{e}} \sim 8 \times 10^{5} \mathrm{~K}$. Contrasting these plasma timescales with the atomic relaxation times in the constant pressure model suggests significant non-equilibrium for iron and a close competition for neon, magnesium, silicon and sulphur in the temperature range $3 \times 10^{5} \mathrm{~K}$ to $1 \times 10^{6} \mathrm{~K}$. A similar conclusion would be drawn for phenomena such as the brightenings of duration $\sim 30 \mathrm{~s}$ which are observed from SOHO. The radiation enhancement (or deficit) in a spectrum line over 
the equilibrium power in a defined transient event is calculable within ADAS in the same manner as the $G$ kernels. However quantitative estimation of the likely perturbative effect on the observed spectral intensities requires a detailed theoretical model for transient events, including filling factors and duty cycles, beyond the scope of this paper.

\section{Conclusions}

Using the data adaptive smoothing approach (Thompson 1990, 1991) together with collisional-radiative theory as implemented in ADAS (McWhirter \& Summers 1984; Summers 1994; Summers 2001) we have investigated the validity and limitations of the differential emission measure (DEM) approach for analysing coronal EUV lines. To this purpose we have analysed the SERTS-89 rocket spectrum of a solar active region between 170 and $450 \AA$ (Thomas \& Neupert 1994) and performed consistency checks between observations and the DEM reconstruction. We were unable to detect large non-equilibrium conditions in the inner coronal plasma that could invalidate the fundamental physical assumptions underlying the differential emission measure method. We have outlined the importance of this type of analysis in line intensity prediction, line identification, the study of blends, and validation of atomic data.

Any spectral analysis based on the DEM requires caution in many aspects. Of fundamental importance is the choice of lines used in the integral inversion. Although these must obviously be reliable and free from blends, and accurate atomic data must be available for them, the temperature coverage must be chosen with care. Lines formed close to the same temperatures must be avoided in the integral inversion to prevent ill-conditioning the problem. However, when such criteria are taken into account, an accurate spectral analysis becomes possible and the fundamental advantages of absolute intensity in comparison with line-ratio analyses stand out. Inconsistencies in the comparison with observations become more easily recognised and the identification of the sources of discrepancies becomes easier. The criterion applied in obtaining the DEM presented here was to avoid, in the integral inversion, the use of more than one line within $\Delta \log \left(T_{\mathrm{p}}\right)=0.05$, where $T_{\mathrm{p}}$ is the peak temperature of line formation, the consequence of which is the selection of one line per ion at most. In total, 17 lines were used to sample the DEM between $\log \left(T_{\mathrm{e}}\right)=5$ and 6.8 , although the spacing below $\log \left(T_{\mathrm{e}}\right)=5$ and above $\log \left(T_{\mathrm{e}}\right)=6.4$ is coarser than desirable because of the paucity of SERTS-89 lines in such temperature intervals.

Another advantage of the method is the possibility of comparing the atomic modelling of different atomic species. It allowed us, in the case of the SERTS-89 spectrum, a comparison of the atomic modelling of Fe ions with the more reliable atomic modelling of less complex atomic species. The discrepancies found for the most density sensitive iron ions points out the need for an improvement to the atomic modelling of this complex species. The striking behaviour of Fe XIV lines can be attributed to inaccuracy in the collision strengths, but our analysis also shows that Fe ionisation/recombination cross sections suffer from a lack of accuracy with respect to that of less complex atomic species. Note, in fact, the systematic overestimate of Fe XIII lines as opposed to the systematic underestimate of Fe XIV lines. We feel that this behaviour is not caused by inaccuracy of the DEM at such temperatures because of the agreement found with other ions.

In order to investigate the consequences of assuming a constant electron pressure or constant electron density, we have used both approximations for the evaluation of the kernels. We found that some density sensitive lines are better reproduced in the former and others in the latter approximation, and therefore we are unable to indicate whether the plasma is closer to having constant electron density or constant electron pressure. An indication of the actual density and temperature distribution would be given by the derivation of the bivariate DEM (differential in temperature and density). However, the weak dependence of $G$ on the electron density combined with the current degree of uncertainties in the atomic modelling prevent us from obtaining such a distribution (see Judge et al. 1997).

We have also shown that, for the SERTS-89 spectrum, analyses which indicate the existence of multiple peaks in the DEM distribution above $\log \left(T_{\mathrm{e}}\right) \sim 6$ are doubtful since they may arise variously from an inaccurate treatment of population densities, density sensitivity of lines used for the inversion, errors in the atomic data and observations, and integral inversion techniques with arbitrary smoothing.

Elemental abundances (with respect to $\mathrm{Ne}$ ) in the SERTS-89 active region are found to be close to those listed in Feldman et al. (1992), except for Si which we find close to its photospheric value. The abundance analysis for Fe, based on Fe XI and Fe XII only, indicates that Fe may have a photospheric abundance too, but this must be confirmed when more accurate atomic data become available.

Acknowledgements. We thank R. W. P. McWhirter for providing the atomic data for Li-like ions, M. Landini and the late B. Monsignori Fossi for providing data for the C-like ions. D. H. Sampson and H. L. Zhang are thanked for providing atomic data. For his help with Fe ionisation/recombination data, we thank M. O'Mullane. Thanks also to J. W. Brosius for useful comments on the original manuscript.

\section{References}

Aggarwal, K. M. 1998, ApJS, 118, 589

Arnaud, M., \& Rothenflug, R. 1985, A\&A, 60, 425

Arnaud, M., \& Raymond, J. 1992, ApJ, 398, 394

Baker, C. T. H. 1977, Numerical treatment of Integral Equation (Oxford University Press, Oxford)

Bashkin, S., \& Stoner, J. O. 1975, Atomic Energy Levels and Grotrian Diagrams, vol. 1 (North Holland Publishing Co) 
Berrington, K. A. 1994, Atom. Data Nucl. Data Tables, 57, 71 Berrington, K. A., Burke, P. G., Dufton, P. L., \& Kingston, A. E. 1981, Atom. Data Nucl. Data Tables, 26, 1

Berrington, K. A., Burke, P. G., Dufton, P. L., \& Kingston, A. E. 1985a, Atom. Data Nucl. Data Tables, 33, 195

Berrington, K. A., Burke, P. G., Dufton, P. L., \& Kingston, A. E. 1985b, Atom. Data Nucl. Data Tables, 33, 345

Bhatia, A. K., \& Doschek, G. A. 1992, Atom. Data Nucl. Data Tables, 521

Bhatia, A. K., \& Doschek, G. A. 1993a, Atom. Data Nucl. Data Tables, 55, 315

Bhatia, A. K., \& Doschek, G. A. 1993b, Atom. Data Nucl. Data Tables, 55, 281

Bhatia, A. K., \& Doschek, G. A. 1995, Atom. Data Nucl. Data Tables, 60, 145

Bhatia, A. K., \& Kastner, S. O. 1988, ApJ, 332, 1063

Bhatia, A. K., \& Kastner, S. O. 1993, Atom. Data Nucl. Data Tables, 54, 133

Bhatia, A. K., \& Mason, H. E. 1980, MNRAS, 190, 925

Bhatia, A. K., \& Mason, H. E. 1997, Atom. Data Nucl. Data Tables, 66, 119

Bhatia, A. K., \& Thomas, R. J., ApJ, 497, 483

Bhatia, A. K., \& Young, P. R. 1998, Atom. Data Nucl. Data Tables, 68, 219

Bhatia, A. K., Feldman, U., \& Doscheck, G. A. 1979, A\&A, 80,22

Bhatia, A. K., Seely, J. F., \& Feldman, U. 1987, Atom. Data Nucl. Data Tables, 36, 453

Bhatia, A. K., Kastner, S. O., Keenan, F. P., Conlon, E. S., \& Widing, K. G. 1994, ApJ, 427, 497

Behring, W. E., Cohen, L., Feldman, U., \& Doshek, G. 1976, ApJ, 203, 521

Brickhouse, N. S., Raymond, J. C., \& Smith, B. W. 1995, ApJS, 97, 551

Brosius, J. W., Davila, J. M., Thomas, R. J., \& MonsignoriFossi, B. C. 1996, ApJS, 106, 143

Brooks, D. H., Ph.D. Thesis, University of Strathclyde, 1997

Burke, V. M. 1992, J. Phys. B, 25, 4197

Butler, K., \& Zeippen, C. J. 1994, A\&AS, 108, 1

Conlon, E. S., Keenan, F. P., \& Aggarwal, K. M. 1992, Phys. Scr., 45, 309

Corliss, C., \& Sugar, J. 1982, J. Phys. Chem. Ref. Data, 11, 135

Cox, M. G., \& Hayes, J. G. 1973, Report NAC26, National Physical Laboratory (Teddington, Middlesex)

Craig, I. J. D., \& Brown, J. C. 1976, A\&A, 49, 239

Craig, I. J. D., \& Brown, J. C. 1986, Inverse Problems in Astronomy (Adam Hilger, Bristol)

Dankwort, E., \& Treffetz, E. 1978, A\&A, 65, 93

Dere, K. P. 1978, ApJ, 221, 1062

Dere, K. P., Landi, E., Mason, H. E., Monsignori Fossi, B. C., \& Young, P. R. 1997, A\&AS, 125, 149

Dufton, P. L., \& Kingston, A. E. 1991, Phys. Scr., 43, 386

Dufton, P. L., Kingston, A. E., \& Scott, N. S. 1983, J. Phys. B, 16,3053

Dwivedi, B. N., Mohan, A., \& Thomas, R. J. 1998, Sol. Phys., 180,157

Edlén, B. 1983a, Phys. Scr., 28, 51

Edlén, B. 1983b, Phys. Scr., 28, 48

Edlén, B. 1984, Phys. Scr., 30, 135

Edlén, B. 1985a, Phys. Scr., 31, 345

Edlén, B. 1985b, Phys. Scr., 32, 59

Edlén, B. 1985c, Phys. Scr., 32, 86
Eissner, W. M., Jones, M., \& Nussbaumer, H. 1974, Comput. Phys Commun., 8, 270

Fawcett, B. C. 1975, Atom. Data Nucl. Data Tables, 16, 138

Fawcett, B. C. 1984, Atom. Data Nucl. Data Tables, 30, 1

Fawcett, B. C. 1985, Atom. Data Nucl. Data Tables, 33, 479

Fawcett, B. C., \& Mason, H. E. 1989, Atom. Data Nucl. Data Tables, 43, 245

Fawcett, B. C., \& Mason, H. E. 1991, Atom. Data Nucl. Data Tables, 47, 17

Feldman, U. 1992, Phys. Scr., 46, 202

Feldman, U., Mandelbaum, P., Seely, J. F., Doschek, G. A., \& Gursky, H. 1992, ApJS, 81, 387

Feldman, U., Purcell, J. D., \& Dohne, B. 1987, Atlas of Skylab EUV Spectroheliograms (Naval Research Laboratory, Washington DC)

Fischer, C. F., \& Liu, B. 1986, Atom. Data Nucl. Data Tables, 34,261

Flower, D. R. 1977, A\&A, 54, 163

Flower, D. R., \& Nussbaumer, H. 1974, A\&A, 31, 353

Froese Fischer, C. 1983, J. Phys. B, 16, 157

Froese Fischer, C., \& Saha, H. P. 1985, Phys. Scr., 32, 181

Golub, G. H., Heath, M., \& Wahba, G. 1979, Technometrics, 21,215

Hibbert, A. 1980, J. Phys. B, 13, 1721

Judge, P. G., Woods, T. N., Brekke, P., \& Rottman, G. J. 1995, ApJ, 455, L85

Judge, P. G., Hubeny, V., \& Brown, J. C., ApJ, 475, 275

Jupén, C., Isler, R. C., \& Träbert, E. 1993, MNRAS, 264, 627

Kato, T., Lang, J., \& Berrington, K. A. 1990, Atom. Data Nucl. Data Tables, 44, 133

Kato, T. 1995, private communication

Keenan, F. P., Conlon, E. S., Warren, G. A., Boone, A. W., \& Norrington, P. H. 1993a, ApJ, 406, 350

Keenan, F. P., Thomas, R. J., Neupert, W. M., Conlon, E. S., \& Burke, V. M. 1993b, Sol. Phys., 144, 69

Keenan, F. P., Thomas, R. J., Neupert, E. S., \& Conlon, E. S. 1994, Sol. Phys., 149, 301

Keenan, F. P., Thomas, R. J., Neupert, W. M., et al. 1996, MNRAS, 278, 773

Keenan, F. P., O'Shea, E., Thomas, R. J., et al. 2000a, MNRAS, 315, 450

Keenan, F. P., Pinfield, D. J., Mathioudakis, M., et al. 2000b, Sol. Phys., 197, 253

Kelly, R. L. 1987, J. Phys. Chem. Ref. Data 16, Suppl. 1

König, R., Kolk, K.-H., \& Kunze, H. J. 1996, Phys. Scr., 53, 679

Landi, E., \& Landini, M. 1997, A\&A, 327, 1230

Lang, J., Mason, H. E., \& McWhirter, R. W. P. 1990, Sol. Phys., 129, 31

Lang, J., Brooks, D. H., O'Mullane, M. G., et al. 2001, Sol. Phys., 201, 37

Malinovsky, M., \& Heroux, L. 1973, ApJ, 181, 1009

Martin, W. C., Sugar, J., Musgrove, A., \& Dalton, G. R. 1995, NIST Database for Atomic Spectroscopy, version 1.0, NIST Standard Ref. Data base, 61

McIntosh, S. W., Charbonneau, P., \& Brown, J. C. 2000, ApJ, 529,1115

McWhirter, R. W. P. 1994, Atom. Data Nucl. Data Tables, 57, 39

McWhirter, R. W. P., \& Summers, H. P. 1984, in Appl. Atom. Coll. Phys., 2, ed. C. F. Barnett, \& M. F. A. Harrison (Academic Press), 51

Merkelis, G., Vilkas, M. J., Gaigalas, G., \& Kisielius, R. 1995, Phys. Scr., 51, 233 
Moore, C. E. 1993, Tables of Spectra of Hydrogen, Carbon, Nitrogen and Oxygen Atoms and Ions, ed. J. W. Gallacher (CRC Press)

Mühlethaler, H. P., \& Nussbaumer, H. 1976, A\&A, 48, 109

Nussbaumer, H., \& Storey, P. J. 1979a, A\&A, 74, 244

Nussbaumer, H., \& Storey, P. J. 1979b, J. Phys. B, 12, 1647

ORNL 1995, in Spectroscopic Data for Iron, ORNL-6089/V4, ed. W. L. Wiese (Oak Ridge National Laboratory)

Penn, M. J., \& Kuhn, J. R. 1994, ApJ, 434, 807

Ramsbottom, C. A., Bell, K. L., \& Keenan, F. P. 1998, MNRAS, 293, 233

Sampson, D. H. 1993, private communication

Sampson, D. H., Goett, S. J., \& Clark, R. E. H. 1984, Atom. Data Nucl. Data Tables, 30, 125

Sampson, D. H., Zhang, H. L., \& Fontes, C. 1990, Atom. Data Nucl. Data Tables, 44, 209

Sampson, D. H., Zhang, H. L., \& Fontes, C. 1994, Atom. Data Nucl. Data Tables, 57, 97

Shirai, T., Funataka, Y., Mori, K., et al. 1990, J. Chem. Phys. Ref. Data, 19, 127

Storey, P. J., Mason, H. E., \& Saraph, H. E. 1996, A\&A, 309, 677

Summers, H. P. 1974, Internal Mem. 367, Astrophys. Res. Div. (Appleton Lab., Abingdon, Oxon)
Summers, H. P. 1994, ADAS manual, JET Joint Undertaking Report JET-IR(94)07

Summers, H. P. 1995, private communication

Summers, H. P. 2001, The ADAS manual, version 2-3, http://adas.phys.strath.ac.uk

Thomas, R. J., \& Neupert, W. M. 1994, ApJS, 91, 461

Tayal, S. S., Henry, R. J. W., \& Pradhan, A. K. 1987, ApJ, 319, 951

Thompson, A. M. 1990, A\&A, 240, 209

Thompson, A. M. 1991, in Intensity Integral Inversion Techniques: a Study in Preparation for the SOHO Mission, ed. R. A. Harrison, \& A. M. Thompson, RAL Report RAL91-092

Thompson, A. M., \& Craig, I. J. D. 1992, A\&A, 262, 359

Tondello, G., \& Paget, T. M. 1970, J. Phys. B, 3, 1757

Wiese, W. L., Smith, M. W., \& Glennon, B. M. 1966, Atom. Trans. Prob., 1, Hydrogen through Neon (NSRDS-NBS4, Washington DC, GPO)

Young, P. R., Landi, E., \& Thomas, R. J. 1998, A\&A, 329, 291

Zhang, H. L., Graziana, M., \& Pradhan, A. K. 1994, A\&A, 283,319

Zhang, H. L., Sampson, D. H., \& Fontes, C. J. 1990, Atomic Data and Nuclear Data Tables, 44, 31 